\title{
An Arabidopsis long noncoding RNA modulates the transcriptome through interactions with a network of splicing factors
}

Richard Rigo ${ }^{1^{*}}$, Jérémie Bazin ${ }^{1 *}$, Natali Romero-Barrios ${ }^{1}$, Michaël Moison ${ }^{1,2}$, Leandro Lucero $^{2}$, Aurélie Christ ${ }^{1}$, Moussa Benhamed ${ }^{1}$, Thomas Blein ${ }^{1}$, Stéphanie Huguet ${ }^{1}$, Céline Charon ${ }^{1}$, Martin Crespi ${ }^{1}$ and Federico Ariel $^{2}$

1 Institute of Plant Sciences Paris-Saclay (IPS2), CNRS, INRA, Universities Paris-Sud, Evry and Paris-Diderot, Sorbonne Paris-Cite, University of Paris-Saclay, Batiment 630, 91405 Orsay, France.

2 Instituto de Agrobiotecnologia del Litoral, CONICET, FBCB, Universidad Nacional del Litoral, Colectora Ruta Nacional 168 km 0, 3000, Santa Fe, Argentina.

* Both authors contributed equally to this work.

Correspondence to: MC (martin.crespi@ips2.universite-paris-saclay.fr) and FA (fariel@santafeconicet.gov.ar)

Running title: LncRNA shapes alternative splicing

\section{ABSTRACT}

Alternative splicing (AS) is a major source of transcriptome and proteome diversity in higher organisms. Long noncoding RNAs (IncRNAs) have emerged as regulators of AS through a range of molecular mechanisms. In Arabidopsis thaliana, the AS regulators NSRa and b, which affect auxin-driven lateral root formation, can interact with the ALTERNATIVE SPLICING COMPETITOR (ASCO) IncRNA. Here, we analyzed the effect of the knockdown and overexpression of $A S C O$ at genome-wide level and found a high number of deregulated and differentially spliced genes, related to flagellin responses and biotic stress. In agreement, roots from ASCO-knocked down plants are more sensitive to flagellin. Surprisingly, only a minor subset of genes overlapped with the AS defects of the nsra/b double mutant. Using biotinlabelled oligonucleotides for RNA-mediated ribonucleoprotein purification, we found that ASCO binds to the highly conserved core spliceosome component PRP8a. ASCO deregulation impairs the recognition of specific flagellin-related transcripts by PRP8a and SmD1b, another spliceosome component, suggesting that $A S C O$ function regulates AS through the interaction with multiple splicing factors. Hence, IncRNAs may interact in a dynamic network with many splicing factors to modulate transcriptome reprogramming in eukaryotes.

Keywords: core splicing factors/flagellin/long noncoding RNA/PRP8a/SmD1b 


\section{Introduction}

Alternative splicing (AS) of pre-mRNAs represents a major mechanism boosting eukaryotic transcriptome and proteome complexity (Chaudhary et al, 2019). In recent years, the advent of novel sequencing technologies allowed us to analyze entire genomes and complete pools of transcripts, leading to the identification of a wide variety of mRNA isoforms in higher organisms. More than $90 \%$ of intron-containing genes in humans and over $60 \%$ in plants are alternatively spliced (Pan et al, 2008; Wang et al, 2008; Marquez et al, 2012; Gerstein et al, 2014). The significant diversity in the number of transcripts compared to the number of genes suggests that a complex regulation occurs at transcriptional and post-transcriptional levels (Syed et al, 2012). Many mRNA isoforms derived from the same DNA locus are tissue-specific or are accumulated under particular conditions (Djebali et al, 2012). In humans, numerous studies suggest that the misregulation of RNA splicing is associated to several diseases (Boon et al, 2007; Tanackovic et al, 2011; Yoshida et al, 2011; Faial, 2015). In plants, AS plays an important role in the control of gene expression for an adequate response of plants to stress conditions (Palusa et al, 2007; Tanabe et al, 2007; Filichkin et al, 2010; Yan et al, 2012; Reddy et al, 2013; Ding et al, 2014; Zhan et al, 2015; Laloum et al, 2018; Jabre et al, 2019; Rigo et al, 2019). Alternative splicing modulates gene expression mainly by (i) increasing gene-coding capacity, thus proteome complexity, through the generation of a subset of mRNA isoforms derived from a single locus, and/or (ii) triggering mRNA degradation through the introduction of a premature termination codon in specific isoforms that would lead to nonsense mediated decay (NMD).

Besides the identification of an increasing number of AS events on mRNAs, next generation sequencing technologies led to the identification of thousands of RNAs with no or low coding potential (the so-called noncoding RNAs, ncRNAs), which are classified by their size and location respect to coding genes (Ariel et al, 2015). The long ncRNAs (IncRNAs, over 200 nt) act directly in a long form or may lead to the production of small ncRNAs (smRNAs) acting through base pairing recognition of their mRNA targets. There is growing evidence that large amounts of IncRNAs accumulate in particular developmental conditions or during diseases, suggesting that they participate in a wide range of biological processes. In recent years, several IncRNAs from higher organisms have been characterized as modulators of virtually every step of gene expression through interaction with proteins involved in chromatin remodeling, transcriptional control, co- and post-transcriptional regulation, miRNA processing, and protein stability during various developmental processes (Zhang et al, 2013; Ariel et al, 2015; Song et al, 2016). In particular, a growing number of IncRNAs have been linked to the modulation of AS in both plants and animals (Romero-Barrios et al, 2018). The main mechanisms involving IncRNAs in AS modulation have been classified as following: (i) IncRNAs interacting with splicing factors (Bardou et al, 2014; Barry et al, 2014; Ji et al, 2014; West et al, 2014; Kong et al, 2016); (ii) IncRNAs forming RNA-RNA duplexes with pre-mRNA molecules (Beltran et al, 2008; Villamizar et al, 2016) and (iii) IncRNAs affecting chromatin remodelling of alternatively spliced target genes (Gonzalez et al, 2015; Conn et al, 2017).

In Arabidopsis thaliana, the IncRNA ASCO (ALLTERNATIVE SPLICING COMPETITOR) is recognized in vivo by the plant-specific NUCLEAR SPECKLE RNA-BINDING PROTEINS 
(NSRs), involved in splicing (Bardou et al, 2014). Notably, there is no evidence that ASCO undergoes splicing, although it is recognized by splicing factors. The analysis of a transcriptomic dataset of the nsra/b mutant compared to wild type (WT) plants, revealed an important number of intron retention events and differential 5' start or 3' end in a subset of genes, notably in response to auxin (Tran et al, 2016). Indeed, the nsra/b mutant exhibits diminished auxin sensitivity, e.g. lower lateral root (LR) number than WT plants in response to auxin treatment. This phenotype was related to the one observed for ASCO overexpressing lines. Interestingly, the splicing of a high number of auxin-related genes was perturbed in nsra/b mutants and several of them behaved accordingly in the ASCO overexpressing lines. The ASCO-NSR interaction was then proposed to regulate AS during auxin responses in roots (Bardou et al, 2014). More recently, an RNA-immunoprecipitation assay followed by RNA-seq (RIP-Seq) served to identify genome-wide RNAs bound in vivo by NSRa (Bazin et al, 2018). Long ncRNAs transpired to be privileged direct targets of NSRs in addition to specific NSR-dependent alternatively spliced mRNAs, suggesting that other IncRNAs than ASCO may interact with NSRs to modulate AS (Bazin et al, 2018).

In this work, we deeply characterize ASCO knocked-down plants and uncovered its general role in AS regulation, not only in response to auxin treatment. A transcriptomic analysis of ASCO knocked-down seedlings revealed a de-regulation of immune response genes and, accordingly, ASCO RNAi-silenced plants exhibited enhanced root growth sensitivity to flagellin 22 (flg22). The transcriptomic analysis of the ASCO over-expressing vs. ASCO knocked-down seedlings revealed distinct and overlapped effects on the whole of the mRNA population. Then, we assessed the genome-wide impact of ASCO function on AS and found many flg22-response regulatory genes showing differential AS in ASCO-deregulated lines. Surprisingly, the effect of ASCO knock-down on AS was clearly distinct from the defects of the nsra/b double mutant suggesting that $A S C O$ impacts AS through a different interaction with the splicing machinery. Searching for ASCO-interacting proteins, we found SmD1b and PRP8a, two core components of the spliceosome that also recognize subsets of AS-regulated flg22-regulatory genes, also differentially spliced in prp8a (prp8-7 allele; Sasaki et al, 2015) and smd1b mutants. Furthermore, ASCO overexpression competes for PRP8a and SmD1b binding to particular mRNA targets. Hence, IncRNAs may interact with key conserved components of the spliceosome to integrate a dynamic splicing network that modulates transcriptome diversity in eukaryotes.

\section{Results}

\section{The ASCO IncRNA participates in lateral root formation}

It was previously shown that ASCO (AT1G67105) overexpression results in a lower number of LRs in response to auxin treatment, a phenotype related to that of the $n s r a / b$ mutant, suggesting that increasing ASCO expression may lead to a titration of NSR activity in splicing (Bardou et al, 2014). To understand the role of $A S C O$ in plant development, we generated independent RNAi lines to down regulate the levels of ASCO expression (RNAi-ASCO1 and RNAi-ASCO2, Fig 
EV1A-B). Under control growth conditions, only RNAi-ASCO1 plants exhibited a significantly longer primary root than the Col-0 wild type (WT) plants (Fig EV1C), whereas both independent lines showed an enhanced LR density in response to auxin treatment (Fig EV1D), the opposite phenotype to the one displayed by the ASCO overexpressing lines (Bardou et al, 2014). Furthermore, we transformed $A$. thaliana with a construct bearing $2631 \mathrm{bp}$ of the $A S C O$ promoter region controlling the expression of the fusion reporter genes GFP::GUS (proASCO::GUS). The proASCO construct includes the full intergenic region upstream of $A S C O$ fusing the reporter gene to the first ATG in the $A S C O$ locus at the position +15 from the transcription start site (Fig EV1E). In roots, proASCO::GUS was active very early in LR development, in pericycle cells undergoing the first division (Fig EV1F), whereas activity was then restricted to the vasculature adjacent to the LR primordium between stages II and VIII of LR development (according to Malamy and Benfey, 1997). Thus, ASCO expression pattern is in agreement with the LR-related phenotype of RNAi-ASCO plants.

\section{Deregulation of $A S C O$ expression triggers a transcriptional response to biotic stress}

In order to decipher the role of $A S C O$ in the regulation of gene expression at a genome-wide level, we performed an RNA-seq of $A$. thaliana 14-day-old seedlings RNAi-ASCO1 vs. WT Columbia (Col-0) accession in standard growth conditions. Overall, more genes were upregulated (321) than downregulated (178) in ASCO silenced plants (Fig 1A). Over 90\% of deregulated transcripts correspond to protein-coding genes, according to Araport11 gene annotation (Fig 1B; Table EV1). To extend our understanding on the genome-wide role of ASCO in the control of gene expression, we searched the putative function of differentially expressed genes using Gene Ontology (GO). This analysis revealed a clear enrichment of deregulated genes involved in immune and defense response (FDR $<8 e-4$ ), as well as related pathways such as "response to chitin" and "glucosinolate metabolic pathways" (Fig 1C). Interestingly, related pathways were also partially observed in $n s r a / b$ mutants in response to auxin (Bazin et al, 2018). The upregulation of biotic stress-related genes was validated by RTqPCR in both RNAi-ASCO lines compared to WT for a subset of 6 chosen transcription factors (TFs) which have been linked to the response to pathogens (Fig EV1G): STZ or ZAT10 (AT1G27730) encodes for a Zn-finger TF involved in the response to oxidative stress (Munekage et al, 2015) and acts as a negative regulator of methyl jasmonate (MeJA) biosynthesis (Pauwels et al, 2008); MYB29 (AT5G07690) positively regulates the biosynthesis of aliphatic glucosinolate (AGSL), an essential defense secondary metabolite in $A$. thaliana ( $\mathrm{Li}$ et al, 2013); WRKY33 (AT2G38470) controls the ABA biosynthetic pathway in response to the necrotrophic fungi Botrytis cinerea (Liu et al, 2015); ERF6 (AT4G17490) is a positive regulator of the MeJA and ethylene-mediated defense against $B$. cinerea (Moffat et al, 2012); ERF104 (AT5G61600) participates in the ethylene-dependent response to flg22 (Bethke et al, 2009); and ERF105 (AT5G51190) was shown to be strongly regulated in response to chitin (Libault et al, 2007) and to bind to the GCC-box pathogenesis-related promoter element (O'Malley et al, 2016). Remarkably, all these pathogen-related TFs are transcriptionally over accumulated in control conditions in the RNAi-ASCO plants (Fig EV1G), indicating that the deregulation of 
ASCO expression triggers molecular defense responses likely through the induction of pathogen-related TFs.

It is known that peptides corresponding to the most conserved domains of eubacterial flagellins ( $\mathrm{flg}$ ) act as potent elicitors in A. thaliana. Notably, flg22 causes callose deposition, induction of genes encoding for pathogenesis-related proteins and a strong inhibition of growth, including root development (Gomez-Gomez et al, 1999; Beck et al, 2014; Poncini et al, 2017). Thus, we first assessed the transcriptional behavior over time of $A S C O$ in response to flg22. As shown in Fig EV1H, ASCO accumulation in roots was not significantly affected by flg22. Then, we characterized the physiological response of both ASCO RNAi-silenced lines to the exogenous treatment with flg22. Five-day-old plantlets were treated or not for 9 additional days with 0.1 or $1 \mu \mathrm{M}$ flg22. Strikingly, the roots of RNAi-ASCO1 and 2 plants exhibited a normal development in control conditions (Fig EV3), whereas they were more sensitive to flg22 treatment, exhibiting a significantly shorter primary root (Figs 1D and $1 F$ ) but a minor reduction in the number of total LR, resulting in a higher density of LRs (Fig 1G). Cell wall staining and microscopic observation allowed us to quantify meristem size and determine that RNAi-ASCO plants show a reduction of the meristematic zone in response to flg22, e.g. shorter distance between the quiescent center and the beginning of the transition zone (Figs 1E, 1H and EV3B). This reduction in size is the result of a significant lower number of cells forming the root meristematic zone (Fig EV3C). Together with the physiological phenotype, we characterized the molecular response to this elicitor. A small subset of flg22-responsive genes was chosen (Asai et al, 2002; Zipfel et al, 2004; Boudsocq et al, 2010) to assess putative expression changes due to ASCO knock-down. In mock conditions, RNAi-ASCO lines exhibited an increased expression for certain flg22-responsive genes tested (Fig EV3D). Interestingly, this subset of genes suffered an overall lower induction by $3 \mathrm{~h}$ flg22 in RNAi-ASCO plants (Fig EV3E), in agreement with the previously observed altered sensitivity to flg22 of RNAi-ASCO roots.

To further demonstrate the link between ASCO and the response to flg22, we searched for additional independent Arabidopsis lines exhibiting a deregulation in ASCO accumulation. We characterized two insertional mutants located at the 5' region (asco-1) and the 3' region of the locus (asco-2; Fig EV4A ). The first line, asco-1, resulted to be an over-expressor of a truncated $A S C O$ version (lacking a minor portion of the 5' region) whereas the asco-2 T-DNA line shows minor changes in ASCO expression (Fig EV4B). Interestingly, the nearly 50-fold over-accumulation of ASCO RNA in asco-1 plants results in a slight reduction of LR density in response to flg22, opposite to RNAi lines (Fig EV4E). Accordingly, when we assessed two independent 35S:ASCO over-expressing lines, reaching an over-accumulation of 1000- to 2500fold RNA levels, plants exhibit a longer main root and a lower density of LRs in response to fg22 (Fig. 4AB). Therefore, ASCO participates in the regulation of biotic-stress related genes, shaping root architecture in response to flg22.

\section{ASCO modulates the alternative splicing but not the accumulation of a subset of pathogen-related mRNAs}

Considering that overexpression of ASCO affected the AS of NSR mRNA targets (Bardou et al, 2014), we searched for mis-spliced genes potentially explaining the global physiological impact 
of ASCO deregulation. To this end, we used two complementary approaches to detect both differential AS based on annotated isoforms (Reference Transcript Dataset for $A$. thaliana, AtRTD2; Zhang et al, 2017), and differential RNA processing using RNAprof (Tran et al, 2016). Based on RNAprof, a total of 303 differential RNA processing events in 281 distinct genes were identified comparing RNAi-ASCO with WT plants in control growth conditions (Table EV2), whereas the SUPPA method (Trincado et al, 2018) identified 205 genes with evidence of differential AS in the AtRTD2 database. Comparison of the two analyses with differentially expressed genes (DEG) in RNAi-ASCO lines revealed that most differentially alternatively spliced (DAS) genes are not differentially accumulated (Fig 2A). In addition, our analyses showed the complementarity between the two approaches since only 24 common DAS genes were identified by both methods. Classification of the location and the relative isoform accumulation (up or down) of these events revealed that the majority of them were located in introns and had higher read coverage in RNAi-ASCO plants, suggesting that ASCO inhibited proper intron splicing on these genes (Fig 2B). Nevertheless, we also identified differential events located within 5'UTR, CDS or 3'UTR suggesting that other RNA processing events, in addition to intron retention, are affected by ASCO expression levels. Analysis of differential AS events with SUPPA revealed 317 significant DAS events $(|\mathrm{dPS}| \mid>0.1$, pval $<0.01)$ on 205 unique genes from the AtRTD2 transcript annotation database (Table EV3). Similarly to the analysis with RNAprof, most of these events corresponded to retained introns (62\%) but we also identified a significant number of alternative 3' splice site and alternative 5' splice site selection modulated in ASCO knock-down lines (Fig 2C). To determine the most significant impact of the AS events, we sought to identify isoform switching events (where major changes in a specific isoform leads to a significant change on protein composition) using the IsoformSwitchAnalyzeR package (Table EV4; Vitting-Seerup and Sandelin, 2017). Strikingly, isoforms switching events were detected for 52 genes, out of which 12 and 34 were common cases detected by RNAprof and AtRTD2-SUPPA, respectively (Fig 2D). In silico analysis of switching isoforms protein sequences identified that the AS events may lead to (i) a change of ORF length; (ii) gain or loss of conserved PFAM protein domain and signal peptides; (iii) or a change of the coding potential and the sensitivity to NMD (Fig 2E). Since AS can often trigger NMD, an important mechanism of plant gene expression regulation (Kalyna et al, 2012), we compared DAS genes to those transcripts over-accumulated in the double mutant of the NMD factor homologs UP FRAMESHIFT1 (UPF1) and UPF3, upf1-upf3 (Drechsel et al, 2013). As shown in Fig 2F, 66 and 29 genes were reported by RNAprof and SUPPA, respectively. Hence, the majority of AS events controlled by ASCO seem to be independent of the UPF1-UPF3 mediated RNA quality control machinery, at least in the conditions previously assessed.

Furthermore, we performed an RNA-seq of 14-day-old seedlings 35S:ASCO1 vs. Col-0 WT plants in standard growth conditions. Interestingly, there is a minimal overlap between DEG and DAS genes in WT vs. RNAi-ASCO1 and 35S:ASCO1. Strikingly, the up- and downderegulation of $A S C O$ resulted in alternative subsets of DAS genes, including only 120 common DAS between RNAi-ASCO1 and 35S:ASCO1, compared to 227 and 137 excluding events, respectively (Fig. $3 \mathrm{C}$ ). Further comparison of DEG fold change revealed a global correlation of gene expression changes in 35S:ASCO1 and RNAi-ASCO1 as compared to WT but also that specific gene subset specifically responded to down or up-regulation of ASCO (Fig 3D). 
Similarly we compared of dPSI (difference of Percent Spliced In), which represent the change of each AS event. The analysis revealed that the group of 120 common AS events are positively correlated between the two lines as compared to wild type (Fig 3E). In addition, this also revealed that $\mathrm{dPSI}$ of $\mathrm{AS}$ events significantly regulated in response to either overexpression or silencing of $A S C O$, respectively, were not correlated between the two lines (Fig 3E). Overall, the effect of ASCO silencing was more extensive on DAS, compared to its overexpression.

In order to better understand the impact of $A S C O$ deregulation on the plant response to flg22, we focused on the transcriptional behavior of specific genes. Strikingly, several pathogenrelated genes appeared differentially spliced in RNAi-ASCO1 line although they were not affected in their global expression levels (Fig 2A). These AS events include two members from the NB-LRR disease resistance genes, RPP4 (Mohr et al, 2010), as well as the splicing regulatory serine-rich protein coding gene SR34 (AT1G02840), needed for accurate response to pathogens (Xu et al, 2011). The splicing of the SR34 own pre-mRNA is auto-regulated and depends on the activity of immune response factors (Zhang et al, 2014). Other relevant AS targets are SNC4 (AT1G66980) which encodes a receptor-like kinase that participates in the activation of the defense response and its AS is impaired in defense-related mutants, affecting the response to pathogens (Zhang et al, 2014); SEN1 (AT4G35770), a senescence marker gene primarily regulated by salicylic acid (SA)- and MeJA-dependent signaling pathways (Schenk et al, 2005) and NUDIX HYDROLASE7 (NUDT7; AT4G12720) which regulates defense and cell death against biotrophic pathogens (Straus et al, 2010). Another interesting target is EPITHIOSPECIFIER PROTEIN (ESP; AT1G54040) a gene involved in the plant defense to insects and also differentially spliced in response to MeJA (Kissen et al, 2012) although this gene was differentially expressed in RNAi-ASCO plants. We also included in the following analysis a NAD(P)-binding Rossmann-fold protein family Gene (NRG) AT2G29290, exhibiting drastically altered AS upon ASCO knock-down. Specific DAS events first identified in silico (Fig 4AD, EV5 and EV6) were validated by RT-PCR and polyacrylamide gel electrophoresis by calculating the ratio between alternatively spliced and fully spliced isoforms (Isoform ratio, Figs 4BCEF, and EV6). Some events were also validated by quantitative RTqPCR where each differential event was normalized with respect to an internal gene probe (called INPUT) which corresponds to a common exon. This allowed to calculate the splicing index (defined in the method section,Figs EV7). Altogether, our results indicate that the knockdown of ASCO expression affects the AS of a subset of genes whose isoforms distribution may modulate the pathogen-related transcriptome and affect the response to flg22.

\section{ASCO interacts with the spliceosome core components PRP8a and SmD1b}

The fact that $A S C O$ interacts with NSRs strongly suggested that $A S C O$ would affect a large subset of NSR-targeted AS events. Surprisingly, DAS genes in the RNAi-ASCO and 35S:ASCO plants only partially coincide with those in $n s r a / b$ double mutants (in response to auxin or not). In all, out of the 589 DAS events identified in nsra/b compared to WT, only $140(32 \%)$ are common with RNAi-ASCO1 and 109 (33\%) with 35S:ASCO, what represents $24 \%$ and $19 \%$ of all DAS events in the nsra/b mutant, respectively (Fig EV8A). Furthermore, nsra/b plants do not respond to flg22 in the same way as RNAi-ASCO plants (Fig EV8C and D), indicating that ASCO further modulates AS in an NSR-independent manner by a yet uncovered mechanism, 
notably affecting the response to biotic stress. Therefore, in order to decipher the AS-related complexes implicating $A S C O$, we performed an antisense oligonucleotides based pull-down method, related to the Chromatin Isolation by RNA Purification (ChIRP; Chu et al, 2011; Ariel et al, 2014) using nuclear extracts to purify ASCO-containing RNPs. Eighteen biotinylated probes matching ASCO were used in independent sets called EVEN and ODD, respectively (Table EV5). ASCO-ChiRP was performed in 4 biological replicates for each set of probes: ODD, EVEN, and an additional set matching the LacZ RNA, used as a negative control. ASCO enrichment was corroborated by ChiRP followed by RNA purification and RT-qPCR (Fig 5A). We then performed a mass spectrometry on the proteins from the purified ASCO-containing RNP to identify potential ASCO protein partners. Strikingly, among the RNA-related proteins identified in the EVEN and ODD samples, but not in the LacZ, we found the pre-mRNAprocessing-splicing factor 8A, PRP8a. PRP8 is a core component of the spliceosome highly conserved in higher organisms and null mutants are generally embryo lethal (Grainger and Beggs, 2005). In Arabidopsis, a PRP8a leaky mutation was found to also affect the AS of the COOLAIR IncRNA (Marquardt et al, 2014) and results in a high number of intron retention events (Sasaki et al., 2015). Therefore, we developed specific antibodies against PRP8a and we tested them in immunolocalization experiments that revealed a nuclear localization pattern (Fig EV9) similar to what was previously observed in Drosophila (Claudius et al, 2014). In order to in vivo validate the interaction with $A S C O$, we performed an RNA-immunoprecipitation assay followed by qPCR (RIP-qPCR) from nuclear extracts, showing that PRP8a can recognize the spliceosomal U5 RNA (Koncz et al, 2012) taken as a positive control, as well as the ASCO IncRNA (Fig 5B). The efficiency of the PRP8a immunoprecipitation (IP) was assessed by western blot comparing nuclei input samples, against the unbound fraction after IP, as well as the anti-PRP8a IP and the anti-lgG IP (Fig 5C). We then assessed the binding of PRP8a to the pathogen-related mRNAs differentially spliced in the RNAi-ASCO lines. PRP8a was indeed able to interact with 4 of these ASCO-related DAS genes. Furthermore, their binding was impaired upon the overexpression of ASCO (Fig 5D), hinting an ASCO-mediated competition of these mRNAs inside the PRP8a-containing spliceosome complex. Interestingly, ASCO is overaccumulated in the prp8a mutant allele (Sasaki et al, 2015 hereafter referred to as prp8a) background (Fig 6A), as it occurs in the nsra/b mutant plants (Bardou et al, 2014). Remarkably, similar AS defects were shown between the prp8a mutant and RNAi-ASCO lines for pathogenrelated genes (Figs $6 \mathrm{BC}$ and EV10), indicating that the flg22 differential phenotype of RNAiASCO plants may be related to the interaction with the spliceosome components. Recently, we identified another core component of the spliceosome, SmD1b, linked to both AS and the recognition of aberrant ncRNAs to trigger gene silencing (Elvira-Matelot et al, 2016). Interestingly, ASCO expression levels are also increased in the smd1b mutant (Fig 6D), exhibiting the same transcript accumulation as in prp8a and nsra/b mutants. Hence, we wondered whether this other core component of the spliceosome also interacts with ASCO IncRNA. Using pUBI:SmD1b-GFP plants (smd1b background, Elvirat-Matelot., 2016), we performed a RIP assay and found that SmD1b also recognizes ASCO in vivo (Fig 6E) as well as the U6 RNA taken as a positive control. Furthermore, SmD1b recognizes the four pathogenrelated transcripts assessed (Fig 6F) although only two out of three pathogen-related transcripts were DAS in smd1b mutants: ESP, SR34, but not NUDT7 (Fig 6GH, and EV10). SNC4 total transcript levels were dramatically reduced in the smd1b mutant, hindering the analysis of 
relative isoforms accumulation (Fig EV10J). Altogether, our results indicate that $A S C O$, an apparently intron-less IncRNA, interacts with PRP8a and SmD1b, two core components of the spliceosome, contributing to determine the dynamic ratio between hundreds of alternatively spliced mRNAs, notably pathogen-related genes. Hence, IncRNA are able to interact with multiple core components of the splicing machinery to modulate the splicing patterns of particular subsets of mRNAs.

\section{Discussion}

\section{Long noncoding RNAs modulate splicing regulatory networks}

We show here that reducing ASCO expression has a major effect on AS at genome-wide level in plants. In animals, different splicing factors can recognize IncRNAs in vivo (Romero-Barrios et al, 2018), e.g. Y-BOX BINDING PROTEIN 1 (YBX1; Suresh et al, 2018), POLY(RC) BINDING PROTEINS 1 and 2 (PCBP1/2; van Dijk et al, 2015), FOX proteins (Yin et al, 2012) and the serine-rich splicing factors, such as SRSF6 (Kong et al, 2016), among others. The IncRNA GOMAFU is recognized through a tandem array of UACUAAC motifs by the splicing factor SF1, which participates in the early stages of spliceosome assembly (Tsuiji et al, 2011). Furthermore, GOMAFU was found to directly interact with the splicing factors QUAKING homolog QKI and SRSF1 (Barry et al, 2013). In adult mice, GOMAFU is expressed in a specific group of neurons and has been implicated in retinal cell development (Rapicavoli and Blackshaw, 2009; Rapicavoli et al, 2010), brain development (Mercer et al, 2010) and postmitotic neuronal function (Sone et al, 2007; Mercer et al, 2008). GOMAFU's downregulation leads to aberrant AS patterns of typically schizophrenia-associated genes (Barry et al, 2013). Other IncRNAs recognized by splicing factors are NUCLEAR PARASPECKLE ASSEMBLY TRANSCRIPT 1 (NEAT1) and NEAT2 (also known as METASTASIS ASSOCIATED LUNG ADENOCARCINOMA TRANSCRIPT 1; MALAT1) (Hutchinson et al, 2007). RNA FISH analyses revealed an intimate association of NEAT1 and MALAT1 with the SC35 splicing factor containing nuclear speckles in both human and mouse cells, suggesting their participation in pre-mRNA splicing. Indeed, the ASCO IncRNA also interacts with NSRs and SmD1b both localized in nuclear speckles, whereas we show here that PRP8a seems to have nuclear localization in Arabidopsis. It was shown that NEAT1 localizes to the speckles periphery, whereas MALAT1 is part of the polyadenylated component of nuclear speckles (Hutchinson et al, 2007). MALAT1 acts as an oncogene transcript and its aberrant expression is involved in the development and progression of many types of cancers (Wang et al, 2015; Li et al, 2017; Malakar et al, 2017). MALAT1 can promote metastasis by interacting with the proline- and glutamine-rich splicing factor SFPQ, blocking its tumor suppression activity (Ji et al, 2014). In plants, little is known about the interaction between splicing factors and IncRNAs (Ariel et al, 2015; Romero-Barrios et al, 2018). NSRs are a family of RNA binding proteins that act as regulators of $A S$ and auxin-regulated developmental processes such as lateral root formation in A. thaliana. These proteins were first shown to interact with some of their alternatively spliced pre-mRNA targets and ASCO IncRNA (Bardou et al, 2014). More recently, a RIP-seq approach on an NSRa fusion protein in $A$. thaliana mutant background allowed the identification of genome-wide NSR targets, e.g. specific alternatively spliced mRNAs as well as a plethora of 
IncRNAs, including ASCO (Bazin et al, 2018). Strikingly, ASCO was detected albeit not among the most abundant IncRNA, suggesting the existence of an intricate network of multiple IncRNAs and splicing factors interactions. In fact, we showed here that the impact of ASCO deregulation on AS at genome-wide level barely overlaps with the defects observed in the $n s r a / b$ mutant background (with or without auxin), indicating that ASCO and NSRs participate in common as well as in independent molecular mechanisms related to AS.

\section{The ASCO IncRNA knocked-down plants show altered sensitivity to flagellin}

The comparison of the transcriptome of RNAi-ASCO and 35S:ASCO plants reveals common and specific subsets of DAS genes. This dual effect caused by the up- or down-regulation of ASCO accumulation hints to the potential relevance of a stoichiometric factor impacting the action of $A S C O$ within the spliceosome. ASCO silenced plants exhibit an enhanced sensitivity to flg22, in contrast to 35S:ASCO and nsra/b plants. In agreement, overexpressing ASCO plants and $n s r a / b$ mutants behave similarly in response to auxin (Bardou et al, 2014). Our results suggest that $A S C O$ has a wider function that the simple titration of NSR activity. Remarkably, we now determined that $A S C O$ is recognized by additional splicing factors: the spliceosome core components PRP8a and SmD1b. Accordingly, RNAi-ASCO lines and a prp8a leaky mutant exhibit similar AS defects of flg22-regulated genes. However, smd1b mutants resulted in a deregulated ratio of isoforms of only ESP and SR34, but not NUDT7. The milder effect of ASCO-related SmD1b over the subset of pathogen-related genes may be due to a compensatory role of SmD1a in the smd1b background. Moreover, core splicing factors null mutants usually gave very severe phenotypes or embryo lethality and smd1b and prp8a mutants are leaky alleles with partial effects on global constitutive splicing. Altogether, our results indicate that a complex network of IncRNAs and splicing factors involving ASCO, PRP8a, SmD1b and NSRs dynamically shapes transcriptome diversity, integrating developmental and environmental cues, thus conditioning the response to biotic stress (Fig 7). In Arabidopsis, the IncRNA ELF18-INDUCED LONG-NONCODING RNA 1 (ELENA1) is regulated by the perception of the translation elongation factor $\mathrm{Tu}$ (elf18) and it was identified as a factor enhancing resistance against Pseudomonas syringae. It was shown that ELENA1 directly interacts with Mediator subunit 19a (MED19a), modulating the enrichment of MED19a on the PATHOGENESIS-RELATED GENE1 (PR1) promoter (Seo et al, 2017). Several other examples of IncRNAs mediating the environmental control of gene expression illustrate the relevance of the noncoding transcriptome as a key integration factor between developmental and external cues (Marquadt et al., 2014; Heo and Sung 2011; Kim and Sung 2017; Kindgren et al 2018.) The sensitivity to pathogens has been shown to be affected in spliceosome-related mutants. For instance, it was recently reported that the prp40c mutants display an enhanced tolerance to Pseudomonas syringae (Hernando et al 2019, FPS). On the other hand, several other siplicing related genes have been identified as positive regulators of plant immunity against Pseudomonas (Jacqueline Monaghan et al., 2009 PLOS Pathogens; Palma, Zhao, Cheng, Bi, \& Monaghan, 2007 Genes and Dev; F. Xu, Xu, Wiermer, Zhang, \& Li, 2012 Plant Journal).

LncRNAs as highly variable components of the conserved spliceosomal machinery 
Here we show that the highly structured IncRNA ASCO, which does not contain introns, is capable to interact with PRP8a and modulate PRP8a binding to ASCO-related AS targets. The spliceosome is a large complex composed of five different small nuclear ribonucleoprotein complexes subunits (snRNPs). Each subunit includes noncoding and non-polyadenylated small nuclear uridine $(U)$-rich RNAs (U snRNAs) and core spliceosomal proteins, along with more than 200 non-snRNPs splicing factors (Herold et al, 2009). PRP8a is one of the largest and most highly conserved proteins in the nucleus of eukaryotic organisms. It occupies a central position in the catalytic core of the spliceosome and has been implicated in several crucial molecular rearrangements (Grainger and Beggs, 2005). In Arabidopsis, analysis of PRP8a leaky mutation suggests that PRP8a recognizes the IncRNA COOLAIR in vivo to modulate its AS (Marquardt et al, 2014) hinting an interaction with IncRNAs. COOLAIR designates a set of transcripts expressed in antisense orientation of the locus encoding the floral repressor FLC (Whittaker and Dean, 2017). Two main classes of COOLAIR IncRNAs are produced by AS and polyadenylation of antisense transcripts generated from the FLC locus. One uses a proximal splice site and a polyadenylation site located in intron 6 of $F L C$, whereas the distal one results from the use of a distal splice and polyadenylation sites located in the FLC promoter (Whittaker and Dean, 2017). Notably, prp8a partial loss of function leads to a reduced usage of COOLAIR proximal polyadenylation site and an increase of $F L C$ transcription which is associated with late flowering phenotypes (Marquardt et al, 2014). Interestingly, the FLC/COOLAIR module is strongly deregulated in the $n s r a / b$ double mutant and NSRa was linked to flowering time further supporting multiple interactions of IncRNAs and the splicing machinery (Bazin et al, 2018). Although NSRa-COOLAIR interaction seems not to occur, it was proposed that the control of NSRa over COOLAIR involves the direct interaction and processing of the polyadenylation regulatory gene FPA (Bazin et al, 2018). In the model legume Medicago truncatula, the NSRs closest homolog, RNA-BINDING PROTEIN 1 (RBP1), is localized in nuclear speckles where many components of the splicing machinery are hosted in plant cells. Remarkably, RBP1 interacts with a highly structured IncRNA, EARLY NODULIN 40 (ENOD40), which participates in root symbiotic nodule organogenesis (Crespi et al, 1994; Charon et al, 1999; Campalans et al, 2004). ENOD40 is highly conserved among legumes and was also found in other species such as rice (Oryza sativa; Gultyaev and Roussis, 2007), but shows no homology to ASCO IncRNA (Bardou et al, 2014). In contrast to the nuclear localization of Arabidopsis ASCO, ENOD40 was found both in the nucleus and the cytoplasm, and it is able to relocalize RBP1 from nuclear speckles into cytoplasmic granules during nodulation. These observations hint a role of the IncRNA ENOD40 in nucleocytoplasmic trafficking, potentially modulating RBP1-dependent splicing (Campalans et al, 2004) and further supporting the multiple interactions of IncRNAs with splicing regulators. A major result shown here is that ASCO is recognized by PRP8a and SmD1b, two central regulators of splicing and not only the NSR proteins which are plant-specific "peripheral" regulators of splicing. Indeed, the nsra/b null double mutants did not display major phenotypes in contrast to null PRP or SmD components. The identification of how the ASCO IncRNA interacts with PRP8a will certainly contribute to decipher the intricate network of IncRNAs fine-tuning the activity of core splicing factors, thus opening wide perspectives for the use of IncRNAs in the modulation of the dynamic population of alternatively spliced mRNAs in higher organisms. Interestingly, a search for ASCO homologues across the Brassicaceae family reveals that 9 additional copies of $A S C O$ exist in $A$. thaliana and related sequences are also 
present in other Brassicaceae species, including $A$. halleri, A. lyrata and the more distant species Capsella rubella and Capsella grandiflora (Fig EV 11A). However, none of the four detectable $A$. thaliana ASCO-like homologues suffered any significant alteration in RNAi-ASCO and 35S:ASCO lines (Fig EV 11B), suggesting that none of them seem to compensate for the absence or presence of the ASCO IncRNA. The existence of ASCO-like sequences in other species suggest that conserved IncRNA-mediated mechanisms of AS regulation may occur through the interaction with highly conserved splicing factors. As PRP8a and SmD1b as well as the snRNAs are highly conserved spliceosomal components in contrast to the outstanding variability of IncRNA sequences along evolution, our results hint to a yet undiscovered evolutionary layer in the regulation of AS in different cell types and environmental conditions without affecting essential splicing activity. Structure and short sequences inside IncRNAs may contribute to the evolution of splicing regulatory networks in eukaryotes.

\section{Materials and Methods}

\section{Plant material and growth conditions}

All the lines used in this study were in the $A$. thaliana Columbia-0 (Col-0) background. We used the $n s r a / b$ double mutant and the ASCO overexpressing lines from Bardou et al (2014). The insertion lines WiscDsLoxHs110_08A (asco-1) and SAIL_812_C08 (asco-2) were obtained from the T-DNA mutant collection at the Salk Institute Genomics Analysis Laboratory (SIGnAL, http://signal.salk.edu/cgi-bin/tdnaexpress) via NASC (http://arabidopsis.info/). Seeds from prp87 (Sasaki et al, 2015) and smd1b (Elvira-Matelot et al, 2016) mutants were provided by $\mathrm{H}$. Vaucheret. The pUBQ10:SmD1b-GFP line (Elvira-Matelot et al, 2016) was used for RNA immunoprecipitation assays. Plants were grown at $20^{\circ} \mathrm{C}$ with a 16 -h light/ 8-h dark photoperiod (long days) on solid half-strength Murashige and Skoog (1/2MS) medium.

\section{Generation of transgenic lines}

\section{ProASCO::GUS transgenic lines}

The promoter region of $A S C O$ (2631-bp upstream of the transcription start) was amplified from A. thaliana genomic DNA using gene-specific primers listed in Table EV5. The amplicon was subcloned into the pENTR/D-TOPO vector and recombined in a pKGWFS7 binary destination vector, upstream of the GFP and GUS sequences. ProASCO::GUS constructs were transferred into $A$. thaliana by standard Agrobacterium-mediated protocol (Clough and Bent, 1998). Three lines were selected based on 3:1 segregation for the transgene (single insertion) and brought to T3 generation where the transgene was in a homozygous state. All lines behave similarly as for GUS expression. 
The first 233-bp of the ASCO transcript was amplified from $A$. thaliana genomic DNA using gene-specific primers listed in Table EV5. Amplicons were sub-cloned into the pENTR/D-TOPO vector and recombined in a pFRN binary destination vector (Ariel et al, 2012) to target the ASCO RNA by long dsRNA hairpin formation.

\section{Root growth analysis}

For analysis of auxin impact on root architecture, plants were grown as described in Bardou et al (2014). Briefly, seeds were sterilized and directly sown on plates containing 1/2MS medium supplemented or not with 100 nM NAA. Plantlet root architecture was analyzed using the RootNav software after 7 days of growth (Pound et al, 2013). For analysis of flagellin impact on root architecture, plants were previously grown 5 days on solid $1 / 2 \mathrm{MS}$ medium $+1 \%$ sucrose and then transferred for additional 9 days in liquid 1/2MS media $+1 \%$ sucrose supplemented or not with $0.1 \mu \mathrm{M}$ or $1 \mu \mathrm{M}$ of synthetic flg22 peptide (GeneCust). For each plantlet, lateral roots were counted, and the primary root length was measured using the RootNav software. Experiments were done at least 2 times, with a minimum of 16 plants per genotype and condition. Statistical tests were performed using the Mann Whitney's $U$ test $(p<0.05)$.

\section{Root meristem measurements}

Plants were grown as for root growth analysis in response to flg22. The treated plants were stained with SCRI Renaissance 2200 (Renaissance Chemicals) as described in Musielak et al (2015). Images were obtained with LSM880 (Zeiss) confocal microscope. The SR2200 fluorescence was excited with a $405 \mathrm{~nm}$ laser line and emission recorded between 410 and 686 $\mathrm{nm}$ (405/410-686). Cell counting and primary root meristem measurements were performed using ImageJ package (https://imagej.nih.gov/ij/). Experiments were done 2 times, with a minimum of 18 plants per genotype and condition. Statistical tests were performed using the Student's T test $(p<0.05)$.

\section{Histochemical GUS staining}

Histochemical GUS staining was performed according to Latrasse et al (2013). Briefly, 10-dayold plantlets grown in standard conditions were fixed in cold $90 \%$ acetone and incubated overnight at $37^{\circ} \mathrm{C}$ in the GUS staining buffer. Roots were subsequently fixed in $4 \%$ paraformaldehyde for $1 \mathrm{~h}$ and washed several times in $70 \%$ ethanol before a final wash in $10 \%$ glycerol prior observation. Images were acquired using an AxiolmagerZ2 microscope (Zeiss).

\section{RNA extraction and RT-PCR analyses}

Total RNA was extracted using Quick-RNA Kit (ZYMO RESEARCH) and DNase treatment was performed according to the manufacturer's protocol. One $\mu \mathrm{g}$ of DNase-free RNA was reverse transcribed using Maxima $\mathrm{H}$ Minus Reverse Transcriptase (Thermo Scientific). cDNA was then amplified in RT-qPCRs using LightCycler 480 SYBR Green I Master (Roche) and transcriptspecific primers on a Roche LightCycler 480 thermocycler following standard protocol (45 cycles, $60^{\circ} \mathrm{C}$ annealing). Experiments were done in biological triplicates with at least three

technical replicates. Expression was normalized to 2 constitutive genes (AT1G13320 and 
AT4G26410; Wang et al, 2014). For analysis of flg22 impact on gene expression, plants were previously grown 9 days on solid 1/2MS medium $+1 \%$ sucrose and then transferred for additional $24 \mathrm{~h}$ in liquid 1/2MS medium $+1 \%$ sucrose before adding or not $1 \mu \mathrm{M}$ of flg22. Five plantlets were pooled for each replicate. The fold induction of expression after flg22 treatment was normalized to the WT response considered as $100 \%$. For analysis of gene expression after a flg22 kinetic, roots from 8 plants were pooled for each replicate. For AS analysis, isoform specific primers were designed for each differential event and the signal was normalized with respect to an internal gene probe (called INPUT) corresponding to a common exon for each group of transcripts. This allows differentiating the change of each isoforms independently of the expression level of the studied gene (splicing index) in each sample (Tran et al, 2016). The

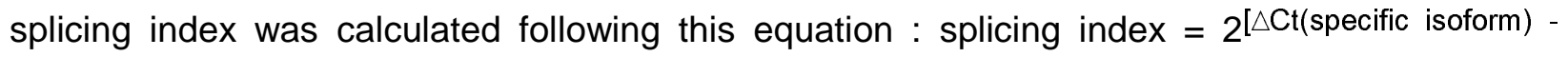

$(\triangle \mathrm{Ct}(\mathrm{INPUT})]$. Error bars on qRT-PCR experiments represent standard deviations, and significant differences were determined using a student's T test $(p<=0.05, n>=3)(n=3)$. All the used primers are listed in Table EV5.

For RT-PCR analysis, the amplification was performed using Phusion High-Fidelity DNA Polymerase and transcript-specific primers as manufacturer's protocol. PCR products were separated on an $8 \%$ polyacrylamide gel stained with SYBR Gold (Thermo Fischer Scientific) and revealed using a ChemiDoc MP Imaging System (Biorad). Band intensity was quantified using ImageJ package (https://imagej.nih.gov/ij/). Isoform ratio was calculated as the ratio of intensity of the two bands corresponding either to the alternatively-spliced or spliced transcript isoforms, respectively.

\section{Transcriptome studies}

Total RNA was extracted using RNeasy plant mini kit (Qiagen) from whole 14-day-old Col-0, 35S:ASCO1 and RNAi-ASCO1 plants grown on 1/2MS medium. Three independent biological replicates were produced per genotype. For each biological repetition and each point, RNA samples were obtained by pooling RNA from more than 200 plants. After RNA extraction, polyA RNAs were purified using Dynabeads mRNA direct micro kit (Ambion). Libraries were constructed using the Tru-Seq Stranded mRNA Sample Prep kit (Illumina®). Sequencing was carried out at the POPS Transcriptomic Platform, Institute of Plant Sciences Paris-Saclay in Orsay, France. The Illumina HiSeq2000 technology was used to perform paired-end 100-bp sequencing. A minimum of 30 million of paired-end reads by sample were generated. RNA-seq preprocessing included trimming library adapters and quality controls with Trimmomatic (Bolger et al, 2014). Paired-end reads with Phred Quality Score Qscore > 20 and read length > 30 bases were kept, and ribosomal RNA sequences were removed with SortMeRNA (Kopylova et al, 2012). Processed reads were aligned using Tophat2 with the following arguments : --maxmultihits 1 -i 20 --min-segment-intron 20 --min-coverage-intron 20 --library-type fr-firststrand -microexon-search -I 1000 --max-segment-intron 1000 --max-coverage-intron 1000 --b2-verysensitive. Reads overlappings exons per genes were counted using the FeatureCounts function of the Rsubreads package using the GTF annotation files from the Araport11 repository (https://www.araport.org/downloads/Araport11_Release_201606/annotation/Araport11_GFF3_g 
enes_transposons.201606.gff.gz). Significance of differential gene expression was estimated using DEseq2 (Love et al 2019), and the FDR correction of the p-value was used during pairwise comparison between genotypes. A gene was declared differentially expressed if its adjusted $p$-value (FDR) was $\leq 0.01$ and its absolute fold change was $\geq 1.5$.

\section{Gene Ontology analysis}

Gene ontology enrichment analysis was done using AgriGO (http://bioinfo.cau.edu.cn/agriGO) and default parameters.

\section{AS analysis}

The RNA profile analysis was performed using the RNAprof software (v1.2.6) according to Tran et al (2016). Briefly, RNAprof software allows detection of differential RNA processing events from the comparison of nucleotide level RNA-seq coverage normalized for change in gene expression between conditions. Here, the RNAprof analysis compared RNA-seq data from biological triplicates of WT, RNAi-ASCO1 and 35S:ASCO1 lines. Differentially processed regions genes were filtered as follows: fold change $>2$; $p$-value $<0.001$. Overlap between gene features and differentially processed regions was done using in-house $R$ scripts (https://github.com/JBazinIPS2/Bioinfo/blob/master/RNAprof events selection.Rrst). Only regions fully included in a gene features were kept for further analysis. The RNAprof software archive, including documentation and test sets, is available at the following address: http://rna.igmors.u-psud.fr/Software/rnaprof.php. Transcript level quantification was performed using pseudo-alignment counts with kallisto (Bray et al, 2016) on AtRTD2 transcripts sequences (https://ics.hutton.ac.uk/atRTD/RTD2/AtRTDv2 QUASI 19April2016.fa) with a K-mer size of 31nt. Differential AS events in the AtRTD2 database were detected using SUPPA2 (Trincado et al, 2018) with default parameters. Only events with an adjusted $p$-val $<0.01$ were kept for further analysis. Isoforms switch identification was performed with the IsoformSwitchAnalyzeR package (Vitting-Seerup and Sandelin 2019) according to Bazin et al (2018).

\section{Whole-mount immunolocalization}

Specific rabbit polyclonal antibodies were developed against PRP8a using the peptide TNKEKRERKVYDDED (Li International). Five-day-old seedlings were fixed with 4\% paraformaldehyde in MicroTubule Stabilization Buffer (MTSB; Pasternak et al, 2015) for $1 \mathrm{~h}$ and rinsed once in glycine $0.1 \mathrm{M}$ and twice with MTSB. Cell walls were partially digested for $45 \mathrm{~min}$ at $37^{\circ} \mathrm{C}$ in cellulase $\mathrm{R} 101 \% \mathrm{w} / \mathrm{v}$ (Onozuka), pectolyase $1 \% \mathrm{w} / \mathrm{v}$ and cytohelicase $0.5 \% \mathrm{w} / \mathrm{v}$ (Sigma) solution. After two PBS washes, root tissues were squashed on polylysine-treated glass slides (VWR International) and dipped in liquid nitrogen. The coverslip was then removed, and the slides were left to dry. After 2 rinses with PBS and 2 with PBS- $0.1 \%$ triton, they were treated with BSA 3\% in PBS-Triton buffer for $1 \mathrm{~h}$ and incubated with the anti-PRP8a antibody (dilution $1: 400$ ) for $16 \mathrm{~h}$ at $4^{\circ} \mathrm{C}$ in a humid chamber. After incubation, slides were rinsed 8-10 times with PBS-Triton and incubated for $1 \mathrm{~h}$ at $37^{\circ} \mathrm{C}$ with the secondary antibody (anti Rabbit IgG coupled to Alexa Fluor ${ }^{\circledR}$ 594, dilution 1:500; Thermo Scientific) and rinsed 10 times with PBS-Triton and 
once with PBS. Slides were mounted in Vectashield(C containing DAPI (VECTOR Laboratories). Images were obtained with LSM880 (Zeiss) confocal microscope equipped with PlanApochromat 63x/NA1,40 Oil M27 lens. Dapi and Alexa 594 fluorescences were respectively excited with $405 \mathrm{~nm}$ and $561 \mathrm{~nm}$ diodes and recorded between 410-500 nm and 570-695 nm.

\section{LncRNA-bound nuclear protein isolation by RNA purification}

A method adapted from the ChIRP protocol (Chu et al, 2011; Ariel et al, 2014; Chu and Chang, 2016) was developed to allow identification of nuclear proteins bound to specific IncRNAs. Briefly, plants were in vivo crosslinked, and nuclei of cells purified and extracted through sonication. The resulting supernatant was hybridized against biotinylated complementary oligonucleotides that tile the IncRNA of interest and putative IncRNA-containing protein complexes were isolated using magnetic streptavidin beads. Co-purified ribonucleoprotein complexes were eluted and used to purify RNA or proteins, which were later subject to downstream assays for identification and quantification.

Probe design. Antisense 20-nt oligonucleotide probes were designed against the ASCO fulllength sequence (AT1G67105) using an online designer at http://singlemoleculefish.com/. All probes were compared with the $A$. thaliana genome using the BLAST tool at the $\mathrm{NCBI}$, and probes returning noticeable homology to non- $A S C O$ targets were discarded. Eighteen probes were finally generated and split into two sets based on their relative positions along the ASCO sequence, such as EVEN-numbered and ODD-numbered probes were separately pooled. A symmetrical set of probes against LacZ RNA (Ariel et al, 2014) was also used as the mock control. All probes were ordered biotinylated at the 3' end (Invitrogen).

Crosslinking and ribonucleoprotein complexes purification. For protein extraction, approximately $250 \mathrm{~g}$ of 7-day-old Col-0 plants grown on solid half-strength MS medium were irradiated three times with UV using a CROSSLINKER® CL-508 (Uvitec) at $0.400 \mathrm{~J} / \mathrm{cm}^{2}$. For RNA extraction, 10 $\mathrm{g}$ of 7-day-old Col-0 plants grown on solid half-strength MS medium were crosslinked under vacuum for $15 \mathrm{~min}$ with $37 \mathrm{~mL}$ of $1 \%(\mathrm{v} / \mathrm{v})$ formaldehyde. The reaction was stopped by adding $2.5 \mathrm{~mL}$ of $2 \mathrm{M}$ glycine and seedlings were rinsed with Milli-Q purified water. For both crosslinking methods, $6 \mathrm{~g}$ of the fixed material was ground in liquid nitrogen and added to $50 \mathrm{~mL}$ tubes with $25 \mathrm{~mL}$ of Extraction Buffer 1 to $15 \mathrm{ml}$ of plant material ground to fine dust (the nuclei were prepared starting with $3050 \mathrm{ml}$-tube; Buffer 1: $10 \mathrm{mM}$ Tris- $\mathrm{HCl} \mathrm{pH} \mathrm{8,} 0.4 \mathrm{M}$ sucrose, 10 $\mathrm{mM} \mathrm{MgCl} 2,5 \mathrm{mM} \beta$-mercaptoethanol, $1 \mathrm{~mL} / 30 \mathrm{~g}$ of sample powder Protease Inhibitor Sigma Plant P9599). The solution was then filtered through Miracloth membrane (Sefar) into a new tube and $5 \mathrm{~mL}$ of Extraction Buffer $2\left(10 \mathrm{mM}\right.$ Tris- $\mathrm{HCl} \mathrm{pH} 8,0.25 \mathrm{M}_{\text {sucrose, }} 10 \mathrm{mM} \mathrm{MgCl}, 5$ $\mathrm{mM} \beta$-mercaptoethanol, 1\% Triton X-100, $50 \mu \mathrm{L}$ Protease Inhibitor) were added. The solution was then centrifuged, the supernatant discarded and $500 \mu \mathrm{L}$ of Extraction Buffer $3(10 \mathrm{mM}$ Tris$\mathrm{HCl} \mathrm{pH} \mathrm{8,} \mathrm{1.7} \mathrm{M} \mathrm{sucrose,} 2 \mathrm{mM} \mathrm{MgCl}, 5 \mathrm{mM} \beta$-mercaptoethanol, 0.15\% Triton X-100, $50 \mu \mathrm{L}$ Protease Inhibitor) and layered on top of fresh Extraction Buffer 3 in a new tube. After centrifugation at $13000 \mathrm{rpm}$ for $2 \mathrm{~min}$ at $4^{\circ} \mathrm{C}$ to pellet nuclei, the supernatant was discarded and the pellet resuspended in $300 \mu \mathrm{L}$ of Nuclei Lysis Buffer $(50 \mathrm{mM}$ Tris- $\mathrm{HCl} \mathrm{pH} 7,1 \% \mathrm{SDS}, 10 \mathrm{mM}$ EDT,; $1 \mathrm{mM}$ DTT, $50 \mu \mathrm{L}$ Protease Inhibitor, $10 \mu \mathrm{L}$ RNAse Inhibitor per tube) to degrade nuclear membranes. Samples were sonicated three times in refrigerated BIORUPTOR Plus 
(Diagenode), 10 cycles $30 \mathrm{sec}$ ON - 30 sec OFF in a Diagenode TPX microtube M-50001. After centrifugation, the supernatant was transferred to a new tube and diluted two times volume in Hybridization Buffer (50 mM Tris- $\mathrm{HCl} \mathrm{pH} \mathrm{7,} 750 \mathrm{mM} \mathrm{NaCl}, 1 \%$ SDS, 15\% Formamide, $1 \mathrm{mM}$ DTT, $50 \mu \mathrm{L}$ Protease Inhibitor, $10 \mu \mathrm{L}$ RNAse Inhibitor). One hundred pmol of probes were added to samples and incubated $4 \mathrm{~h}$ at $50^{\circ} \mathrm{C}$ in a thermocycler. Samples were transferred to tubes containing Dynabeads-Streptavidin C1 (Thermo Fisher Scientific) and incubated $1 \mathrm{~h}$ at $50^{\circ} \mathrm{C}$. Then samples were placed on a magnetic field and washed three times with $1 \mathrm{~mL}$ of Wash Buffer (2x SSC, 0.5\% SDS, 1 mM DTT, $100 \mu \mathrm{L}$ Protease Inhibitor).

Protein purification. Samples for protein extraction were DNase-treated according to the manufacturer (Thermo Scientific). After addition of $1.8 \mathrm{~mL}$ of TCA-Acetone ( $5 \mathrm{~mL} 6.1 \mathrm{~N} \mathrm{TCA}+$ $45 \mathrm{~mL}$ Acetone $+35 \mu \mathrm{L} \beta$-mercaptoethanol), samples were incubated overnight at $-80^{\circ} \mathrm{C}$. After centrifugation at $20000 \mathrm{rpm}$ for $20 \mathrm{~min}$ and $4^{\circ} \mathrm{C}$, the supernatant was discarded and $1.8 \mathrm{~mL}$ of Acetone Wash Buffer (120 mL Acetone, $84 \mu \mathrm{L} \beta$-mercaptoethanol) was added to the samples. Then, samples were incubated $1 \mathrm{~h}$ at $-20^{\circ} \mathrm{C}$, and centrifuged again at $20000 \mathrm{rpm}$ for $20 \mathrm{~min}$ and $4^{\circ} \mathrm{C}$. The supernatant was discarded, and the dry pellet was used for Mass Spectrometry analysis.

RNA purification. Samples for RNA extraction were boiled for 15 min after washing with $1 \mathrm{~mL}$ of Wash Buffer (2X SSC, 0.5\% SDS, $1 \mathrm{mM}$ DTT, $100 \mu \mathrm{L}$ Protease Inhibitor). Beads were removed in a magnetic field and Trizol/Chloroform RNA extraction was performed according to the manufacturer (Sigma). RNAs were precipitated using 2 volumes $\mathrm{EtOH} \mathrm{100 \% ,} \mathrm{10 \%} 3 \mathrm{M}$ sodium acetate and $1 \mu \mathrm{L}$ glycogen, and washed with $\mathrm{EtOH} 70 \%$. RNAs were kept at $-20^{\circ} \mathrm{C}$ before use for reverse transcription and RT-qPCR analysis.

\section{Liquid Chromatography - Mass Spectrometry (LC-MS) analysis}

Proteins purified from ribonucleoprotein complexes were analyzed using the King Abdullah University of Science and Technology proteomic facilities. Dry pellets of samples purified with either ODD, EVEN or LacZ probe sets were solubilized in Trypsin Buffer (Promega) for digestion into small peptides. The solubilized peptides were then injected into a $Q$ Exactive ${ }^{\mathrm{TM}}$ HF hybrid quadrupole-Orbitrap mass spectrometer (Thermo Scientific) with a Liquid Chromatography (LC) Acclaim PepMap C18 column (25 cm length x $75 \mu \mathrm{m}$ I.D. $\times 3 \mu \mathrm{m}$ particle size, $100 \AA$ porosity, Dionex). Data were analyzed for each sample using Mascot software (Matrix Science), with a minimal sensitivity of 2 detected peptides per identified protein.

\section{RNA immunoprecipitation}

Eleven-day-old plants grown in Petri dishes were irradiated three times with UV using a CL-508 cross-linker (Uvitec) at $0.400 \mathrm{~J} / \mathrm{cm}^{2}$. Briefly, fixed material was ground in liquid nitrogen and homogenized and nuclei isolated and lysed according to Gendrel et al (2005). RNA immunoprecipitation was basically performed as described by Carlotto et al (2015). The nuclei extract (input) was used for immunoprecipitation with $50 \mu \mathrm{L}$ of Dynabeads-Protein A (Thermo Fisher Scientific) and $1 \mu \mathrm{g}$ of anti-GFP antibodies (Abcam ab290) or anti-PRP8a (Li International), respectively. Beads were washed twice for $5 \mathrm{~min}$ at $4^{\circ} \mathrm{C}$ with wash buffer $1(150$ 
$\mathrm{mM} \mathrm{NaCl}, 1 \%$ Triton X-100, 0.5\% Nonidet P-40, 1 mM EDTA, and $20 \mathrm{mM}$ Tris- $\mathrm{HCl}, \mathrm{pH} 7.5)$ and twice with wash buffer $2(20 \mathrm{mM}$ Tris- $\mathrm{HCl}, \mathrm{pH} 8)$ and finally resuspended in $100 \mu \mathrm{L}$ Proteinase $\mathrm{K}$ buffer (100 mM Tris- $\mathrm{HCl}, \mathrm{pH} 7.4,50 \mathrm{mM} \mathrm{NaCl}$, and $10 \mathrm{mM}$ EDTA). Twenty microliters were saved for further immunoblot analysis. After Proteinase K (Ambion AM2546) treatment, beads were removed with a magnet, and the supernatants were transferred to a $2 \mathrm{~mL}$ tube. RNA was extracted using TriReagent (Sigma-Aldrich) as indicated by the manufacturer. Eighty microliters of nuclei extracts was used for input RNA extraction. The immunoprecipitation and input samples were treated with DNase, and random hexamers were used for subsequent RT. Quantitative real-time PCR reactions were performed using specific primers (Table EV5). Results were expressed as a percentage of cDNA detected after immunoprecipitation, taking the input sample as $100 \%$. For immunoblot analysis, immunoprecipitated proteins were eluted by incubating $20 \mu \mathrm{L}$ of beads in $20 \mu \mathrm{L}$ of $2 x$ SDS-loading buffer without $\beta$-mercaptoethanol (100 $\mathrm{mM}$ Tris- $\mathrm{HCl} \mathrm{pH} 6.8,20 \%$ glycerol, $12.5 \mathrm{mM}$ EDTA, $0.02 \%$ bromophenol blue) at $50^{\circ} \mathrm{C}$ for 15 min. Input, unbound and eluted fractions were boiled in 2x SDS loading buffer with $1 \% \beta$ mercaptoethanol for $10 \mathrm{~min}$, loaded onto a 4-20\% Mini-PROTEAN ${ }^{\circledR}$ TGX $^{\mathrm{TM}}$ Precast Protein Gels (Biorad) and transferred onto a PVDF membrane using the Mini Trans-Blot ${ }^{\circledR}$ Cell system (BioRad) for $3 \mathrm{~h}$ at $70 \mathrm{~V}$. Membranes were blocked in 5\% dry non-fat milk in PBST and probed using PRP8a antibody (1:500) and an HRP coupled anti-Rabbit secondary antibody (Biorad, $1: 10000)$. All antibodies were diluted in 1\% dry nonfat milk in PBST. Blots were revealed with the Clarity ECL substrate according the manufacturer instruction (BioRad) and imaged using the ChemiDoc system (BioRad).

\section{Data deposition}

Data was deposited in CATdb database (Gagnot et al, 2008; http://tools.ips2.u-psud.fr/CATdb/) with ProjectID NGS2016-07-ASCOncRNA. This project was submitted from CATdb into the international repository GEO (http://www.ncbi.nlm.nih.gov/geo) with ProjetID GSE135376.

\section{Acknowledgements}

Synthetic flg22 peptide was kindly provided by J. Colcombet (IPS2). Seeds from the prp8-7 (Sasaki et al, 2015) and the smd1b (Elvira-Matelot et al, 2016) leaky mutants were kindly provided by $\mathrm{H}$. Vaucheret. This work was supported by grants from ANPCyT (PICT 2016-0289 and -0007, Argentina), CNRS (Laboratoire International Associé NOCOSYM), the 'Laboratoire d'Excellence (LABEX)' Saclay Plant Sciences (SPS; ANR-10-LABX-40), the Ministère Français de l'Enseignement Supérieur et de la Recherche (RR) and the ANR grants (ANR- 15-CE200002-01 EPISYM and ANR 16-CE20-0003-04 SPLISIL) as well as the EPIMMUNITY International project between IPS2, France and KAUST University, Saudi Arabia. The POPS platform benefits from the support of the LabEx Saclay Plant Sciences-SPS (ANR-10-LABX0040-SPS). 


\section{Author contributions}

$\mathrm{RR}, \mathrm{JB}, \mathrm{NRB}, \mathrm{MM}, \mathrm{LL}, \mathrm{AC}, \mathrm{CC}$ and FA performed the experiments; RR, JB, CC, MB, MC and FA analyzed the data; JB performed bioinformatic analyses; JB, MC and FA designed the experiments; MC and FA conceived the study and wrote the manuscript.

\section{Conflict of interest}

The authors declare that they have no conflict of interest.

\section{References}

Alamancos GP, Pages A, Trincado JL, Bellora N \& Eyras E (2015) Leveraging transcript quantification for fast computation of alternative splicing profiles. RNA 21: 1521-1531

Ariel F, Brault-Hernandez M, Laffont C, Huault E, Brault M, Plet J, Moison M, Blanchet S, Ichante JL, Chabaud M, Carrere S, Crespi M, Chan RL \& Frugier F (2012) Two direct targets of cytokinin signaling regulate symbiotic nodulation in Medicago truncatula. Plant Cell 24: 3838-3852

Ariel F, Jegu T, Latrasse D, Romero-Barrios N, Christ A, Benhamed M \& Crespi M (2014) Noncoding transcription by alternative RNA polymerases dynamically regulates an auxin-driven chromatin loop. Mol. Cell 55: 383-396

Ariel F, Romero-Barrios N, Jegu T, Benhamed M \& Crespi M (2015) Battles and hijacks: noncoding transcription in plants. Trends Plant Sci. 20: 362-371

Asai T, Tena G, Plotnikova J, Willmann MR, Chiu W-L, Gomez-Gomez L, Boller T, Ausubel FM \& Sheen J (2002) MAP kinase signalling cascade in Arabidopsis innate immunity. Nature 415: 977-983

Bardou F, Ariel F, Simpson CG, Romero-Barrios N, Laporte P, Balzergue S, Brown JWS \& Crespi M (2014) Long Noncoding RNA Modulates Alternative Splicing Regulators in Arabidopsis. Dev. Cell 30: 166-176

Barry G, Briggs JA, Vanichkina DP, Poth EM, Beveridge NJ, Ratnu VS, Nayler SP, Nones K, Hu J, Bredy TW, Nakagawa S, Rigo F, Taft RJ, Cairns MJ, Blackshaw S, Wolvetang EJ \& Mattick JS (2014) The long non-coding RNA Gomafu is acutely regulated in response to neuronal activation and involved in schizophrenia-associated alternative splicing. Mol. Psychiatry 19: 486-494 
Bazin J, Romero N, Rigo R, Charon C, Blein T, Ariel F \& Crespi M (2018) Nuclear Speckle RNA Binding Proteins Remodel Alternative Splicing and the Non-coding Arabidopsis Transcriptome to Regulate a Crosstalk Between Auxin and Immune Responses. Front. Plant Sci. 9: 1209

Beck M, Wyrsch I, Strutt J, Wimalasekera R, Webb A, Boller T \& Robatzek S (2014) Expression patterns of flagellin sensing 2 map to bacterial entry sites in plant shoots and roots. J. Exp. Bot. 65: 6487-6498

Beltran M, Puig I, Pena C, Garcia JM, Alvarez AB, Pena R, Bonilla F \& de Herreros AG (2008) A natural antisense transcript regulates Zeb2/Sip1 gene expression during Snail1-induced epithelial-mesenchymal transition. Genes Dev. 22: 756-769

Bethke G, Unthan T, Uhrig JF, Poschl Y, Gust AA, Scheel D \& Lee J (2009) Flg22 regulates the release of an ethylene response factor substrate from MAP kinase 6 in Arabidopsis thaliana via ethylene signaling. Proc. Natl. Acad. Sci. U. S. A. 106: 80678072

Bolger AM, Lohse M \& Usadel B (2014) Trimmomatic: a flexible trimmer for Illumina sequence data. Bioinformatics 30: 2114-2120

Boon K-L, Grainger RJ, Ehsani P, Barrass JD, Auchynnikava T, Inglehearn CF \& Beggs JD (2007) prp8 mutations that cause human retinitis pigmentosa lead to a U5 snRNP maturation defect in yeast. Nat. Struct. Mol. Biol. 14: 1077-1083

Boudsocq M, Willmann MR, McCormack M, Lee H, Shan L, He P, Bush J, Cheng S-H \& Sheen J (2010) Differential innate immune signalling via $\mathrm{Ca}(2+)$ sensor protein kinases. Nature 464: 418-422

Bray NL, Pimentel H, Melsted P \& Pachter L (2016) Near-optimal probabilistic RNA-seq quantification. Nat. Biotechnol. 34: 525-527.

Campalans A, Kondorosi A \& Crespi M (2004) Enod40, a Short Open Reading Frame Containing mRNA, Induces Cytoplasmic Localization of a Nuclear RNA Binding Protein in Medicago truncatula. Plant Cell 16: 1047-1059

Carlotto N, Wirth S, Furman N, Ferreira Solari N, Ariel F, Crespi M \& Kobayashi K (2015) The chloroplastic DEVH $\square$ box RNA helicase INCREASED SIZE EXCLUSION LIMIT 2 involved in plasmodesmata regulation is required for group II intron splicing. Plant Cell \& Environment 39: 165-173

Charon C, Sousa C, Crespi M \& Kondorosi A (1999) Alteration of enod40 Expression Modifies Medicago truncatula Root Nodule Development Induced by Sinorhizobium meliloti. Plant Cell 11: 1953-1965 
Chaudhary S, Jabre I, Reddy ASN, Staiger D \& Syed NH (2019) Perspective on Alternative Splicing and Proteome Complexity in Plants. Trends Plant Sci. 24: 496-506

Chu C, Qu K, Zhong FL, Artandi SE \& Chang HY (2011) Genomic maps of long noncoding RNA occupancy reveal principles of RNA-chromatin interactions. Mol. Cell 44: 667678

Chu C \& Chang HY (2016) Understanding RNA-chromatin interactions using chromatin isolation by RNA purification (ChIRP). Methods Mol. Biol. 1480: 115-123

Claudius A-K, Romani P, Lamkemeyer T, Jindra M \& Uhlirova M (2014) Unexpected role of the steroid-deficiency protein ecdysoneless in pre-mRNA splicing. PLoS Genet. 10: e1004287

Clough SJ \& Bent AF (1998) Floral dip: a simplified method for Agrobacterium-mediated transformation of Arabidopsis thaliana. Plant J 16: 735-743

Conn VM, Hugouvieux V, Nayak A, Conos SA, Capovilla G, Cildir G, Jourdain A, Tergaonkar V, Schmid M, Zubieta C \& Conn SJ (2017) A circRNA from SEPALLATA3 regulates splicing of its cognate mRNA through R-loop formation. Nat. plants 3: 17053

Crespi MD, Jurkevitch E, Poiret M, d'Aubenton-Carafa Y, Petrovics G, Kondorosi E \& Kondorosi A (1994) enod40, a gene expressed during nodule organogenesis, codes for a non-translatable RNA involved in plant growth. EMBO J. 13: 5099-5112

Ding F, Cui P, Wang Z, Zhang S, Ali S \& Xiong L (2014) Genome-wide analysis of alternative splicing of pre-mRNA under salt stress in Arabidopsis. BMC Genomics 15: 431

Djebali S, Davis CA, Merkel A, Dobin A, Lassmann T, Mortazavi A, Tanzer A, Lagarde J, Lin W, Schlesinger F, Xue C, Marinov GK, Khatun J, Williams BA, Zaleski C, Rozowsky J, Roder M, Kokocinski F, Abdelhamid RF, Alioto T, et al (2012) Landscape of transcription in human cells. Nature 489: 101-108

Drechsel G, Kahles A, Kesarwani AK, Stauffer E, Behr J, Drewe P, Rätsch G \& Wachter A (2013) Nonsense-mediated decay of alternative precursor mRNA splicing variants is a major determinant of the Arabidopsis steady state transcriptome. Plant Cell 25: 37263742

Elvira-Matelot E, Bardou F, Ariel F, Jauvion V, Bouteiller N, Le Masson I, Cao J, Crespi MD \& Vaucheret $H$ (2016) The Nuclear Ribonucleoprotein SmD1 Interplays with Splicing, RNA Quality Control, and Posttranscriptional Gene Silencing in Arabidopsis. Plant Cell 28: 426-438

Faial T (2015) RNA splicing in common disease. Nat. Genet. 47: 105 
Filichkin SA, Priest HD, Givan SA, Shen R, Bryant DW, Fox SE, Wong W-K \& Mockler TC (2010) Genome-wide mapping of alternative splicing in Arabidopsis thaliana. Genome Res. 20: 45-58

Gagnot S, Tamby JP, Martin-Magniette ML, Bitton F, Taconnat L, Balzergue S, Aubourg S, Renou JP, Lecharny A \& Brunaud V (2008) CATdb: a public access to Arabidopsis transcriptome data from the URGV-CATMA platform. Nucleic Acids Res. 36: D986-90

Gendrel A-V, Lippman Z, Martienssen R \& Colot V (2005) Profiling histone modification patterns in plants using genomic tiling microarrays. Nat. Methods 2: 213-218

Gerstein MB, Rozowsky J, Yan K-K, Wang D, Cheng C, Brown JB, Davis CA, Hillier L, Sisu C, Li JJ, Pei B, Harmanci AO, Duff MO, Djebali S, Alexander RP, Alver BH, Auerbach R, Bell K, Bickel PJ, Boeck ME, et al (2014) Comparative analysis of the transcriptome across distant species. Nature 512: 445-448

Gomez-Gomez L, Felix G \& Boller T (1999) A single locus determines sensitivity to bacterial flagellin in Arabidopsis thaliana. Plant J. 18: 277-284

Gonzalez S, Garcia A, Vazquez E, Serrano R, Sanchez M, Quintales L \& Antequera F (2016) Nucleosomal signatures impose nucleosome positioning in coding and noncoding sequences in the genome. Genome Res. 26: 1532-1543

Grainger RJ \& Beggs JD (2005) Prp8 protein: at the heart of the spliceosome. RNA 11: 533-557

Gultyaev AP \& Roussis A (2007) Identification of conserved secondary structures and expansion segments in enod40 RNAs reveals new enod40 homologues in plants. Nucleic Acids Res. 35: 3144-3152

Herold N, Will CL, Wolf E, Kastner B, Urlaub H \& Luhrmann R (2009) Conservation of the protein composition and electron microscopy structure of Drosophila melanogaster and human spliceosomal complexes. Mol. Cell. Biol. 29: 281-301

Hutchinson JN, Ensminger AW, Clemson CM, Lynch CR, Lawrence JB \& Chess A (2007) A screen for nuclear transcripts identifies two linked noncoding RNAs associated with SC35 splicing domains. BMC Genomics 8: 39

Jabre I, Reddy ASN, Kalyna M, Chaudhary S, Khokhar W, Byrne LJ, Wilson CM \& Syed $\mathrm{NH}$ (2019) Does co-transcriptional regulation of alternative splicing mediate plant stress responses? Nucleic Acids Res. 47: 2716-2726

Ji Q, Zhang L, Liu X, Zhou L, Wang W, Han Z, Sui H, Tang Y, Wang Y, Liu N, Ren J, Hou $F$ \& Li Q (2014) Long non-coding RNA MALAT1 promotes tumour growth and metastasis in colorectal cancer through binding to SFPQ and releasing oncogene PTBP2 from SFPQ/PTBP2 complex. Br. J. Cancer 111: 736-748 
Kalyna M, Simpson CG, Syed NH, Lewandowska D, Marquez Y, Kusenda B, Marshall J, Fuller J, Cardle L, McNicol J, Dinh HQ, Barta A \& Brown JWS (2012) Alternative splicing and nonsense-mediated decay modulate expression of important regulatory genes in Arabidopsis. Nucleic Acids Res. 40: 2454-2469

Kissen R, Hyldbakk E, Wang C-W V, Sørmo CG, Rossiter JT \& Bones AM (2012) Ecotype dependent expression and alternative splicing of epithiospecifier protein (ESP) in Arabidopsis thaliana. Plant Mol. Biol. 78: 361-375

Koncz C, Dejong F, Villacorta N, Szakonyi D \& Koncz Z (2012) The spliceosome-activating complex: molecular mechanisms underlying the function of a pleiotropic regulator. Front. Plant Sci. 3: 9

Kong J, Sun W, Li C, Wan L, Wang S, Wu Y, Xu E, Zhang H \& Lai M (2016) Long noncoding RNA LINC01133 inhibits epithelial-mesenchymal transition and metastasis in colorectal cancer by interacting with SRSF6. Cancer Lett. 380: 476-484

Kopylova E, Noé L \& Touzet H (2012) SortMeRNA: fast and accurate filtering of ribosomal RNAs in metatranscriptomic data. Bioinformatics 28: 3211-3217

Laloum T, Martin G \& Duque P (2018) Alternative Splicing Control of Abiotic Stress Responses. Trends Plant Sci. 23: 140-150

Latrasse D, Jégu T, Meng PH, Mazubert C, Hudik E, Delarue M, Charon C, Crespi M, Hirt H, Raynaud C, Bergounioux C \& Benhamed M. (2013) Dual function of MIPS1 as a metabolic enzyme and transcriptional regulator. Nucleic Acids Res. 41: 2907-2917

Li Y, Sawada Y, Hirai A, Sato M, Kuwahara A, Yan X \& Hirai MY (2013) Novel insights into the function of Arabidopsis R2R3-MYB transcription factors regulating aliphatic glucosinolate biosynthesis. Plant Cell Physiol. 54: 1335-1344

Li Y, Wu Z, Yuan J, Sun L, Lin L, Huang N, Bin J, Liao Y \& Liao W (2017) Long non-coding RNA MALAT1 promotes gastric cancer tumorigenicity and metastasis by regulating vasculogenic mimicry and angiogenesis. Cancer Lett. 395: 31-44

Libault M, Wan J, Czechowski T, Udvardi M \& Stacey G (2007) Identification of 118 Arabidopsis transcription factor and 30 ubiquitin-ligase genes responding to chitin, a plant-defense elicitor. Mol. Plant. Microbe. Interact. 20: 900-911

Liu S, Kracher B, Ziegler J, Birkenbihl RP \& Somssich IE (2015) Negative regulation of ABA signaling by WRKY33 is critical for Arabidopsis immunity towards Botrytis cinerea 2100. Elife 4: e07295

Malakar P, Shilo A, Mogilevsky A, Stein I, Pikarsky E, Nevo Y, Benyamini H, Elgavish S, Zong X, Prasanth K V \& Karni R (2017) Long Noncoding RNA MALAT1 Promotes 
Hepatocellular Carcinoma Development by SRSF1 Upregulation and mTOR Activation. Cancer Res. 77: 1155-1167

Malamy JE \& Benfey PN (1997) Organization and cell differentiation in lateral roots of Arabidopsis thaliana. Development 124: 33-44

Marquardt S, Raitskin O, Wu Z, Liu F, Sun Q \& Dean C (2014) Functional consequences of splicing of the antisense transcript COOLAIR on FLC transcription. Mol. Cell 54: 156165

Marquez Y, Brown JWS, Simpson C, Barta A \& Kalyna M (2012) Transcriptome survey reveals increased complexity of the alternative splicing landscape in Arabidopsis. Genome Res. 22: 1184-1195

Mercer TR, Dinger ME, Sunkin SM, Mehler MF \& Mattick JS (2008) Specific expression of long noncoding RNAs in the mouse brain. Proc Natl Acad Sci USA 105: 716-721

Mercer TR, Qureshi IA, Gokhan S, Dinger ME, Li G, Mattick JS \& Mehler MF (2010) Long noncoding RNAs in neuronal-glial fate specification and oligodendrocyte lineage maturation. BMC Neurosci. 11: 14

Moffat CS, Ingle RA, Wathugala DL, Saunders NJ, Knight H \& Knight MR (2012) ERF5 and ERF6 play redundant roles as positive regulators of JA/Et-mediated defense against Botrytis cinerea in Arabidopsis. PLoS One 7: e35995

Mohr TJ, Mammarella ND, Hoff T, Woffenden BJ, Jelesko JG \& McDowell JM (2010) The Arabidopsis downy mildew resistance gene RPP8 is induced by pathogens and salicylic acid and is regulated by $\mathrm{W}$ box cis elements. Mol. Plant. Microbe. Interact. 23: $1303-1315$

Munekage YN, Inoue S, Yoneda Y \& Yokota A (2015) Distinct palisade tissue development processes promoted by leaf autonomous signalling and long-distance signalling in Arabidopsis thaliana. Plant. Cell Environ. 38: 1116-1126

Musielak TJ, Schenkel L, Kolb M, Henschen A \& Bayer M (2015) A simple and versatile cell wall staining protocol to study plant reproduction. Plant Reprod. 28: 161-169

O'Malley RC, Huang S-SC, Song L, Lewsey MG, Bartlett A, Nery JR, Galli M, Gallavotti A \& Ecker JR (2016) Cistrome and Epicistrome Features Shape the Regulatory DNA Landscape. Cell 165: 1280-1292

Palusa SG, Ali GS \& Reddy ASN (2007) Alternative splicing of pre-mRNAs of Arabidopsis serine/arginine-rich proteins: regulation by hormones and stresses. Plant J. 49: 10911107 
Pan Q, Shai O, Lee LJ, Frey BJ \& Blencowe BJ (2008) Deep surveying of alternative splicing complexity in the human transcriptome by high-throughput sequencing. Nat. Genet. 40: 1413-1415

Pasternak T, Tietz O, Rapp K, Begheldo M, Nitschke R, Ruperti B \& Palme K (2015) Protocol: an improved and universal procedure for whole-mount immunolocalization in plants. Plant Methods 11: 50

Pauwels L, Morreel K, De Witte E, Lammertyn F, Van Montagu M, Boerjan W, Inze D \& Goossens A (2008) Mapping methyl jasmonate-mediated transcriptional reprogramming of metabolism and cell cycle progression in cultured Arabidopsis cells. Proc. Natl. Acad. Sci. U. S. A. 105: 1380-1385

Pedroza-Garcia J-A, Mazubert C, Del Olmo I, Bourge M, Domenichini S, Bounon R, Tariq Z, Delannoy E, Pineiro M, Jarillo JA, Bergounioux C, Benhamed M \& Raynaud C (2017) Function of the Plant DNA Polymerase Epsilon in Replicative Stress Sensing, a Genetic Analysis. Plant Physiol. 173: 1735-1749

Poncini L, Wyrsch I, Denervaud Tendon V, Vorley T, Boller T, Geldner N, Metraux J-P \& Lehmann S (2017) In roots of Arabidopsis thaliana, the damage-associated molecular pattern AtPep1 is a stronger elicitor of immune signalling than flg22 or the chitin heptamer. PLoS One 12: e0185808

Pound MP, French AP, Atkinson JA, Wells DM, Bennett MJ \& Pridmore T (2013) RootNav: navigating images of complex root architectures. Plant Physiol. 162: 1802-1814

Rapicavoli NA \& Blackshaw S (2009) New meaning in the message: noncoding RNAs and their role in retinal development. Dev. Dyn. 238: 2103-2114

Rapicavoli NA, Poth EM \& Blackshaw S (2010) The long noncoding RNA RNCR2 directs mouse retinal cell specification. BMC Dev. Biol. 10: 49

Reddy ASN, Marquez Y, Kalyna M \& Barta A (2013) Complexity of the alternative splicing landscape in plants. Plant Cell 25: 3657-3683

Rigo R, Bazin J, Crespi M \& Charon C (2019) Alternative splicing in the regulation of plantmicrobe interactions. Plant Cell Physiol. 60: 1906-1916

Romero-Barrios N, Legascue MF, Benhamed M, Ariel F \& Crespi M (2018) Splicing regulation by long noncoding RNAs. Nucleic Acids Res. 46: 2169-2184

Sasaki T, Kanno T, Liang SC, Chen AY, Liao WW, Lin WD, Matzke A \& Matzke M (2015) An Rtf2 domain-containing protein influences pre-mRNA splicing and is essential for embryonic development in Arabidopsis thaliana. Genetics 200: 523-535 
Schenk PM, Kazan K, Rusu AG, Manners JM \& Maclean DJ (2005) The SEN1 gene of Arabidopsis is regulated by signals that link plant defence responses and senescence. Plant Physiol. Biochem. 43: 997-1005

Seo JS, Sun HX, Park BS, Huang CH, Yeh SD, Jung C \& Chua NH (2017) ELF18INDUCED LONG-NONCODING RNA associates with mediator to enhance expression of innate immune response genes in Arabidopsis. Plant Cell 29:1024-1038

Sone M, Hayashi T, Tarui H, Agata K, Takeichi M \& Nakagawa S (2007) The mRNA-like noncoding RNA Gomafu constitutes a novel nuclear domain in a subset of neurons. J. Cell Sci. 120: 2498-2506

Song X, Liu G, Huang Z, Duan W, Tan H, Li Y \& Hou X (2016) Temperature expression patterns of genes and their coexpression with LncRNAs revealed by RNA-Seq in nonheading Chinese cabbage. BMC Genomics 17: 297

Suresh PS, Tsutsumi R \& Venkatesh T (2018) YBX1 at the crossroads of non-coding transcriptome, exosomal, and cytoplasmic granular signaling. Eur. J. Cell Biol. 97: 163-167

Straus MR, Rietz S, Ver Loren van Themaat E, Bartsch M \& Parker JE (2010) Salicylic acid antagonism of EDS1-driven cell death is important for immune and oxidative stress responses in Arabidopsis. Plant J. 62: 628-640

Syed NH, Kalyna M, Marquez Y, Barta A \& Brown JWS (2012) Alternative splicing in plants--coming of age. Trends Plant Sci. 17: 616-623

Tanabe N, Yoshimura K, Kimura A, Yabuta Y \& Shigeoka S (2007) Differential expression of alternatively spliced mRNAs of Arabidopsis SR protein homologs, atSR30 and atSR45a, in response to environmental stress. Plant Cell Physiol. 48: 1036-1049

Tanackovic G, Ransijn A, Ayuso C, Harper S, Berson EL \& Rivolta C (2011) A missense mutation in PRPF6 causes impairment of pre-mRNA splicing and autosomal-dominant retinitis pigmentosa. Am. J. Hum. Genet. 88: 643-649

Tran VDT, Souiai O, Romero-Barrios N, Crespi M \& Gautheret D (2016) Detection of generic differential RNA processing events from RNA-seq data. RNA Biol. 13: 59-67

Trincado JL, Entizne JC, Hysenaj G, Singh B, Skalic M, Elliott DJ \& Eyras E (2018) SUPPA2: fast, accurate, and uncertainty-aware differential splicing analysis across multiple conditions. Genome Biol. 19: 40

Tsuiji $H$, Yoshimoto R, Hasegawa $Y$, Furuno M, Yoshida M \& Nakagawa S (2011) Competition between a noncoding exon and introns: Gomafu contains tandem UACUAAC repeats and associates with splicing factor-1. Genes Cells 16: 479-490 
van Dijk M, Visser A, Buabeng KML, Poutsma A, van der Schors RC \& Oudejans CBM (2015) Mutations within the LINC-HELLP non-coding RNA differentially bind ribosomal and RNA splicing complexes and negatively affect trophoblast differentiation. Hum. Mol. Genet. 24: 5475-5485

Villamizar O, Chambers CB, Riberdy JM, Persons DA \& Wilber A (2016) Long noncoding RNA Saf and splicing factor 45 increase soluble Fas and resistance to apoptosis. Oncotarget 7: 13810-13826

Vitting-Seerup K \& Sandelin A (2017) The landscape of isoform switches in human cancers. Mol. Cancer Res. 15: 1206-1220

Vitting-Seerup K \& Sandelin A (2019) IsoformSwitchAnalyzeR: analysis of changes in genome-wide patterns of alternative splicing and its functional consequences. Bioinformatics 35: 4469-4471

Wang D, Ding L, Wang L, Zhao Y, Sun Z, Karnes RJ, Zhang J \& Huang H (2015) LncRNA MALAT1 enhances oncogenic activities of EZH2 in castration-resistant prostate cancer. Oncotarget 6: 41045-41055

Wang ET, Sandberg R, Luo S, Khrebtukova I, Zhang L, Mayr C, Kingsmore SF, Schroth GP \& Burge CB (2008) Alternative isoform regulation in human tissue transcriptomes. Nature 456: 470-476

Wang H, Wang J, Jiang J, Chen S, Guan Z, Liao Y \& Chen F (2014) Reference genes for normalizing transcription in diploid and tetraploid Arabidopsis. Sci. Rep. 4: 6781

West JA, Davis CP, Sunwoo H, Simon MD, Sadreyev RI, Wang PI, Tolstorukov MY \& Kingston RE (2014) The long noncoding RNAs NEAT1 and MALAT1 bind active chromatin sites. Mol. Cell 55: 791-802

Whittaker C \& Dean C (2017) The FLC Locus: A Platform for Discoveries in Epigenetics and Adaptation. Annu. Rev. Cell Dev. Biol. 33: 555-575

Xu S, Zhang Z, Jing B, Gannon P, Ding J, Xu F, Li X \& Zhang Y (2011) Transportin-SR is required for proper splicing of resistance genes and plant immunity. PLoS Genet. 7: e1002159

Yan K, Liu P, Wu C-A, Yang G-D, Xu R, Guo Q-H, Huang J-G \& Zheng C-C (2012) Stressinduced alternative splicing provides a mechanism for the regulation of microRNA processing in Arabidopsis thaliana. Mol. Cell 48: 521-531

Yin Q-F, Yang L, Zhang Y, Xiang J-F, Wu Y-W, Carmichael GG \& Chen L-L (2012) Long noncoding RNAs with snoRNA ends. Mol. Cell 48: 219-230 
Yoshida K, Sanada M, Shiraishi Y, Nowak D, Nagata Y, Yamamoto R, Sato Y, SatoOtsubo A, Kon A, Nagasaki M, Chalkidis G, Suzuki Y, Shiosaka M, Kawahata R, Yamaguchi T, Otsu M, Obara N, Sakata-Yanagimoto M, Ishiyama K, Mori $H$, et al (2011) Frequent pathway mutations of splicing machinery in myelodysplasia. Nature 478: $64-69$

Zhan X, Qian B, Cao F, Wu W, Yang L, Guan Q, Gu X, Wang P, Okusolubo TA, Dunn SL, Zhu J-K \& Zhu J (2015) An Arabidopsis PWI and RRM motif-containing protein is critical for pre-mRNA splicing and ABA responses. Nat. Commun. 6: 8139

Zhang R, Calixto CPG, Marquez Y, Venhuizen P, Tzioutziou NA, Guo W, Spensley M, Entizne JC, Lewandowska D, Ten Have S, Frei Dit Frey N, Hirt H, James AB, Nimmo HG, Barta A, Kalyna M \& Brown JWS (2017) A high quality Arabidopsis transcriptome for accurate transcript-level analysis of alternative splicing. Nucleic Acids Res. 45: 5061-5073

Zhang X-N, Mo C, Garrett WM \& Cooper B (2014) Phosphothreonine 218 is required for the function of SR45.1 in regulating flower petal development in Arabidopsis. Plant Signal. Behav. 9: e29134

Zhang Y, Zhang X-O, Chen T, Xiang J-F, Yin Q-F, Xing Y-H, Zhu S, Yang L \& Chen L-L (2013) Circular intronic long noncoding RNAs. Mol. Cell 51: 792-806

Zhang Z, Liu Y, Ding P, Li Y, Kong Q \& Zhang Y (2014) Splicing of receptor-like kinaseencoding SNC4 and CERK1 is regulated by two conserved splicing factors that are required for plant immunity. Mol. Plant 7: 1766-1775

Zipfel C, Robatzek S, Navarro L, Oakeley EJ, Jones JDG, Felix G \& Boller T (2004) Bacterial disease resistance in Arabidopsis through flagellin perception. Nature 428: 764-767

\section{Figure legends}

Figure 1. ASCO modulates steady-state levels of transcripts involved in plant immune responses affecting the sensitivity to flg22 peptide.

A Number of differentially up- and down-regulated genes (DEG) in RNAi-ASCO1 seedlings as compared to wild type (WT) according to the RNA-seq approach (FDR $<0.01,|\log 2 \mathrm{FC}|>=$ 0.75).

B Fraction of DEG found in each transcript class as defined in the Araport11 gene annotation. AS stands for antisense.

C Enriched Gene Ontology (GO) of DEG in RNAi-ASCO1 seedlings as compared to WT, x-axis represent the -log10 FDR for the enrichment of each GO category over genome frequency. 
D A representative picture of 14-day-old plants grown 9 days in liquid 1/2MS supplemented with $1 \mu \mathrm{M}$ flg22.

E Lateral root density of WT and two independent RNAi-ASCO lines 9 days after transfer in 1/2MS supplemented with $0.1 \mu \mathrm{M}$ or $1 \mu \mathrm{M}$ flg22.

F A representative picture of root apical meristems after cell wall staining, in response to flg22.

TZ: Transition Zone; QC: Quiescent Center.

G Root apical meristem size of WT and RNAi-ASCO1.

Error bars indicate the standard error. The asterisk $\left(^{*}\right)$ indicates a significant difference as determined by Mann Whitney's $U$ test $p<0.05, n=18$.

Figure 2. ASCO modulates alternative splicing.

A Comparison of differentially processed transcripts (RNAprof) and differential AS genes (AtRTD2-SUPPA) with Differentially Expressed Genes (DEG).

B Number of genes containing at least one differential RNA processing event (as defined by RNAprof p.adj < 0.001) in CDS, introns, 5'UTR and 3'UTR between RNAi-ASCO1 and WT. Up and Down fractions correspond to increase or decrease, respectively, of RNA-seq coverage in RNAi-ASCO1 for each specified gene feature.

C Proportion of DAS events identified by AtRTD2-SUPPA in RNAi-ASCO1 compared to WT; Alternative 3' site (A3'), Alternative 5' site (A5'), Intron Retention (IR), Exon skipping (ES).

D Comparison of differentially processed transcripts (RNAprof) and differentially AS genes (AtRTD2-SUPPA) with genes showing significant isoform switch events (Isoswitch).

E Summary of the predicted consequence of the isoform switch events as shown by the feature acquired by the upregulated isoform. ncRNA stands for noncoding RNA, and NMD stands for nonsense mediated decay.

F Comparison of differentially processed transcripts (RNAprof), differentially AS genes (AtRTD2-SUPPA) and differentially expressed genes (DEG) with genes significantly upregulated in the upf1upf3 mutant, indicating genes potentially regulated by NMD.

Figure 3. RNAi:ASCO and 35S:ASCO lines exhibit altered sensitivity to flg22 peptide and share some DEG and DAS targets.

A, B Primary root length (A) and lateral root density (B) of WT, two RNAi-ASCO and two 35S:ASCO independent lines 9 days after transfer in 1/2MS supplemented with $1 \mu \mathrm{M}$ flg22. Error bars indicate the standard error. The asterisk $\left(^{*}\right)$ indicates a significant difference as determined by Mann Whitney's U test $<0.05, \mathrm{n}=24$.

C Overlap between differentially expressed (DEG) and spliced (DAS) genes in RNAi-ASCO and 35S:ASCO as compared to WT.

D Scatter plot showing the respective gene expression fold change in RNAi-ASCO and 35S:ASCO lines as compared to WT. Genes showing significant changes in RNAi-ASCO and 35S:ASCO are highlighted as yellow and blue dots, respectively. 
E Scatter plot showing the respective Percent Spliced In difference (dPSI) in RNAi-ASCO and 35S:ASCO lines as compared to WT. Genes showing significant changes in RNAi-ASCO, 35S:ASCO or in both lines are highlighted as red, green or blue dot, respectively.

Figure 4. Validation of AS events in RNAi-ASCO lines.

A, D Differential RNA processing events of SR34 (AT1G02840) and NUDT7 (AT4G12720) transcripts detected by RNAprof from the comparison of RNA-seq libraries of 14-day-old WT (red) and RNAi-ASCO1 (blue) plants. Three biological replicates were used. Vertical purple lines and $\mathrm{p}$-values indicate significant differential processing events. Structure of SR34 (A) and NUDT7 (D) RNA isoforms. Large black boxes indicate exons, narrow black boxes indicate UTRs, black lines indicate introns. Colored boxes indicate protein domains affected by an AS event. Red arrows indicate probes used for gel electrophoresis.

B, E Analyses of RT-PCR products of SR34 (B) and NUDT7 (E) transcripts on $8 \%$ acrylamide gel.

C, F Quantification of the ratio of SR34 (C) and NUDT7 (D) isoforms detected in the gel in (B) and $(\mathbf{E})$ respectively. RNAs were extracted from WT and RNAi-ASCO1 14-day-old plants. The asterisk $\left({ }^{*}\right)$ indicates a significant difference as determined by Student's $T$ test $<0.05, n=3$.

\section{Figure 5. ASCO modulates the activity of the spliceosome component PRP8a.}

A Analysis of ASCO enrichment by ChIRP using two sets of independent biotinylated probes ODD and EVEN compared to negative control with probes designed against the LacZ RNA. The fold enrichment was calculated between ODD or EVEN samples against LacZ. These samples were used for protein precipitation and Mass Spectrometry analyses (ChIRP-MS), from which PRP8a was identified as a potential ASCO partner.

B Validation of PRP8a-ASCO interaction by PRP8a-RIP. U5 RNA was used as a positive control.

C Immunoblot analysis was performed on input, unbound and IP fraction (anti-GFP and anti-lgG negative control)

D PRP8a recognition of a subset of DAS RNAs is impaired in the 35S:ASCO plants. In B and D, the results are expressed as a percentage of the Input for PRP8a RIP followed by RT-qPCR, and IgG RIP was used as a negative control. Error bars represent the standard error of 3 biological replicates. N/D stands for non-detectable.

\section{Figure 6. PRP8a and SmD1b regulate AS of ASCO mRNA targets.}

A ASCO transcript levels in WT and prp8a mutants.

B, C prp8a leaky mutant displays similar AS events as observed in RNAi-ASCO. Quantification of $S R 34(\mathbf{B})$ and $E S P(\mathbf{C})$ isoforms by RT-qPCR. 
D ASCO transcript levels in smd1b mutant. In A and D RNAs were extracted from WT, prp8a and smd1b 14-day-old plants.

E SmD1b can bind ASCO in vivo. U6 RNA was used as a positive control and a housekeeping gene (HKG2, AT4G26410) RNA as a negative control.

$\mathbf{F}$ SmD1b recognizes in vivo the RNAs of 4 genes regulated by $A S C O$. In $\mathbf{E}$ and $\mathbf{F}$ the results were expressed as \% INPUT in SmD1b-RIP and IgG-RIP used as a negative control.

G, H smd1b mutant displays similar AS events as observed in RNAi-ASCO. Quantification of SR34 $(\mathbf{G})$ and ESP $(\mathbf{H})$ isoforms by RT-qPCR.

The asterisk $\left(^{*}\right)$ indicates a significant difference as determined by Student's $T$ test $<0.05, \mathrm{n}=$ 3.

Figure 7. The interaction of ASCO IncRNA and the spliceosome components PRP8a and SmD1b shapes the transcriptional response to flg22 modulating alternative splicing.

Proposed mechanism of ASCO IncRNA action. ASCO hijacks NSR proteins to modulate the population of alternatively spliced transcripts. Additionally, ASCO is recognized by PRP8a and SmD1b, two core components of the spliceosome, conditioning the SmD1b/PRP8a-dependent transcriptome diversity in response to flagellin.

\section{Expanded View Figure Legends}

Figure EV1. The response to flg22 is altered in RNAi-ASCO lines.

A ASCO transcript levels in 2 independent 14-day-old RNAi-ASCO lines compared to WT.

B RNA-seq read coverage on ASCO IncRNA in RNAi-ASCO and WT seedlings RNA-seq data. The region cloned to generate dsRNA is indicated on the gene structure. Coverage plots were made with IGV software (Robinson et al., 2018) using normalized (read per million) bigwig files. The same scale (0-200) was used for each track.

C, D Primary root length (C) and lateral root density (D) of WT and two independent RNAiASCO lines grown on media with or without 100 nM NAA and measured 7 days after germination. The asterisk $\left({ }^{*}\right)$ indicates a significant difference as determined by Mann Whitney's $U$ (test $<0.05, \mathrm{n}=16$ ).

E Scheme of the transcriptional fusion to GFP:GUS used to analyze the ASCO promoter activity.

F Activity of proASCO during LR development. Scale bar corresponds to $20 \mu \mathrm{m}$.

Figure EV2 Expression of immunity-related TF in RNAi-ASCO lines and ASCO expression in roots during flg22 treatment.

A Transcript levels of stress-related DEG identified in the RNA-seq data in the WT and the two independent RNAi-ASCO lines, measured by RT-qPCR. RNAs were extracted from 14-day-old plants. Data are mean of 3 independent biological replicates. Error bars represent standard 
deviation. The asterisk $\left(^{*}\right)$ indicates a significant difference as determined by Student's T (test < $0.05, \mathrm{n}=3)$.

B Time-course analysis of ASCO and CYP81F2 (AT5G57220) expression levels after treatment with media supplemented or not with $1 \mu \mathrm{M}$ flg22. RNAs were extracted from 10-day-old plants. Data are mean of 3 independent biological replicates. Error bars represent standard deviation.

\section{Figure EV3 The response to flg22 is altered in RNAi-ASCO lines.}

A A representative picture of 14-day-old plants grown 9 days in liquid 1/2MS corresponding to Mock condition.

B A representative picture of root apical meristems after cell wall staining, in Mock condition. TZ: Transition Zone; QC: Quiescent Center.

C Primary root length of WT and two independent RNAi-ASCO lines 9 days after transfer in $1 / 2 \mathrm{MS}$ supplemented with $0.1 \mu \mathrm{M}$ or $1 \mu \mathrm{M}$ flg22.

D Mean of meristematic cell number in WT and RNAi-ASCO1 primary root apex, treated or not with $1 \mu \mathrm{M}$ flg22. In (C) and (D) error bars indicate the standard error. The asterisk $\left({ }^{*}\right)$ indicates a significant difference as determined by Mann Whitney's $U$ test $(p<0.05, n=18)$.

E Transcript levels of a subset of flg22 responsive genes (AGls are indicated in Table EV5) in control conditions.

$\mathbf{F}$ Relative modulation of the same genes as in $\mathbf{D}$, in response to flg22. Results are normalized against the response in WT plants, taken as $100 \%$. The asterisk $\left({ }^{*}\right)$ indicates a significant difference as determined by Student's T test $(p<0.05, n=3)$.

\section{Figure EV4 ASCO insertion mutants do not exhibit strong expression changes}

A Scheme of T-DNA insertions along ASCO locus in asco-1 and asco-2 mutants. Red arrows indicate probes used for qPCR expression analysis.

B ASCO transcript levels in 2 independent 14-day-old 35-ASCO lines, asco-1 and asco-2 compared to WT.

C Quantification of ASCO transcript levels targeting different regions of the locus by RT-qPCR in WT and asco mutants. A, B, C and D probe positions are indicated in $\mathbf{A}$.

D, E Primary root length (D) and lateral root density (E) of WT, asco-1 and asco-2 plants 9 days after transfer in 1/2MS supplemented with $1 \mu \mathrm{M}$ flg22.

Figure EV5 Differential RNA processing events identified in RNAi-ASCO.

A, B, C, D, E, F Differential RNA processing events of SR34 (AT1G02840, A), NUDT7 (AT4G12720, B), NRG (AT2G29290, C), SEN1 (AT4G35770, D), SNC4 (AT1G66980, E) and RPP4 (AT4G16860, F) transcripts detected by RNAprof from the comparison of RNA-seq libraries of 14-day-old plants. Comparative transcriptional abundance are indicated for WT (red) and RNAi-ASCO1 (blue) plants. Three biological replicates were used for the analyses. Vertical purple lines and $p$-values indicate significant differential processing events. Each profile is 
associated with the structure of the corresponding RNA isoforms. Large black boxes indicate exons, narrow black boxes indicate UTRs and black lines indicate introns.

\section{Figure EV6. Validation of AS events in RNAi-ASCO lines.}

A, D, G, J, M Differential RNA processing events of ESP (AT1G54040), NRG, SEN1, SNC4 and RPP4 transcripts detected by IsoSwitch (ESP) or RNAprof (NRG, SEN1, SNC4 and RPP4) from the comparison of mRNA-seq libraries of 14-day-old plants. For NRG, SEN1, SNC4 and RPP4, comparative transcriptional abundance are indicated for WT (red) and RNAi-ASCO1 (blue) plants. Three biological replicates were used for the analyses. Vertical purple lines in $\mathbf{D}, \mathbf{G}, \mathbf{J}$ and $\mathbf{M}$ and $\mathbf{p}$-values indicate significant differential processing events. The structure of each associated RNA isoform is represented as follows : large black boxes indicate exons, narrow black boxes indicate UTRs, black lines indicate introns. Red arrows indicate probes used for gel electrophoresis. Colored boxes indicate protein domains affected by an AS event.

$\mathbf{B}, \mathbf{E}, \mathbf{H}, \mathbf{K}, \mathbf{N}$ Analyses of RT-PCR products of corresponding transcripts on $8 \%$ acrylamide gel.

C, F, I, L, O Quantification of the ratio of the corresponding isoforms detected in gels in $\mathbf{B}, \mathbf{E}, \mathbf{H}$, $\mathbf{K}$ and $\mathbf{N}$, respectively.

RNAs were extracted from WT and RNAi-ASCO 14-day-old plants. The asterisk ( $\left.{ }^{*}\right)$ indicates a significant difference as determined by Student's T test $(p<0.05, n=3)$.

Figure EV7. qPCR analysis of several AS events identified in RNAi-ASCO lines.

A, B, C and D Quantification of SR34 (A), ESP (B), NUDT7 (C) and SNC4 (D) isoforms by RTqPCR. The asterisk $\left({ }^{*}\right)$ indicates a significant difference as determined by Student's $T$ test $(p<$ $0.05, n=3)$.

Figure EV8 nsra/b affect root responses to flg22 and splicing of subsets of genes partially overlapping with RNAi-ASCO and 35S:ASCO

A Overlap between differentially spliced events in RNAi-ASCO, 35S:ASCO and WT and nsra/b mutant and WT treated with NAA (Bardou et al, 2014). B,Primary root length and $\mathbf{C}$, lateral root density of WT and nsra/b double mutants 9 days after transfer in 1/2MS supplemented with 1 $\mu \mathrm{M}$ flg22. The asterisk $\left(^{*}\right)$ indicates a significant difference as determined by Mann Whitney's $U$ test $(p<0.05, n \geq 16)$

Figure EV9. Novel specific antibody against AtPRP8a confirmed the protein localization in the cell nucleus.

A Whole-mount immunolocalization using the specific antibody against PRP8a. The signals of DAPI (grey channel) and AtPRP8a protein (red channel) colocalized in the nuclei of $A$. thaliana WT plants. The negative control corresponds to the immunolocalization assay without antiAtPRP8a antibody. Scale bar represents $10 \mu \mathrm{m}$. 
Figure EV10. Analyses of NUDT7 and SNC4 in the smd1b background.

A, D, G Structure of NUDT7 (A, G) and SNC4 (D) RNA isoforms. Large black boxes indicate exons, narrow black boxes indicate UTRs, black lines indicate introns. Red arrows indicate probes used for gel electrophoresis. Colored boxes indicate protein domains affected by an AS event.

B, E, $\mathbf{H}$ Analyses of RT-PCR products of corresponding transcripts on $8 \%$ acrylamide gel.

C, F, I Quantification of the ratio of the corresponding isoforms detected in gels in $\mathbf{B}, \mathbf{E}$ and $\mathbf{H}$, respectively. J. SNC4 transcript levels in smd1b mutant compared to WT. RNAs were extracted from WT, prp8a and smd1b 14-day-old plants. The asterisk $\left(^{*}\right)$ indicates a significant difference as determined by Student's $T$ test $(p<0.05, n=3)$.

Figure EV11 Identification of ASCO homologs in A.thaliana and the Arabidopsis Brassicaceae family

A Maximum likelihood tree depicting the evolutionary history of ASCO in the Brassicaceae family. Bootstrap support values are indicated above branches. Sequences identifiers are colored by species.

B Normalized expression level of detectable ASCO-like transcripts in WT (blue bars), RNAiASCO (green bars) and 35S:ASCO (red bars) RNA-seq data.

\section{Appendix}

Table EV1. List of differentially expressed genes in WT vs RNAi-ASCO1

Table EV2. List of differential RNA processing events determined by RNAprof.

Table EV3. List of differential AS events determined by SUPPA.

Table EV4. List of differential RNA processing events determined by IsoformSwitchAnalyzeR package.

Table EV5. List of oligonucleotides used for this work. 


\section{Figure 1}

A

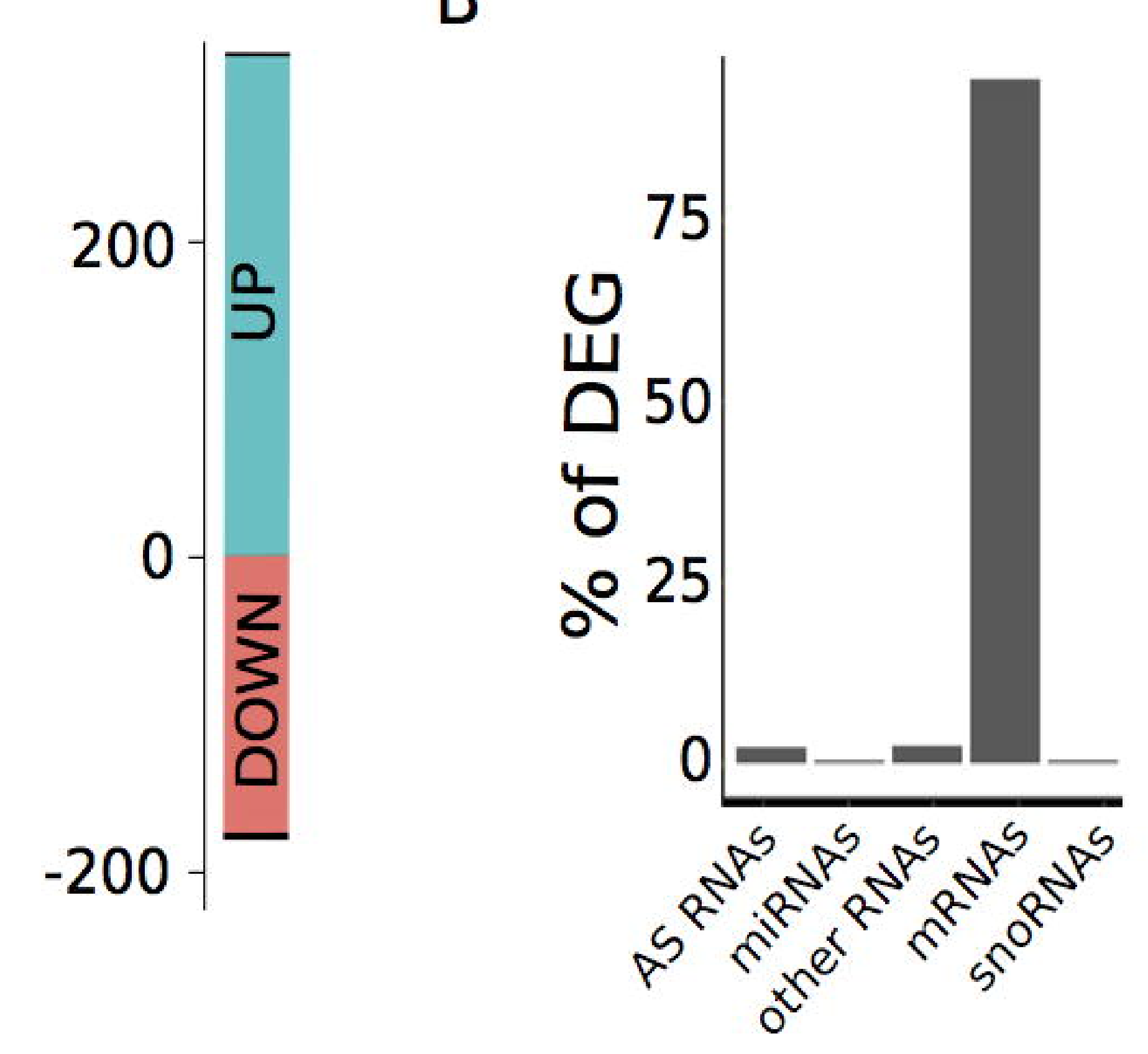

D
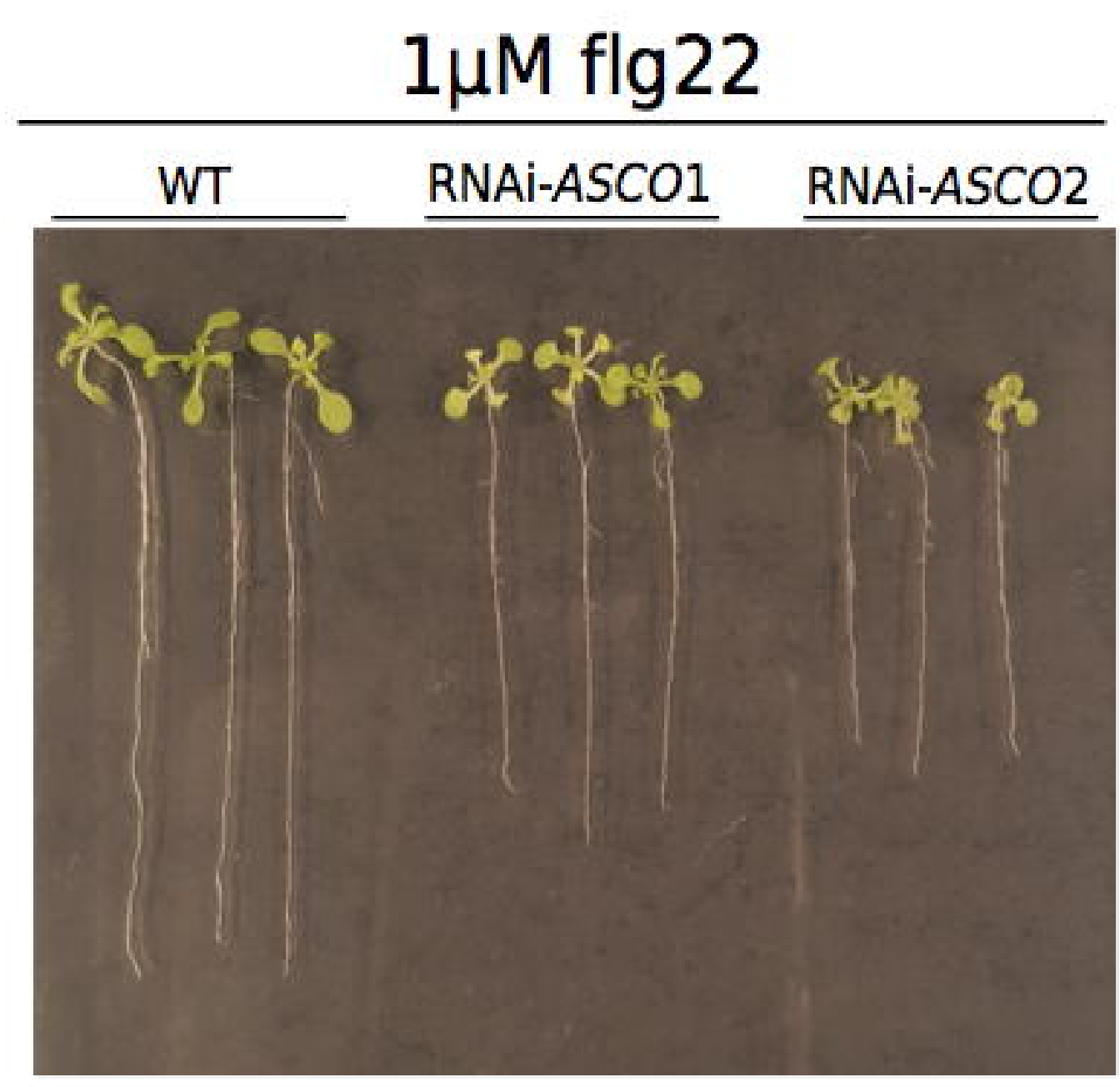

E

Rense to external stimulus

S-glycoside metabolic pathway

Glucosinolate metabolic pathway

Cellular response to nutrient levels

Immune response

Immune system process

Response to organic substance

Apoptotic process

Response to chitin

Glycoside metabolic process

Glycoside biosynthetic process

Response to chemical Response to stress

Lipid localization

Defense response

0 1 $-\log _{10} F D R$

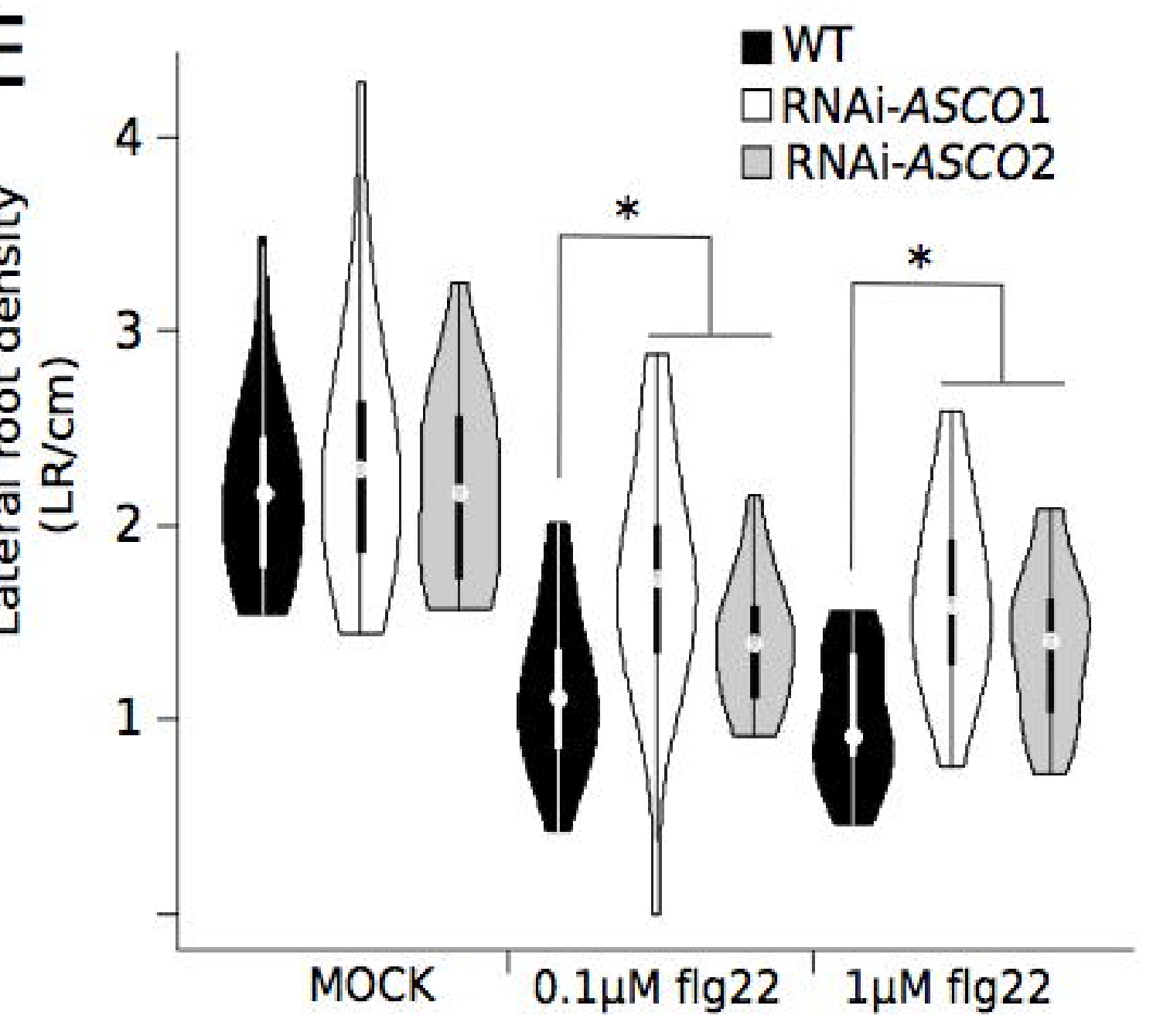

F
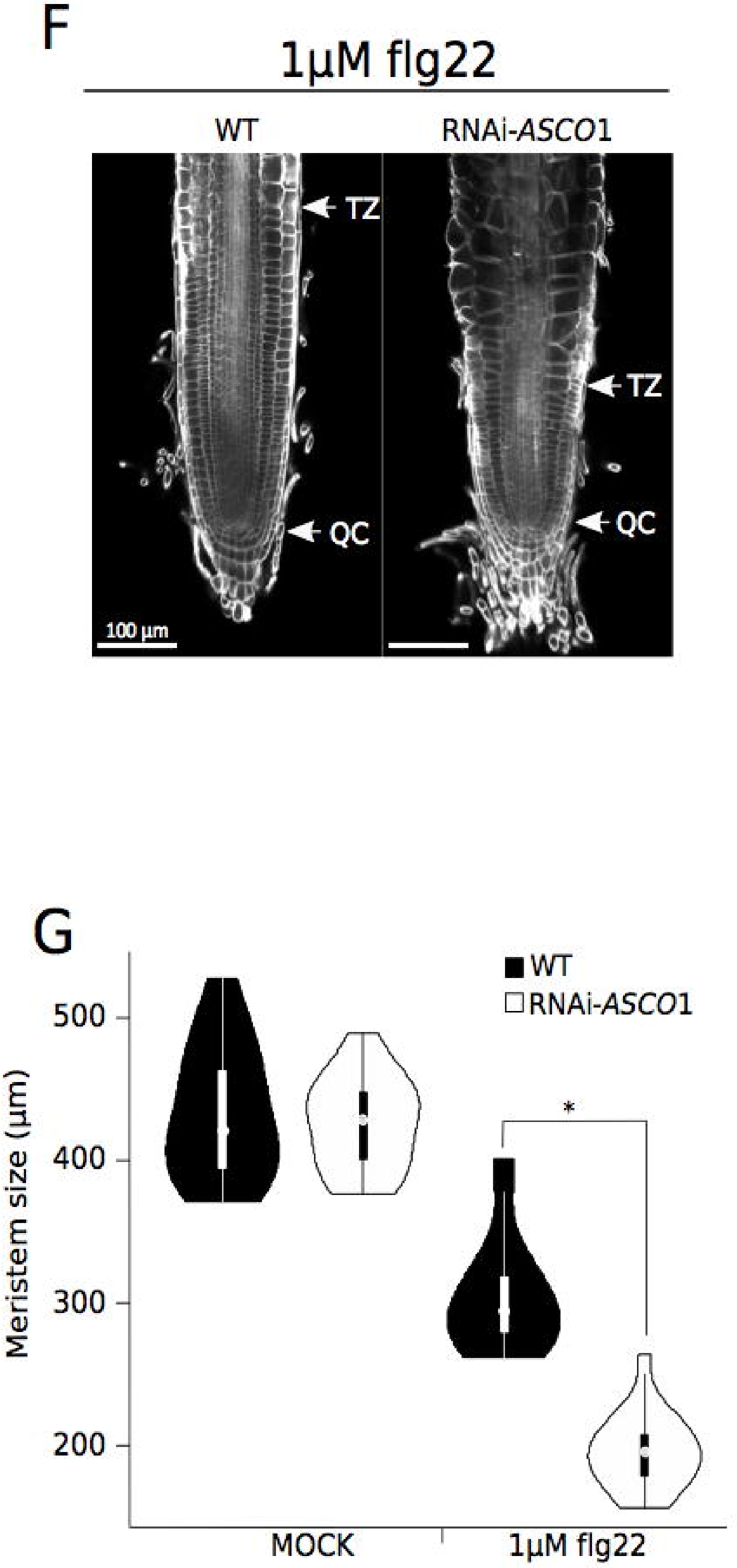
Figure 2

A

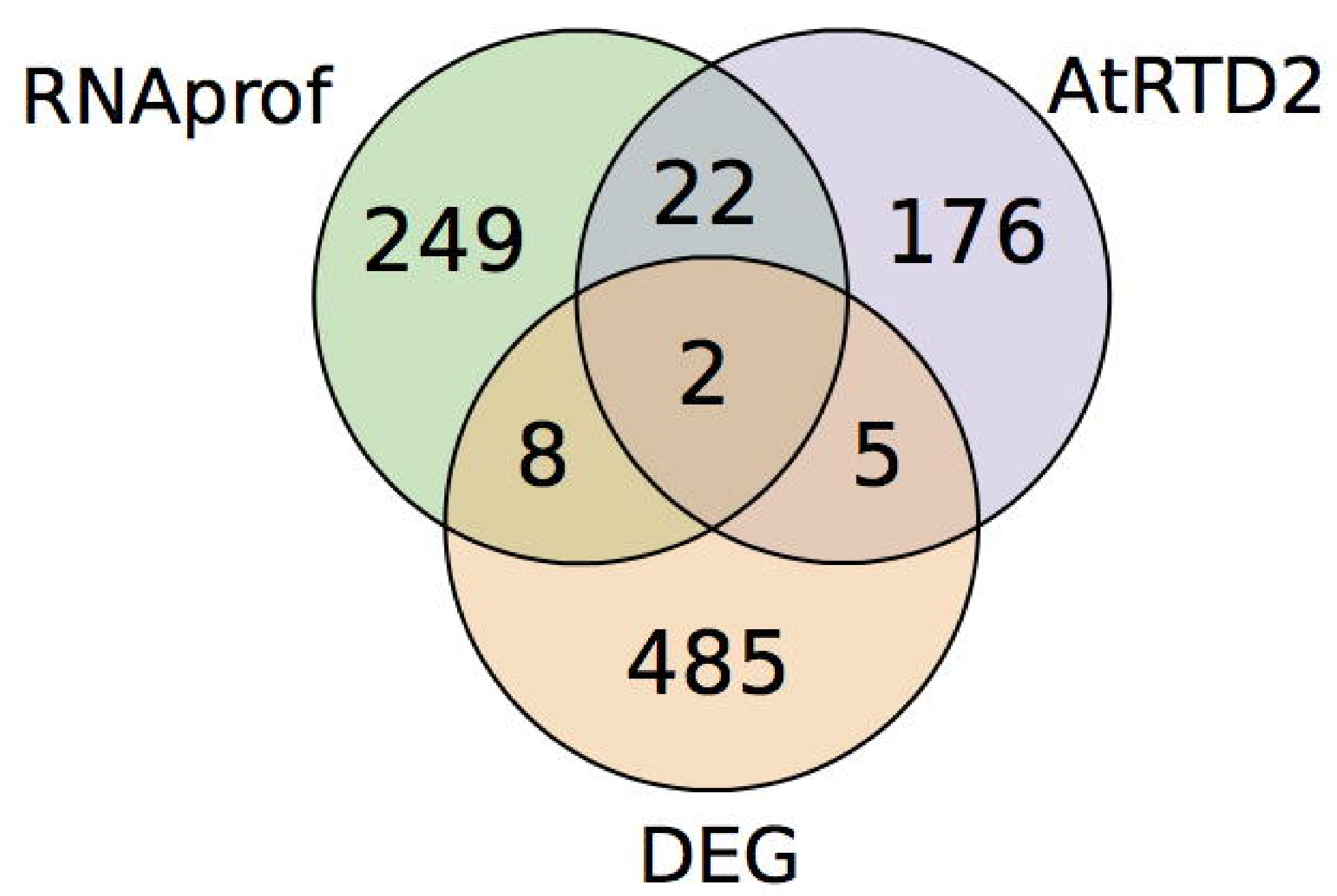

B

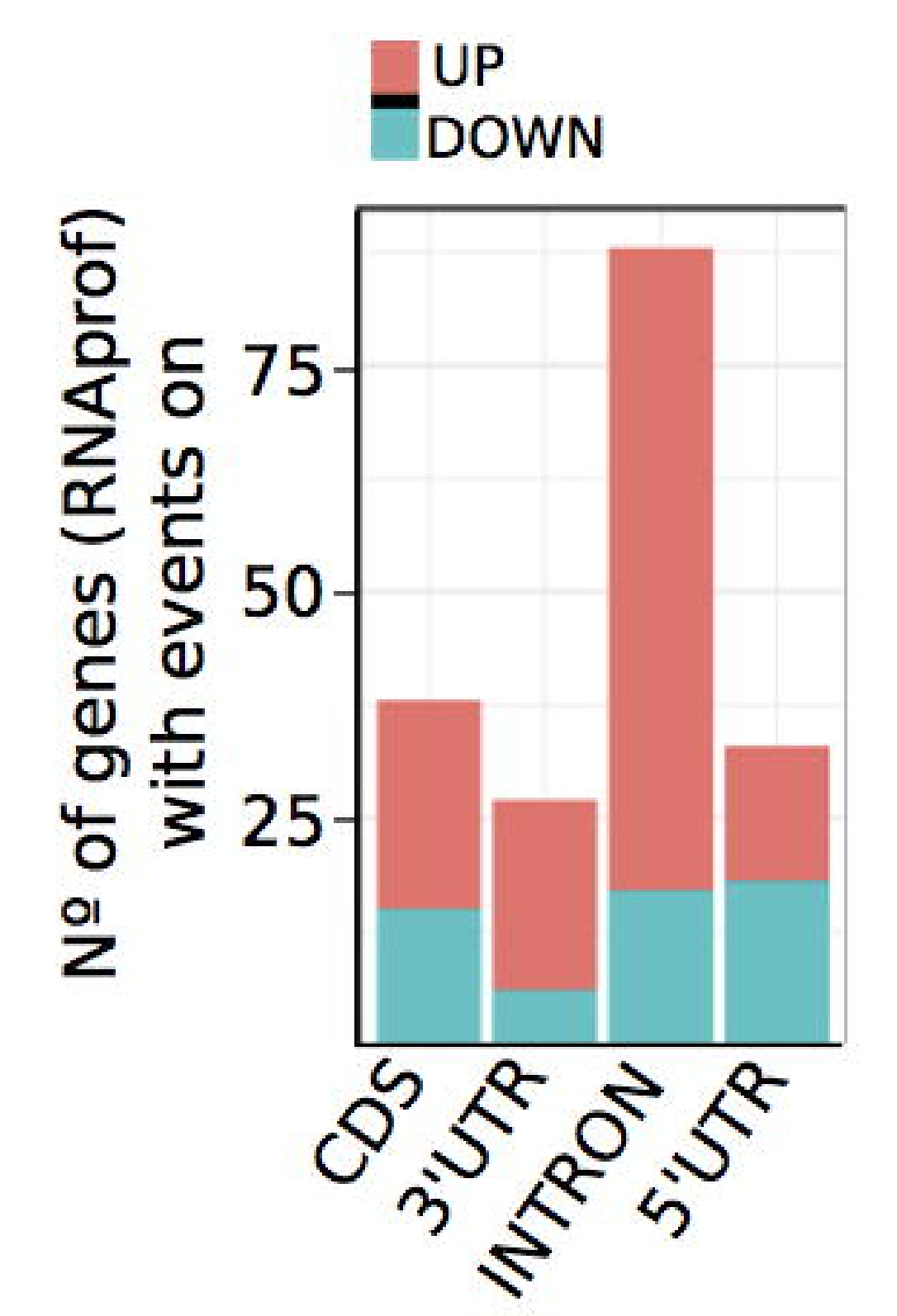

C

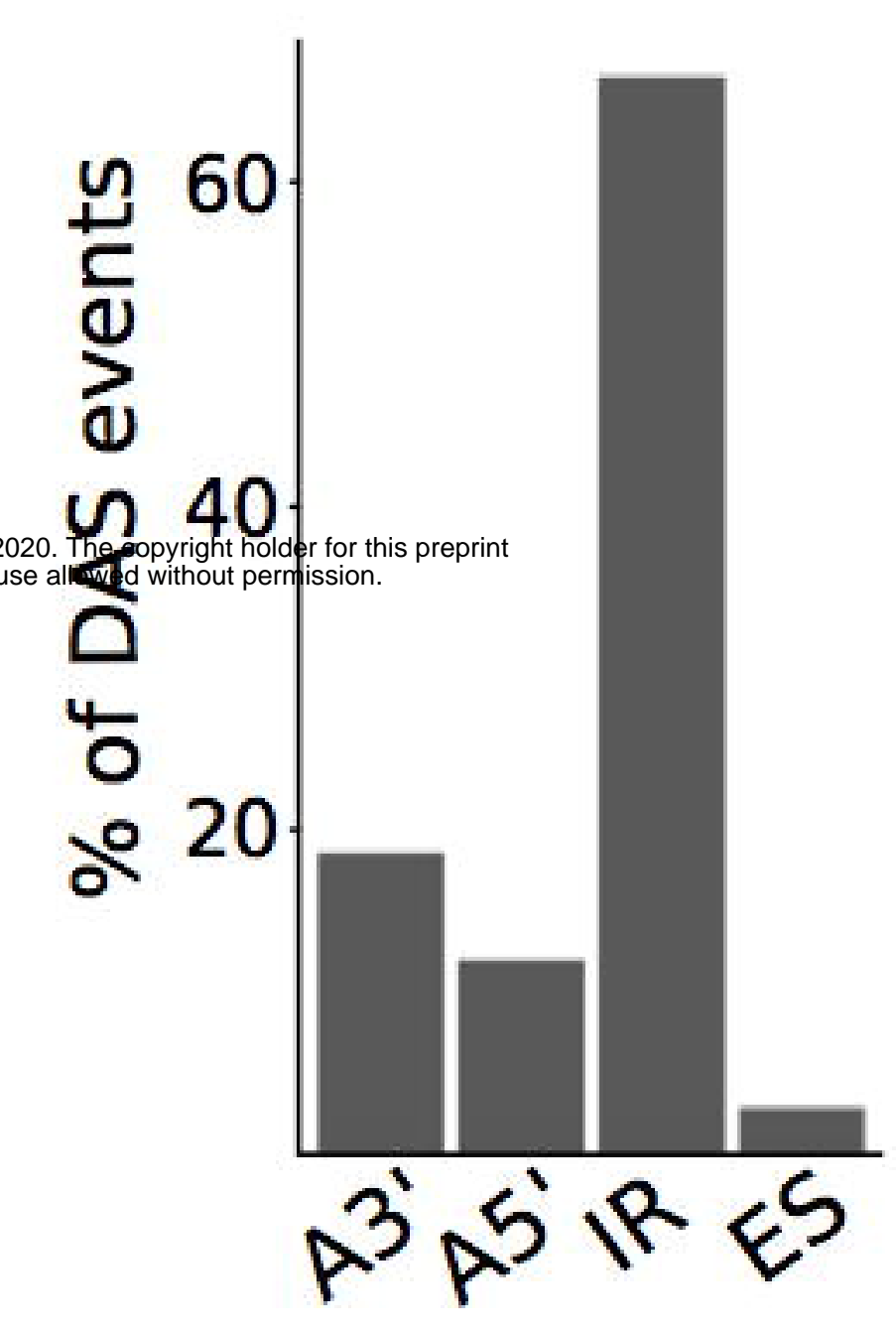

D

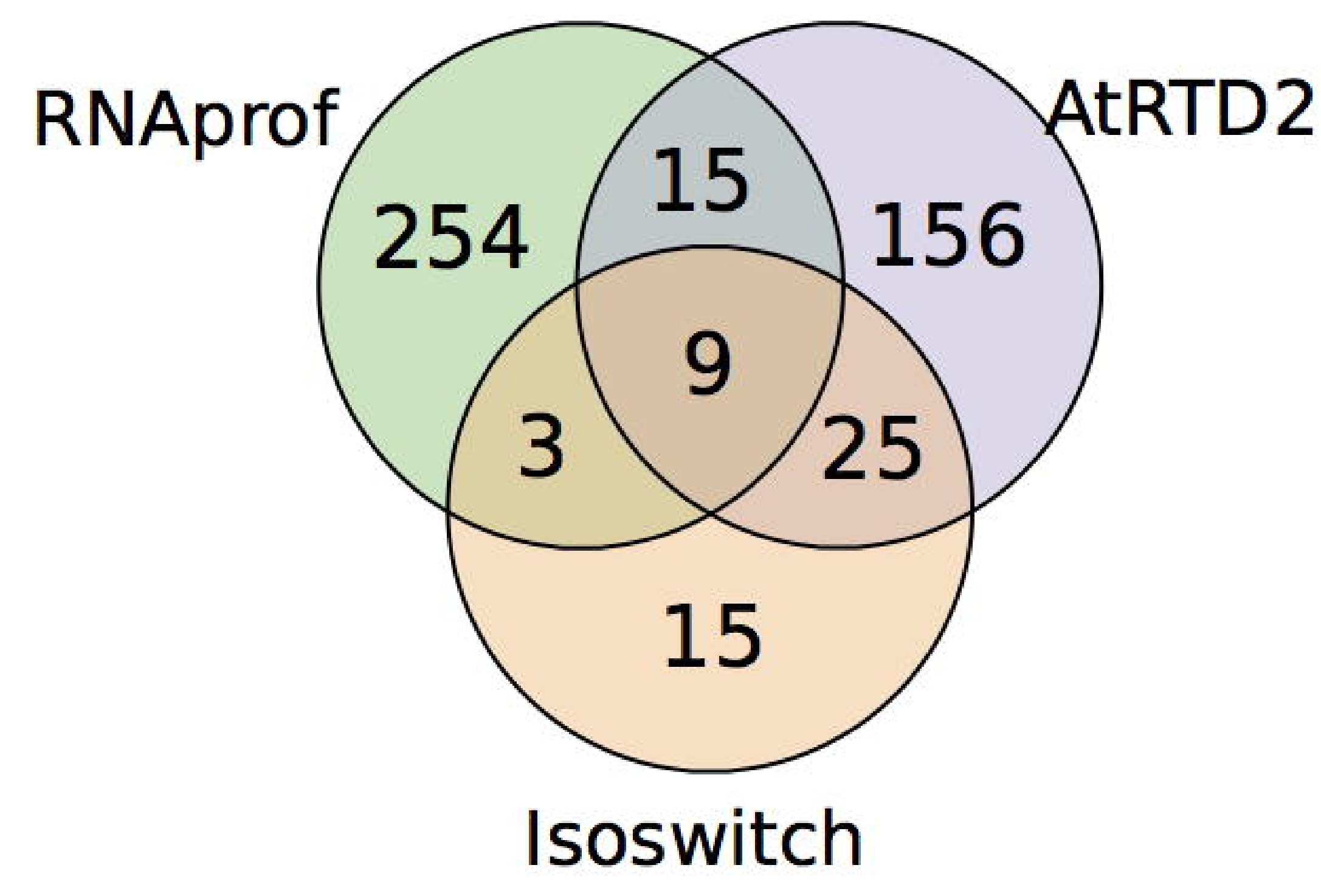

E Number of genes

Transcript is coding Transcript is noncoding Domain gain Domain loss NMD insensitive NMD sensitive Consequence of switch (upregulated isoform)

$$
\begin{array}{r}
\text { ORF gain } \\
\text { ORF loss } \\
\text { ORF longer } \\
\text { ORF shorter }
\end{array}
$$

Signal peptide gain

F

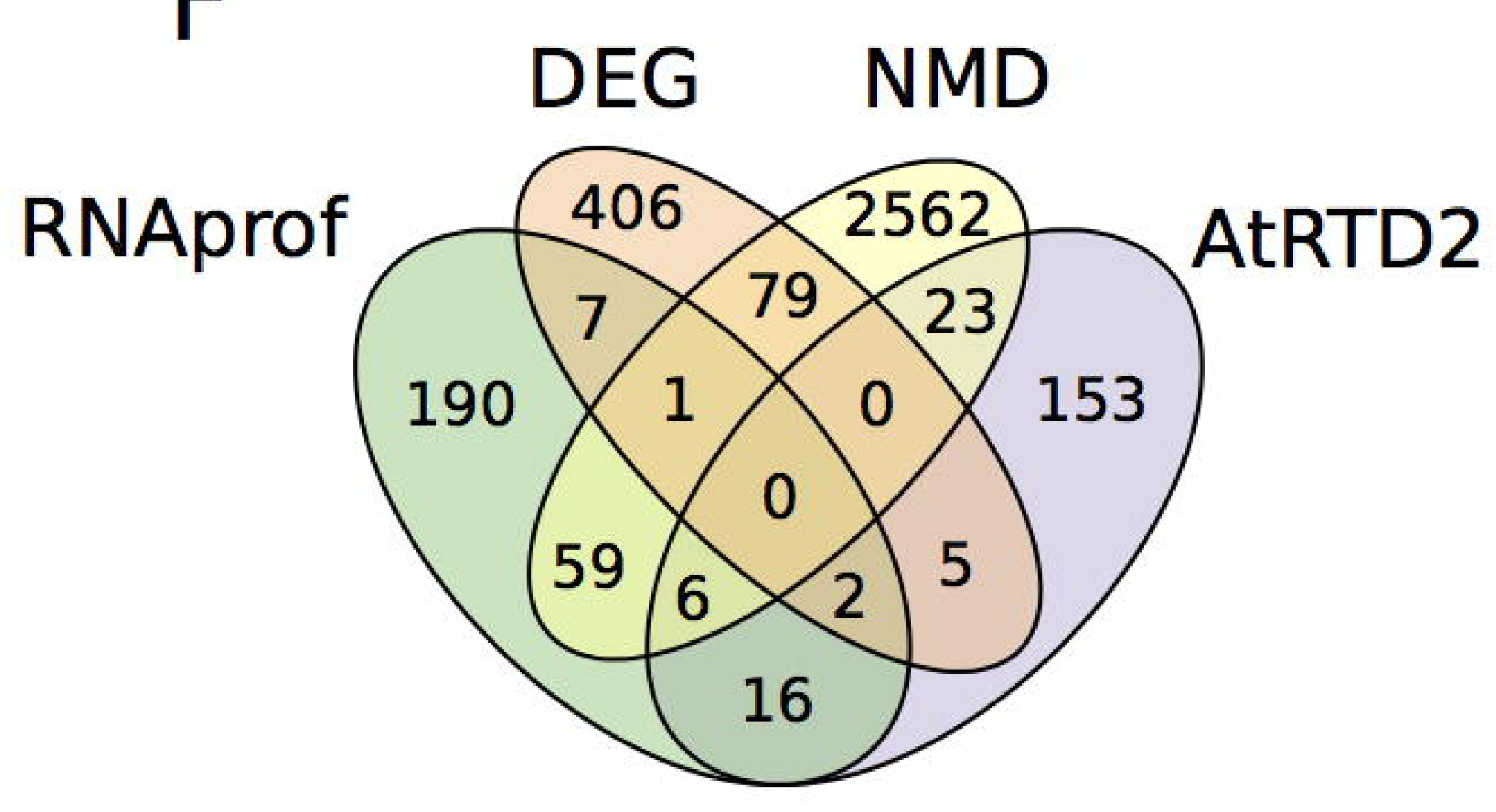




\section{Figure 3}

A

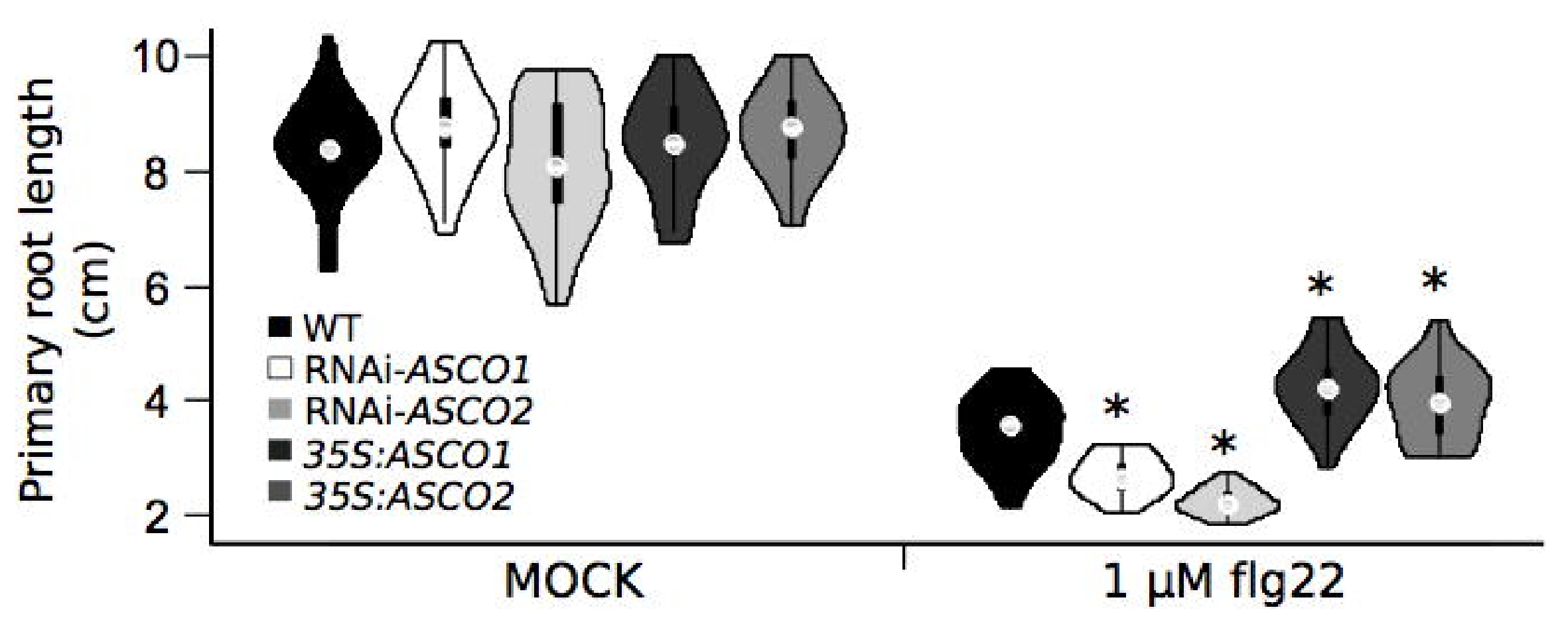

C

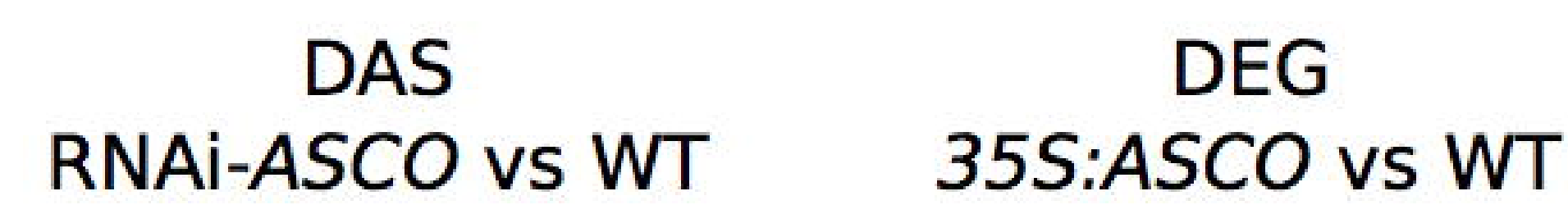

214

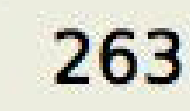

$113 \quad 5$

159

131

DAS

35S:ASCO vs WT

1

1

1

480

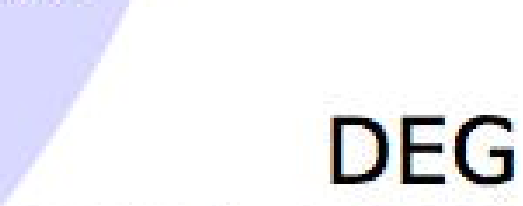

RNAi-ASCO vs WT

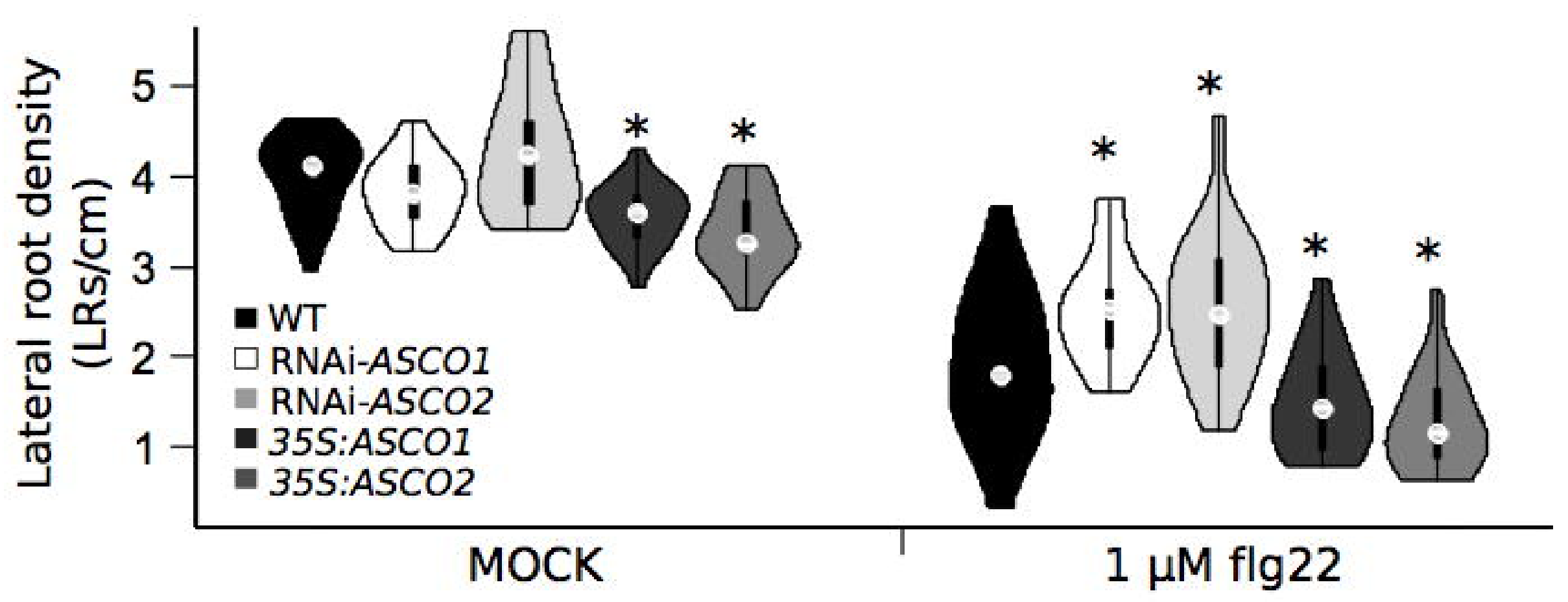

D RNAi-ASCO DEG

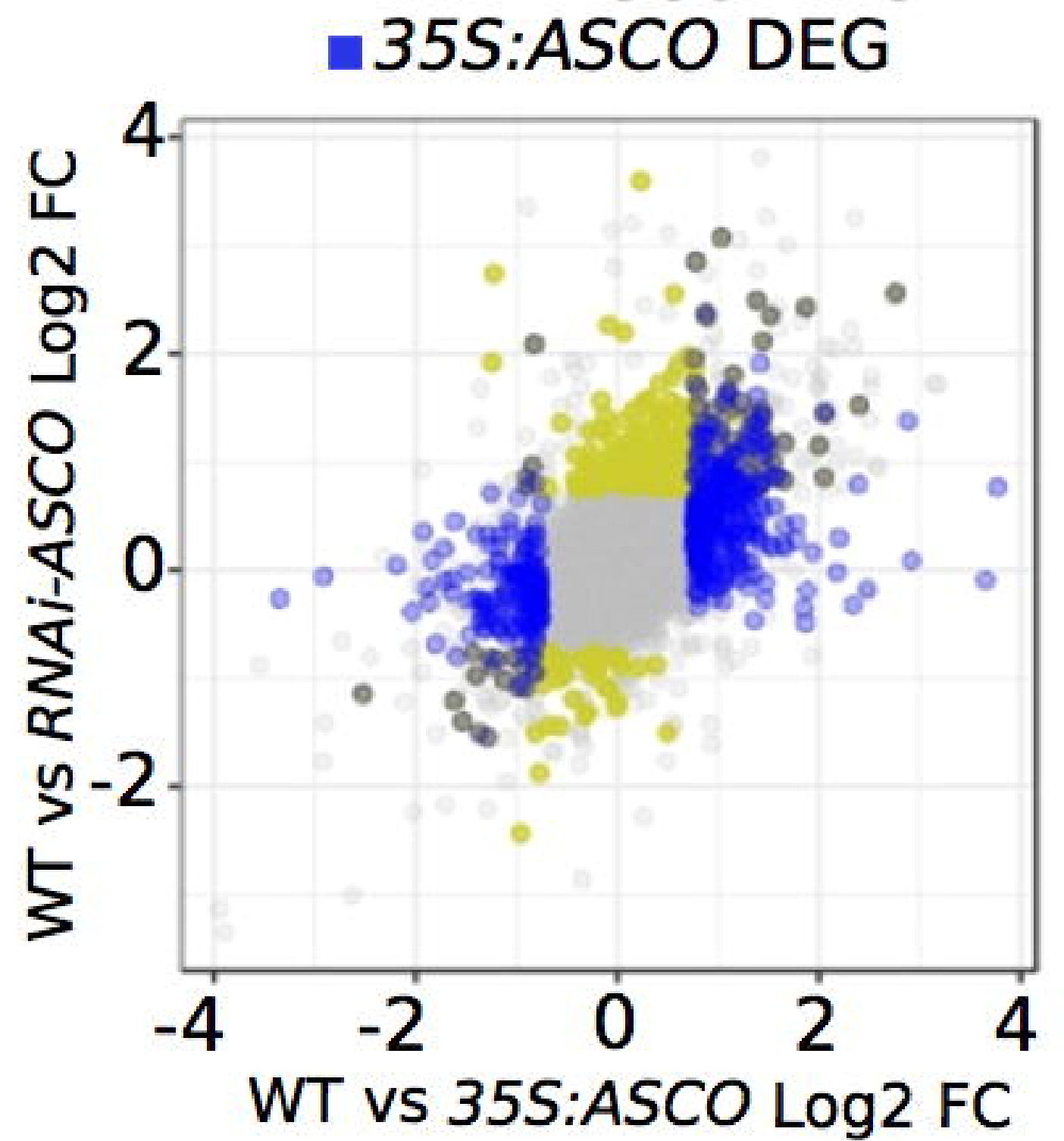

E

RNAi-ASCO DAS

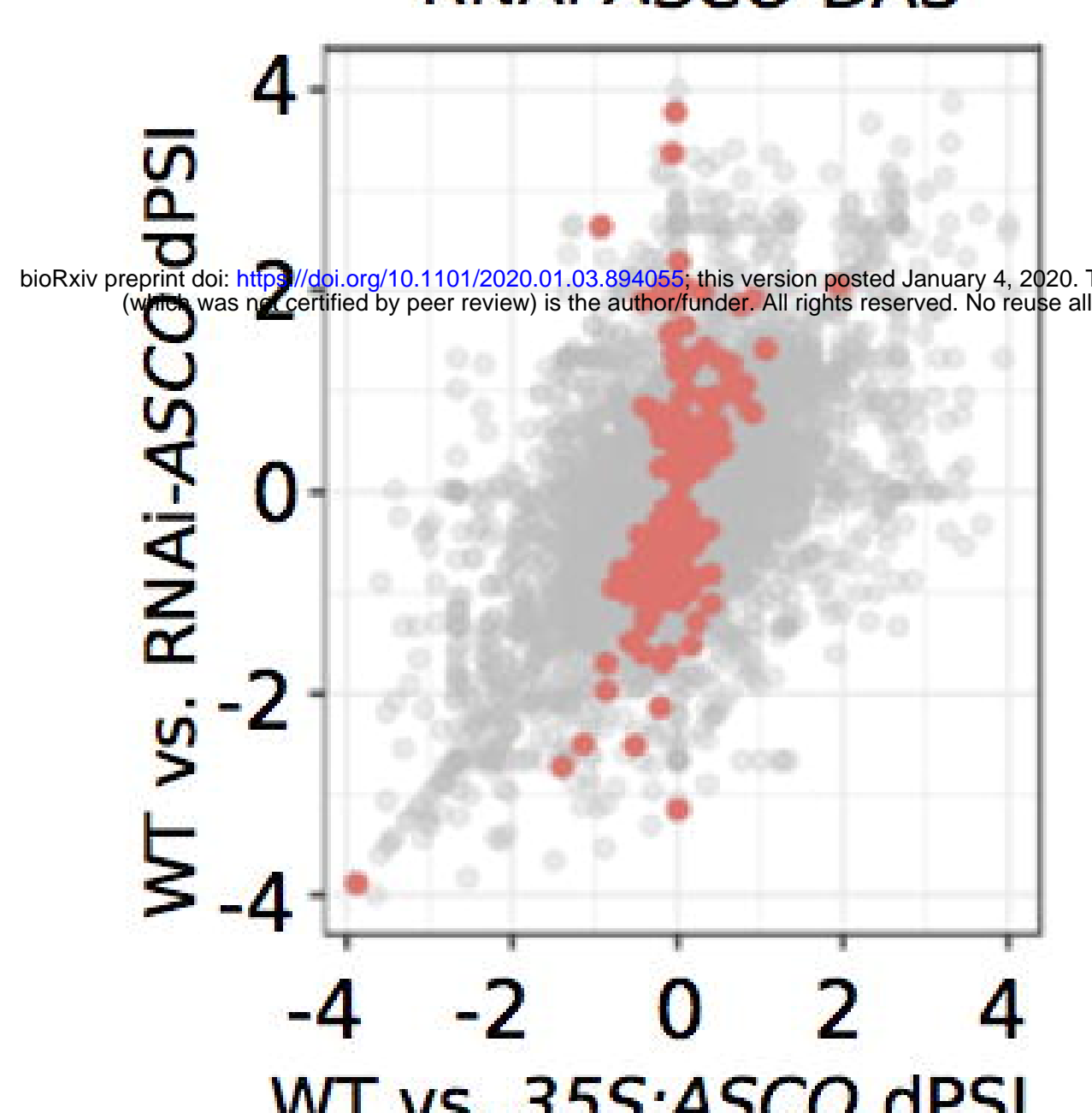

WT vs. 35S:ASCO dPSI
RNAi-ASCO \& 35S:ASCO DAS

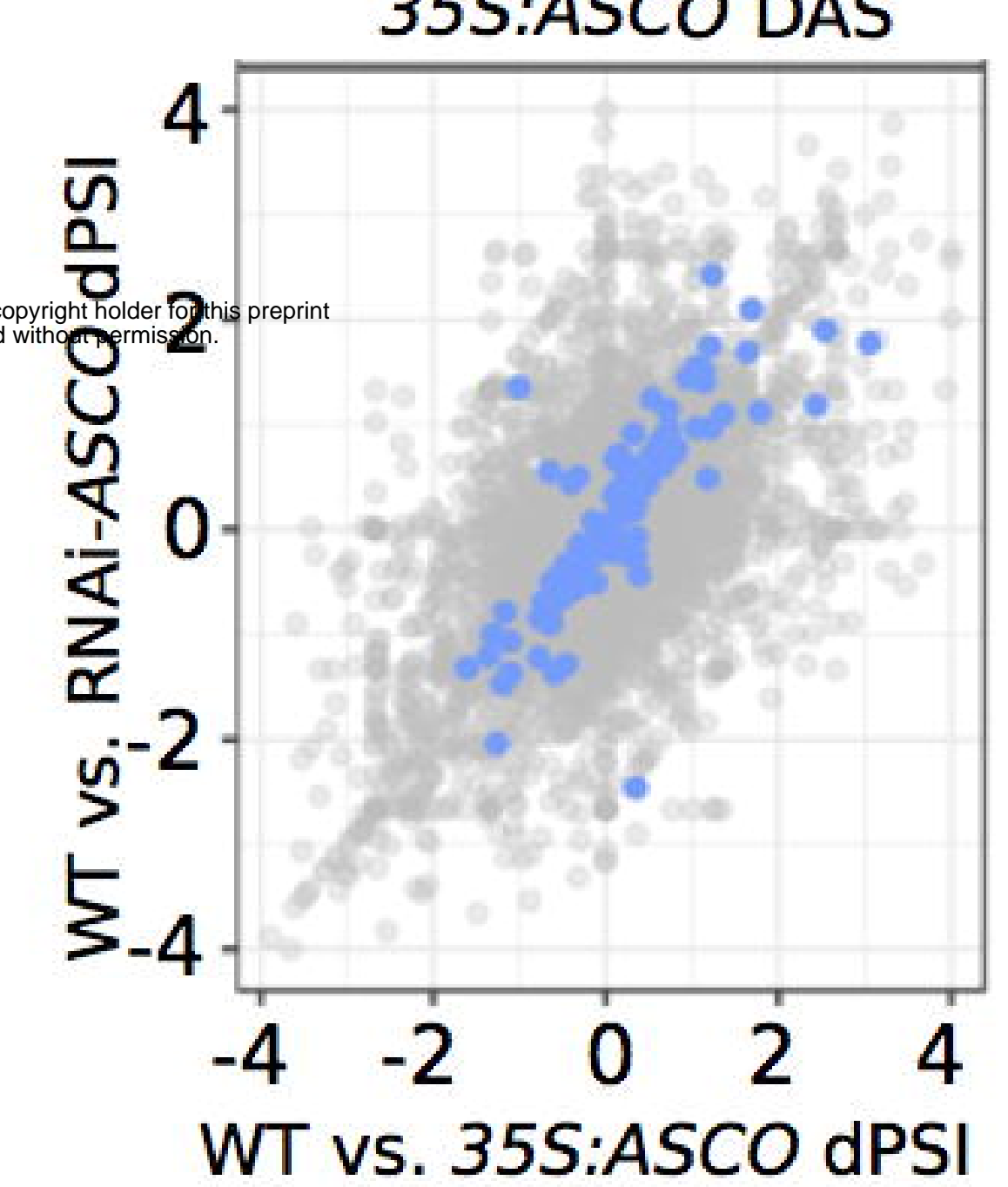

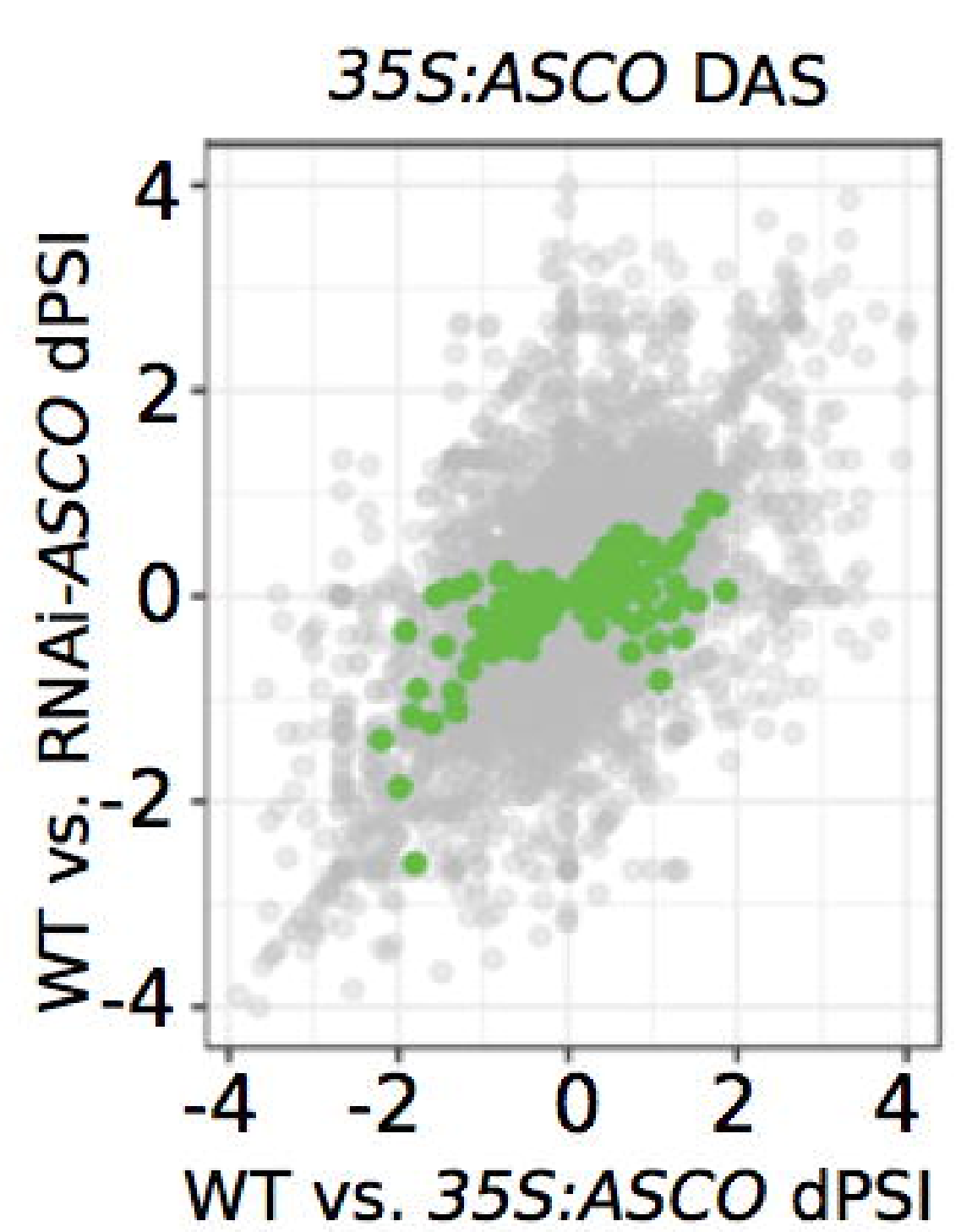


Figure 4

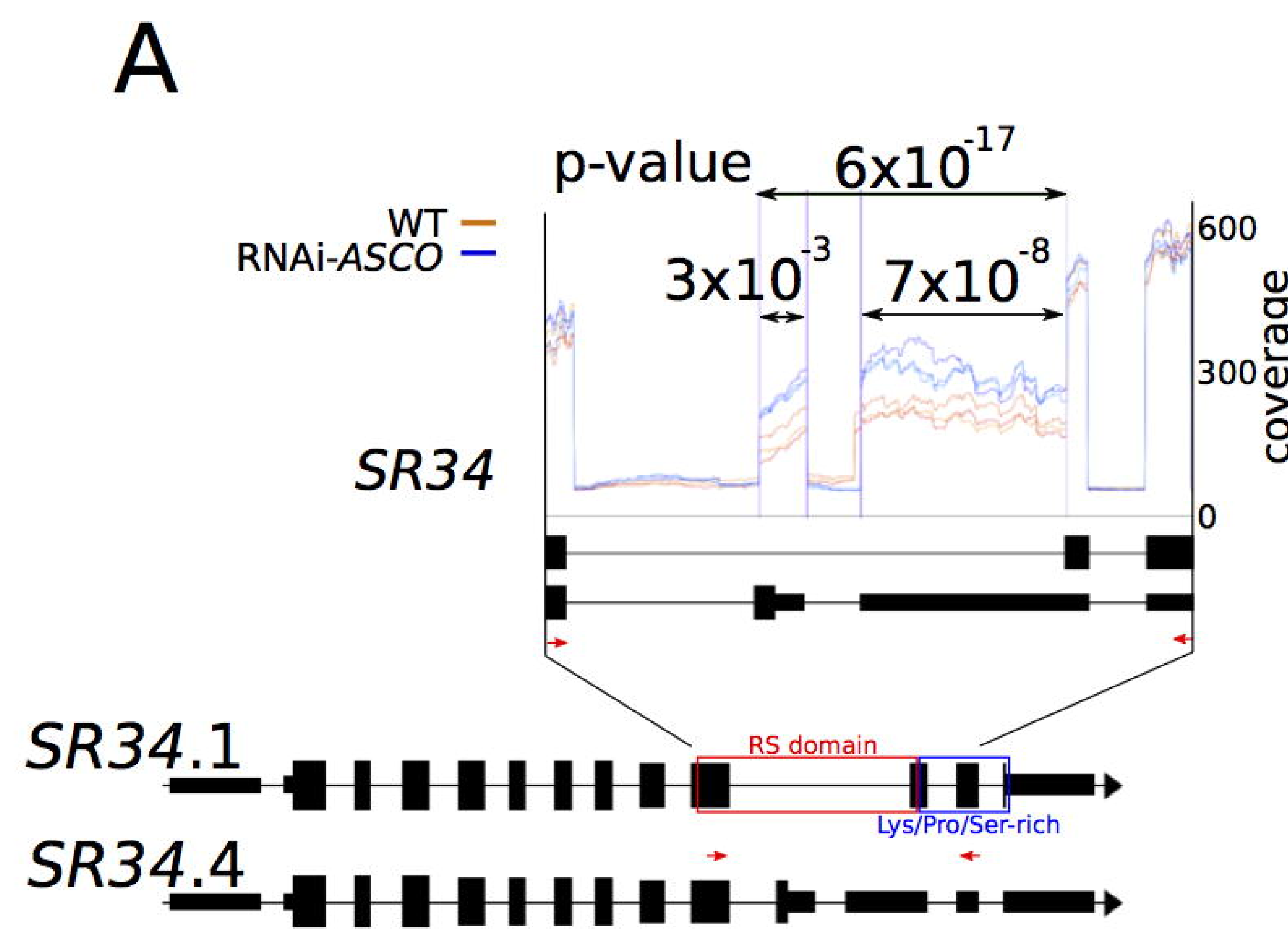

B

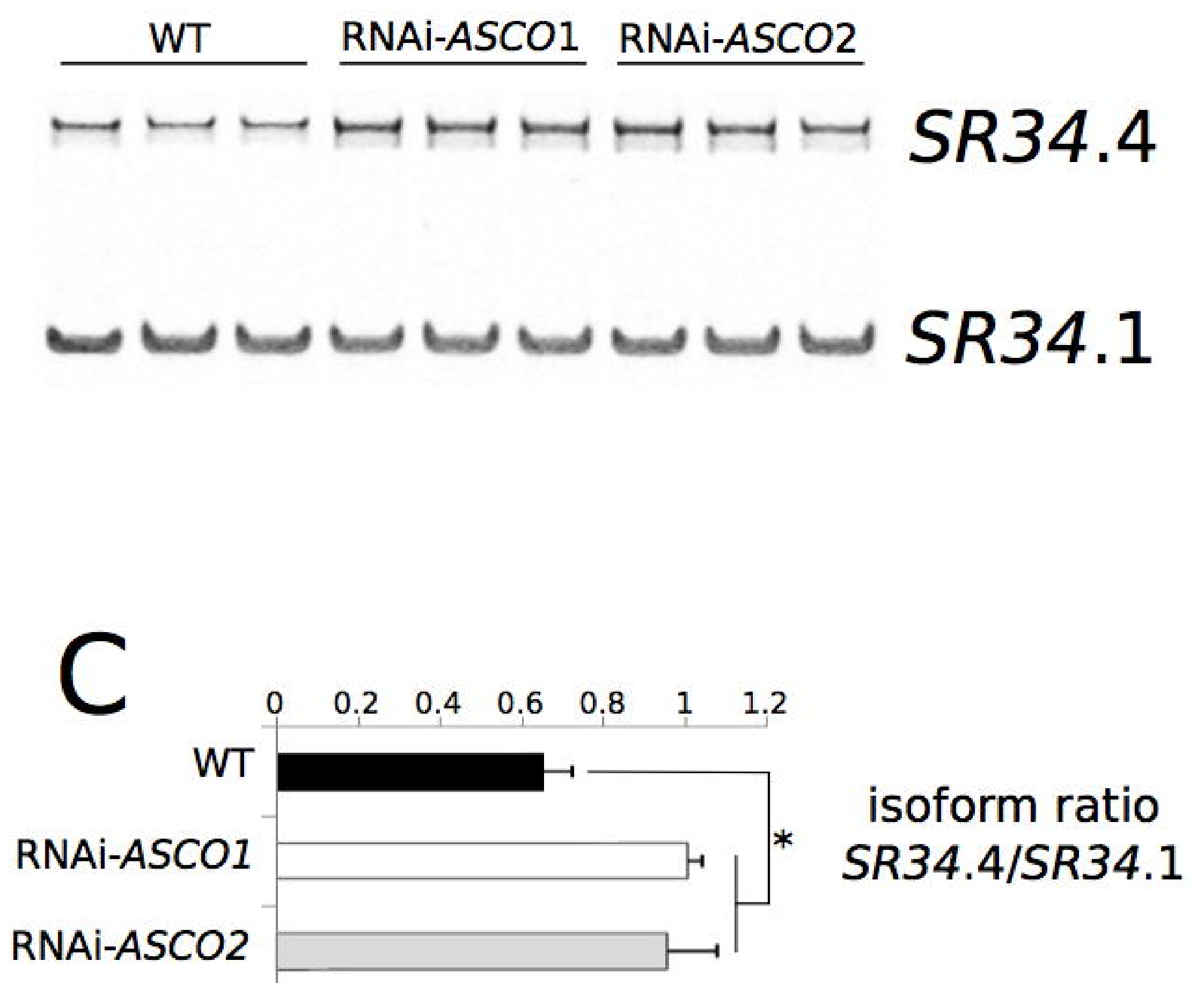

D

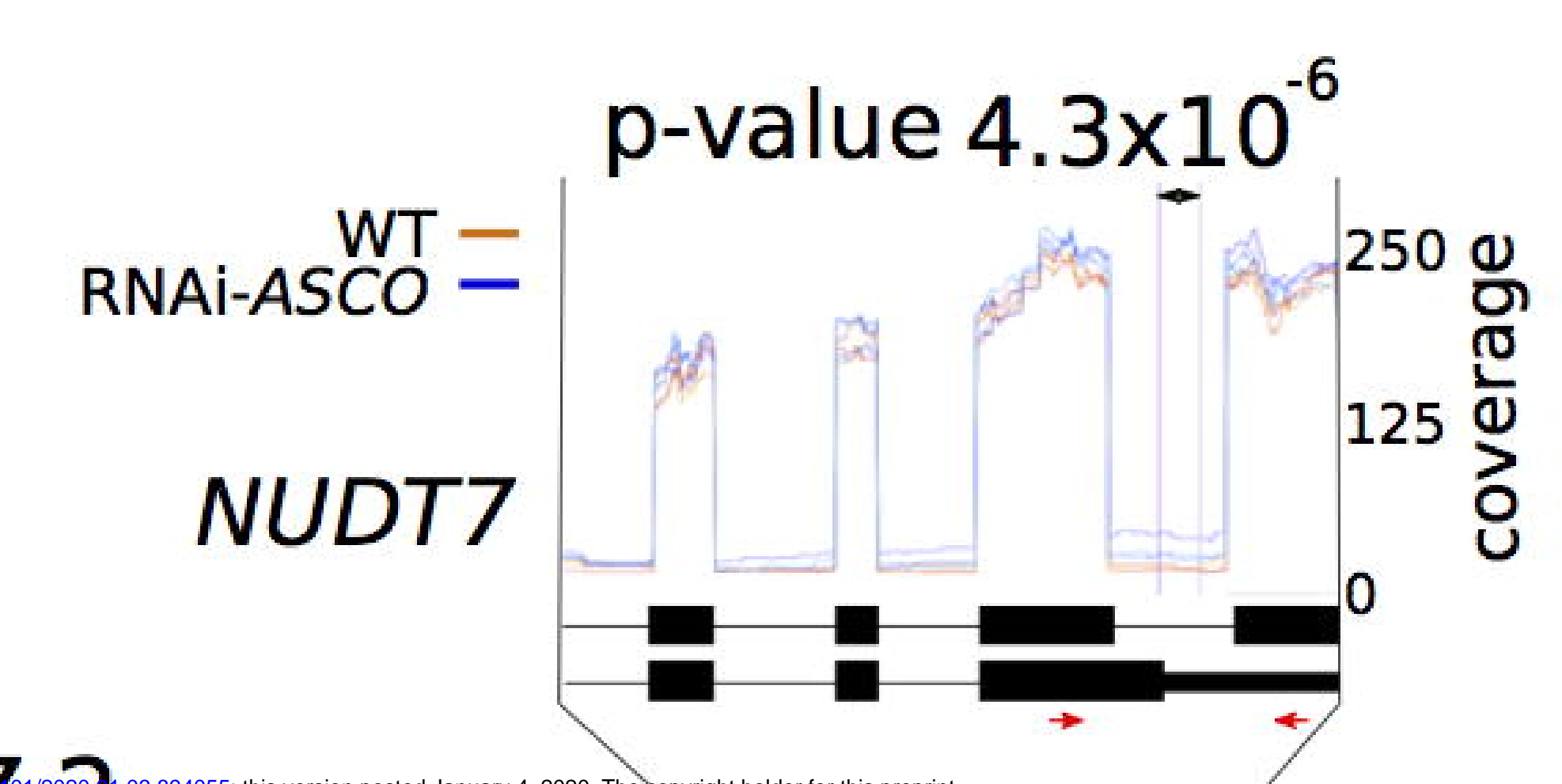

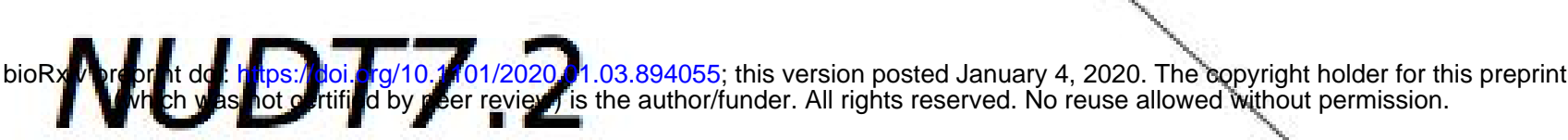

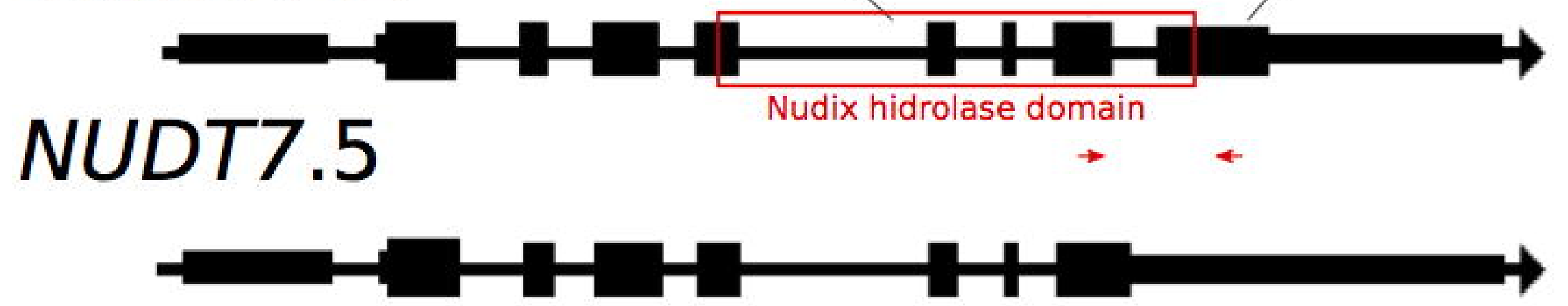

E WT RNAi-ASCO1 RNAi-ASCO2 NUDT7.5 NUDT7.2 $F$

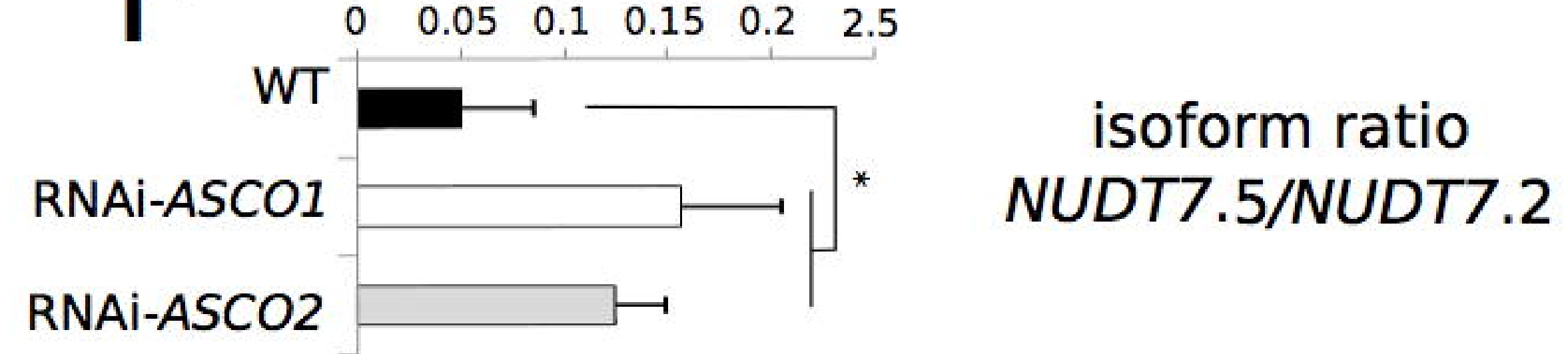


Figure 5

A

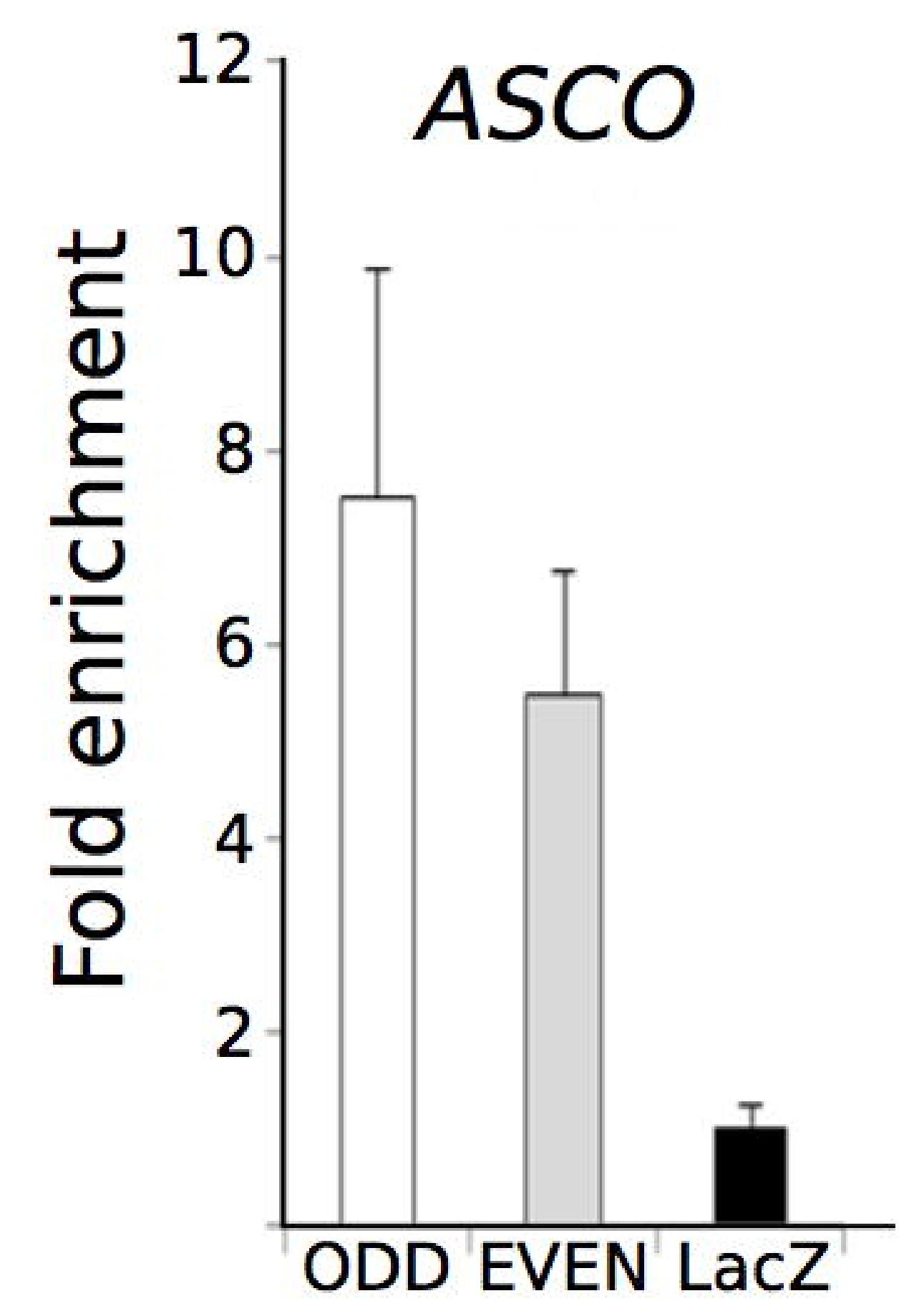

B

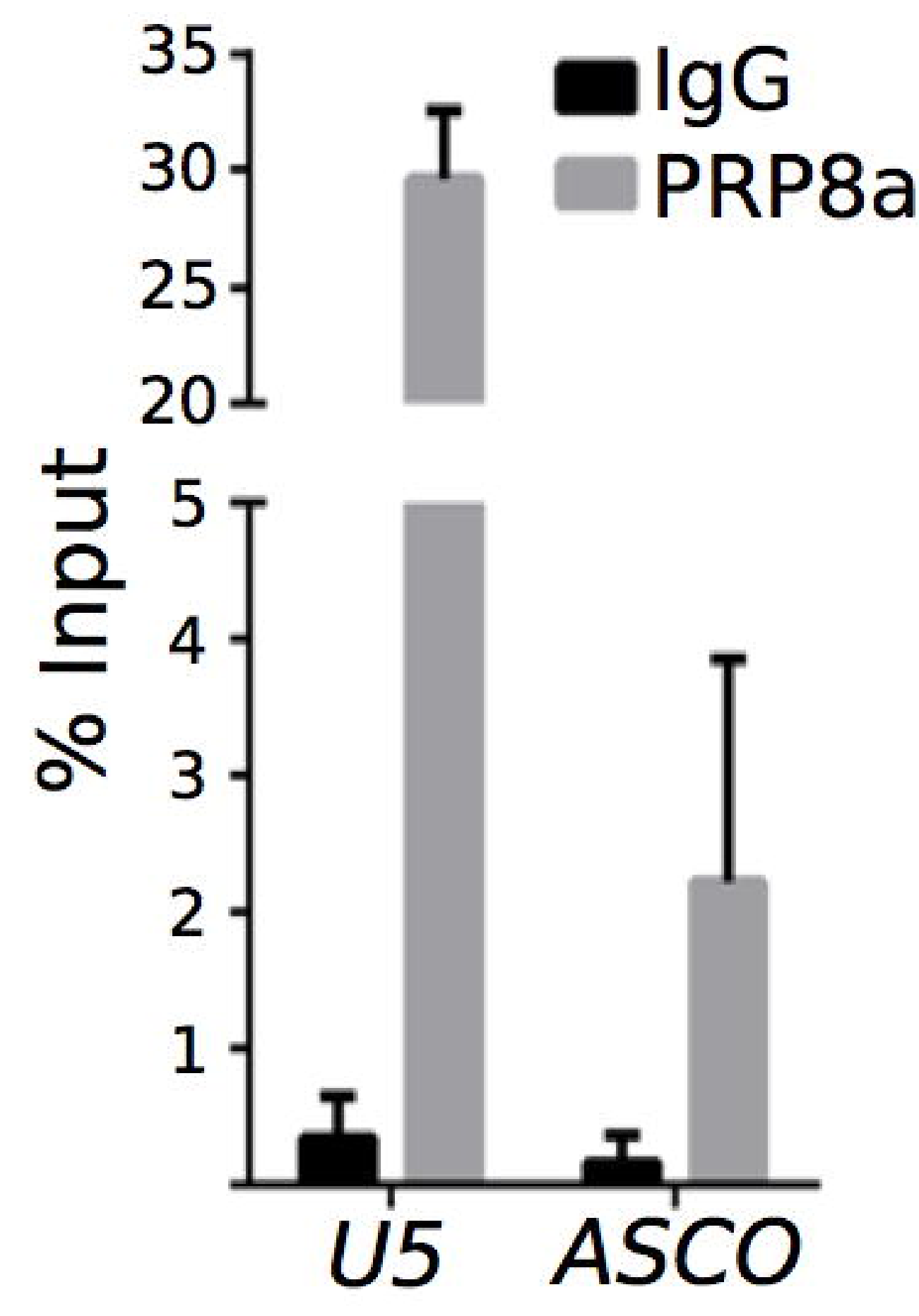

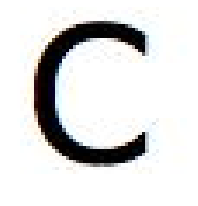

$$
\text { INPUT UNBOUND } \frac{2}{\text { aPRP8 } \quad \alpha \operatorname{lgG}}
$$

250 kDA

\section{D}

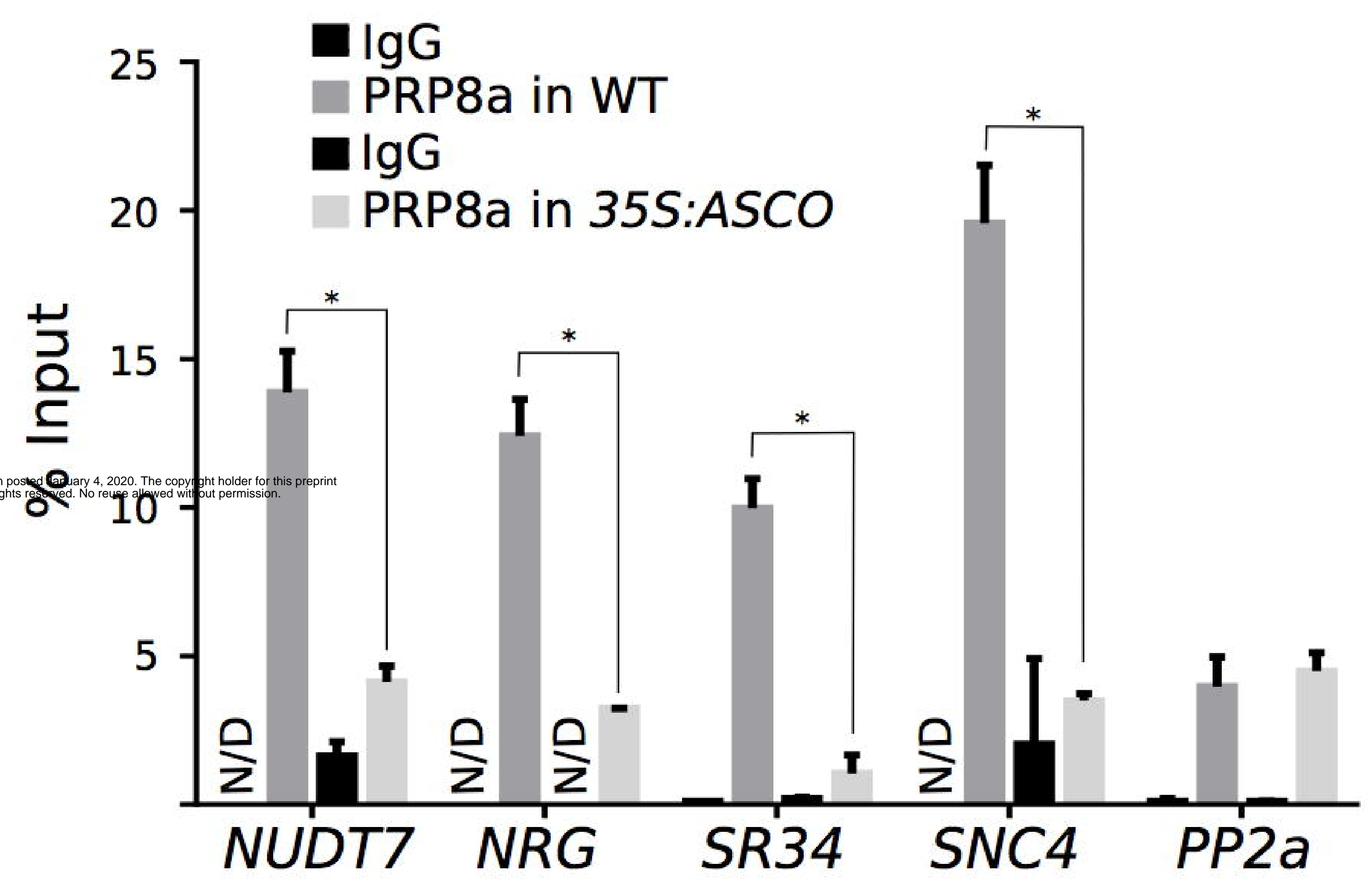


Figure 6

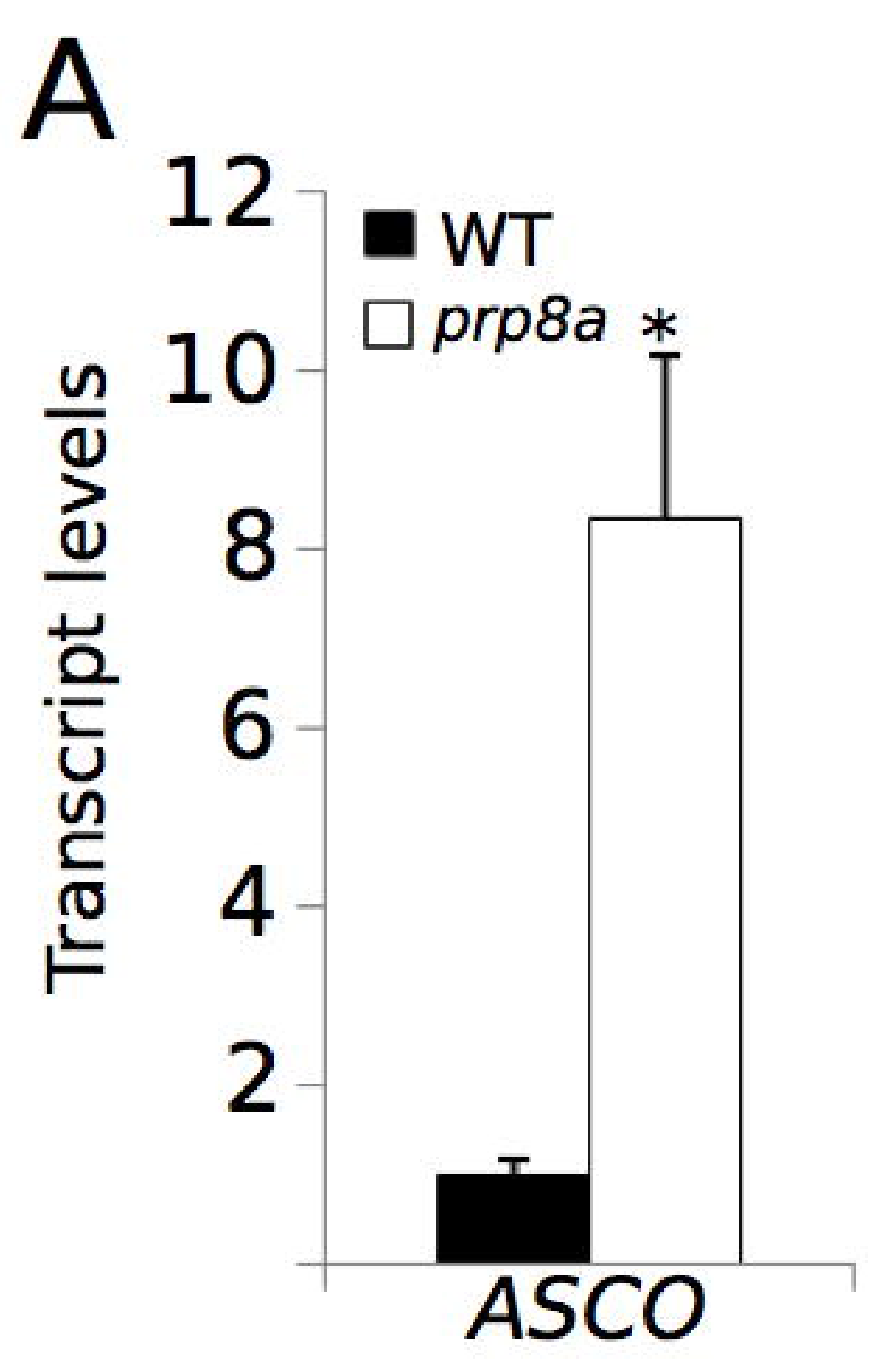

B

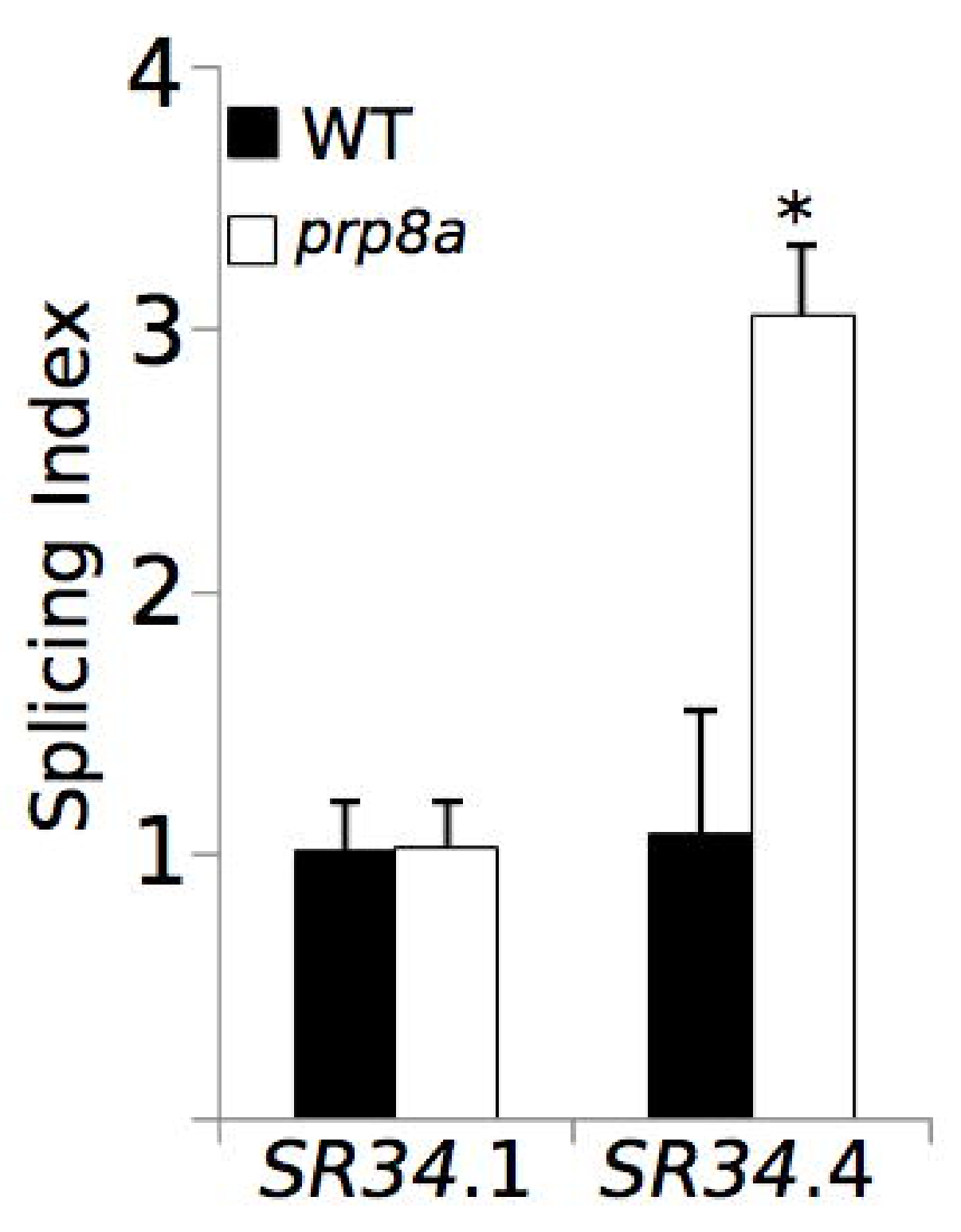

C

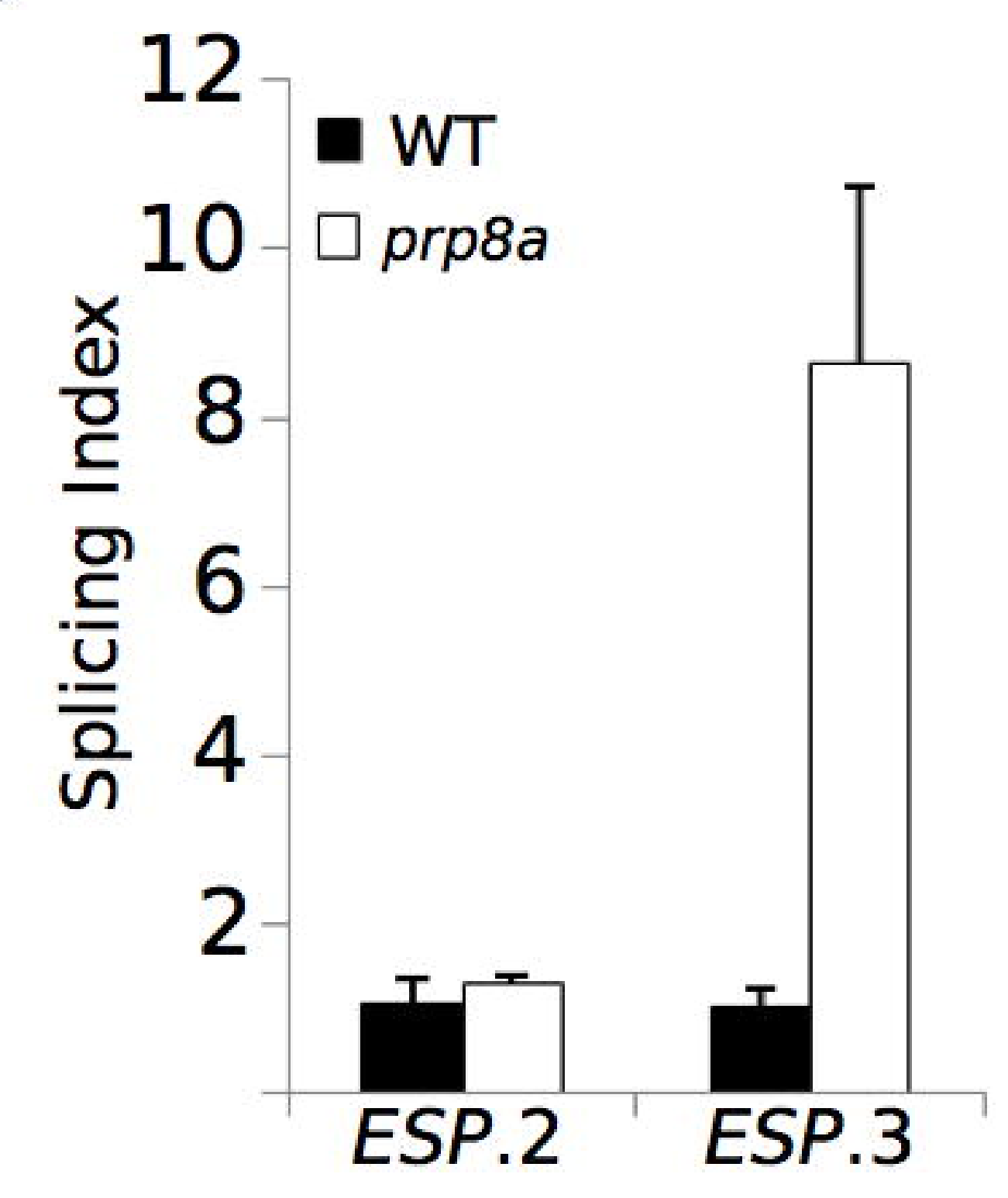

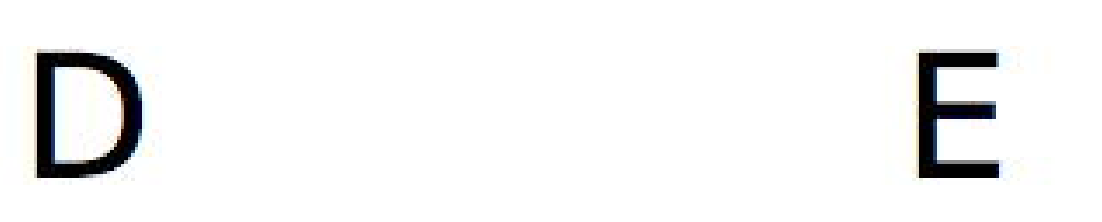
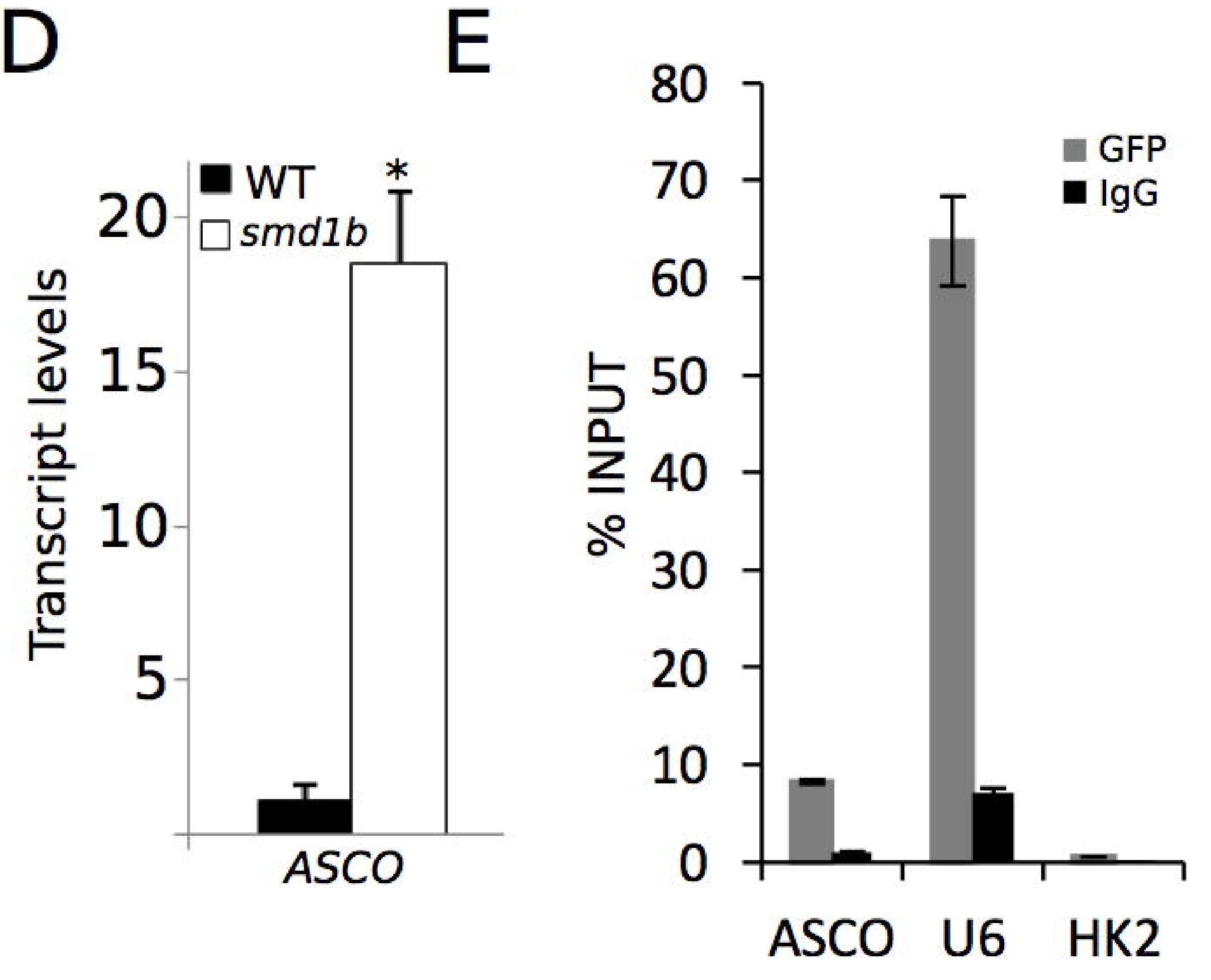

F

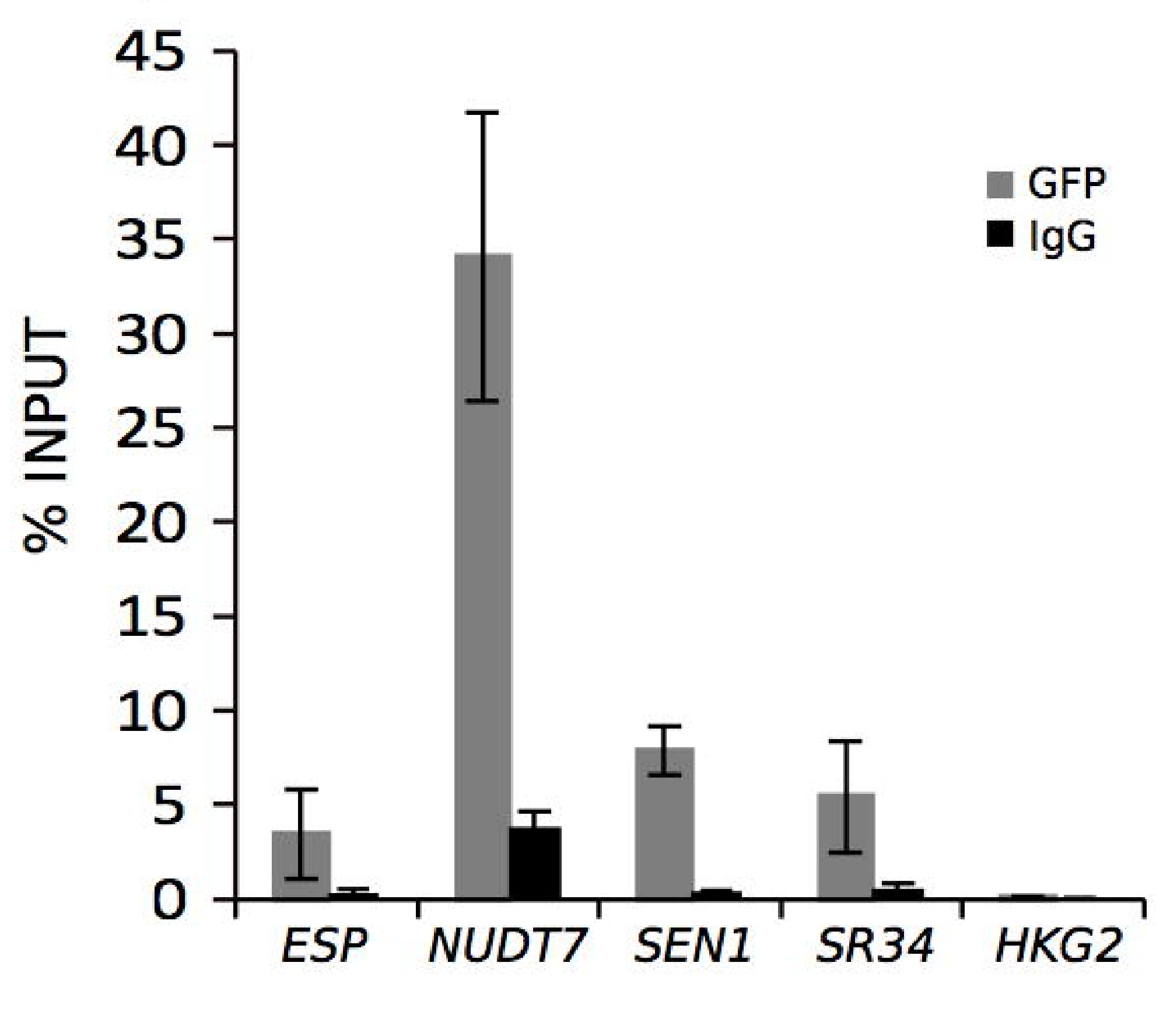

G

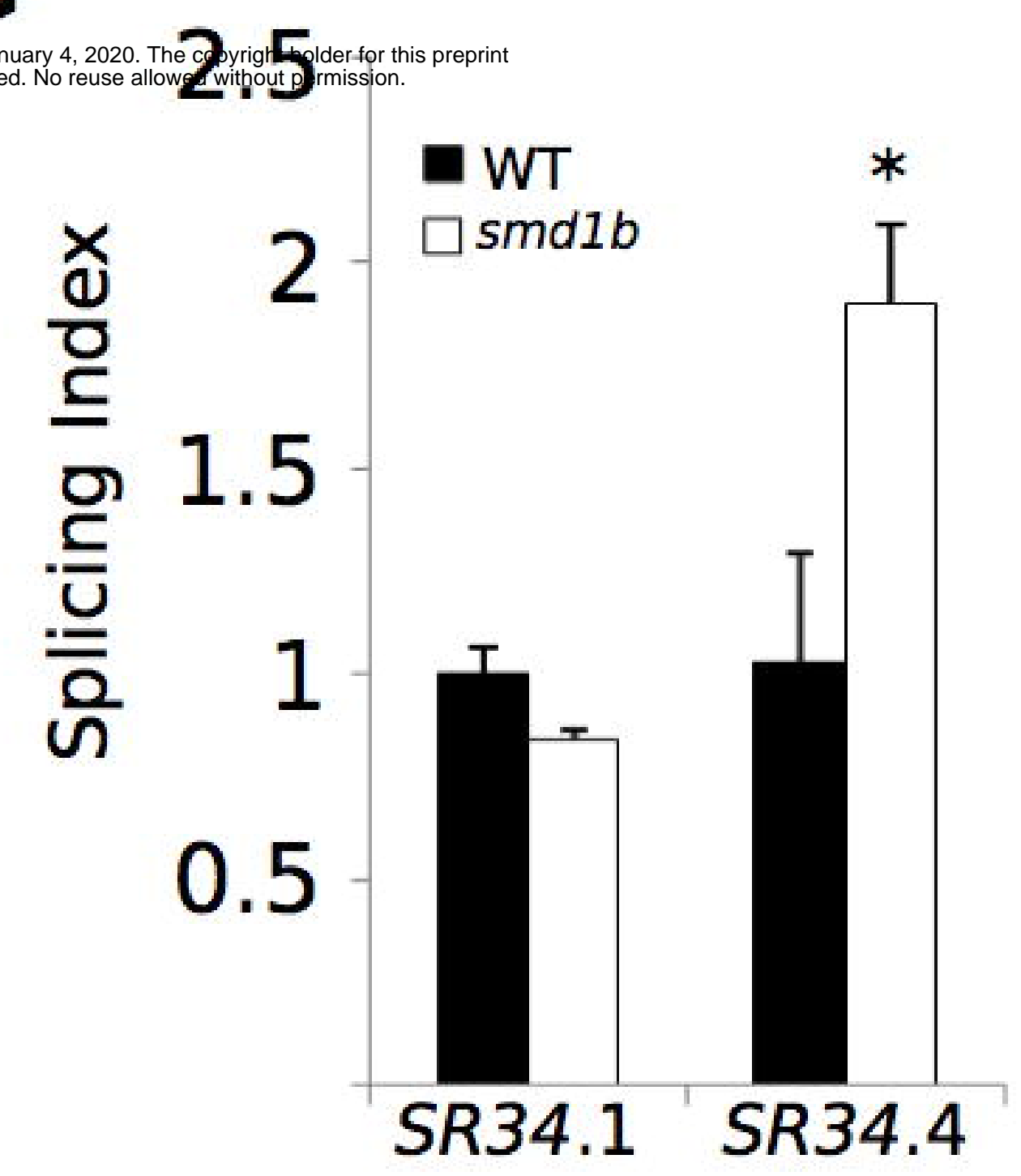

$\mathrm{H}$

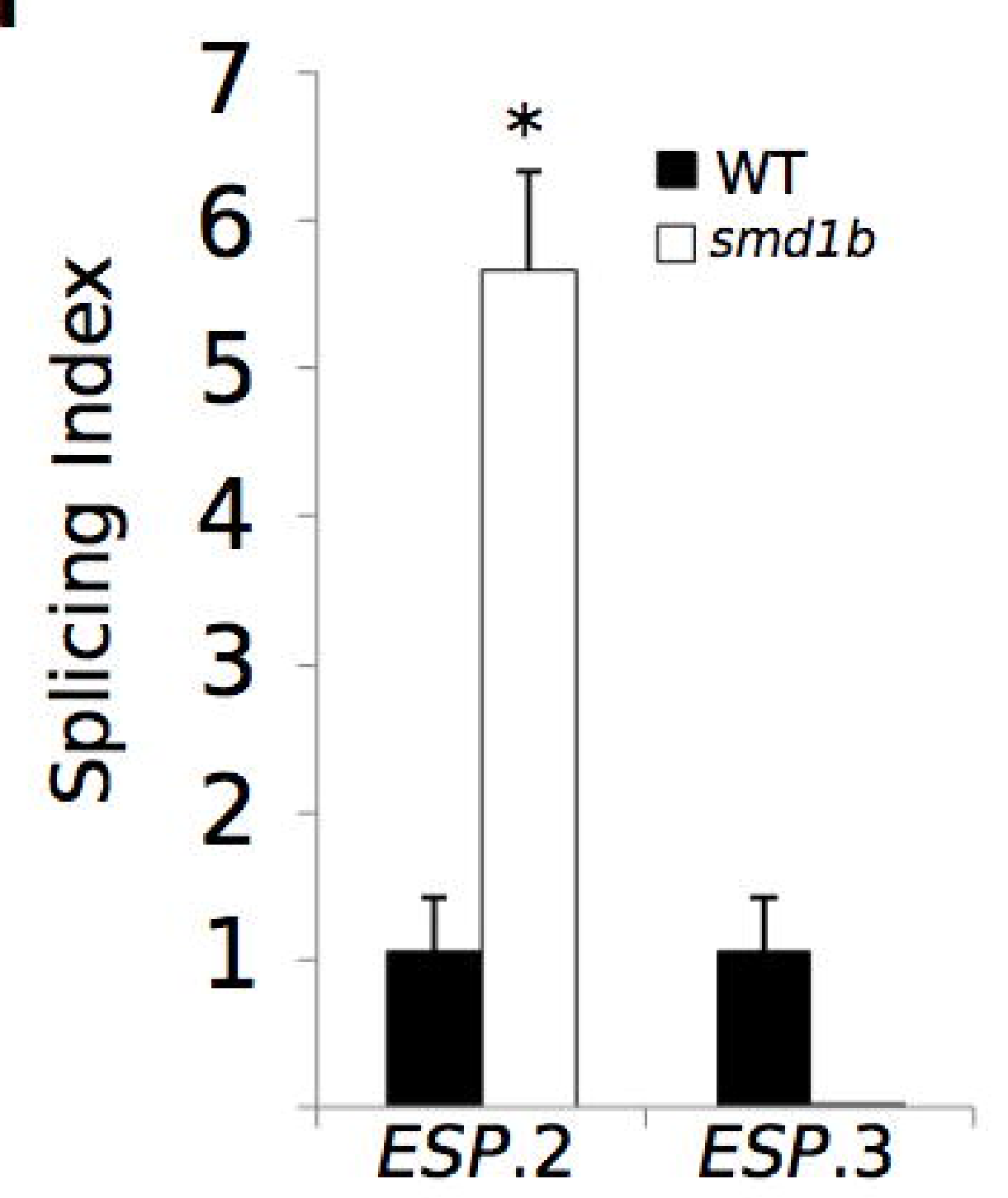


Figure 7

flg responsive genes
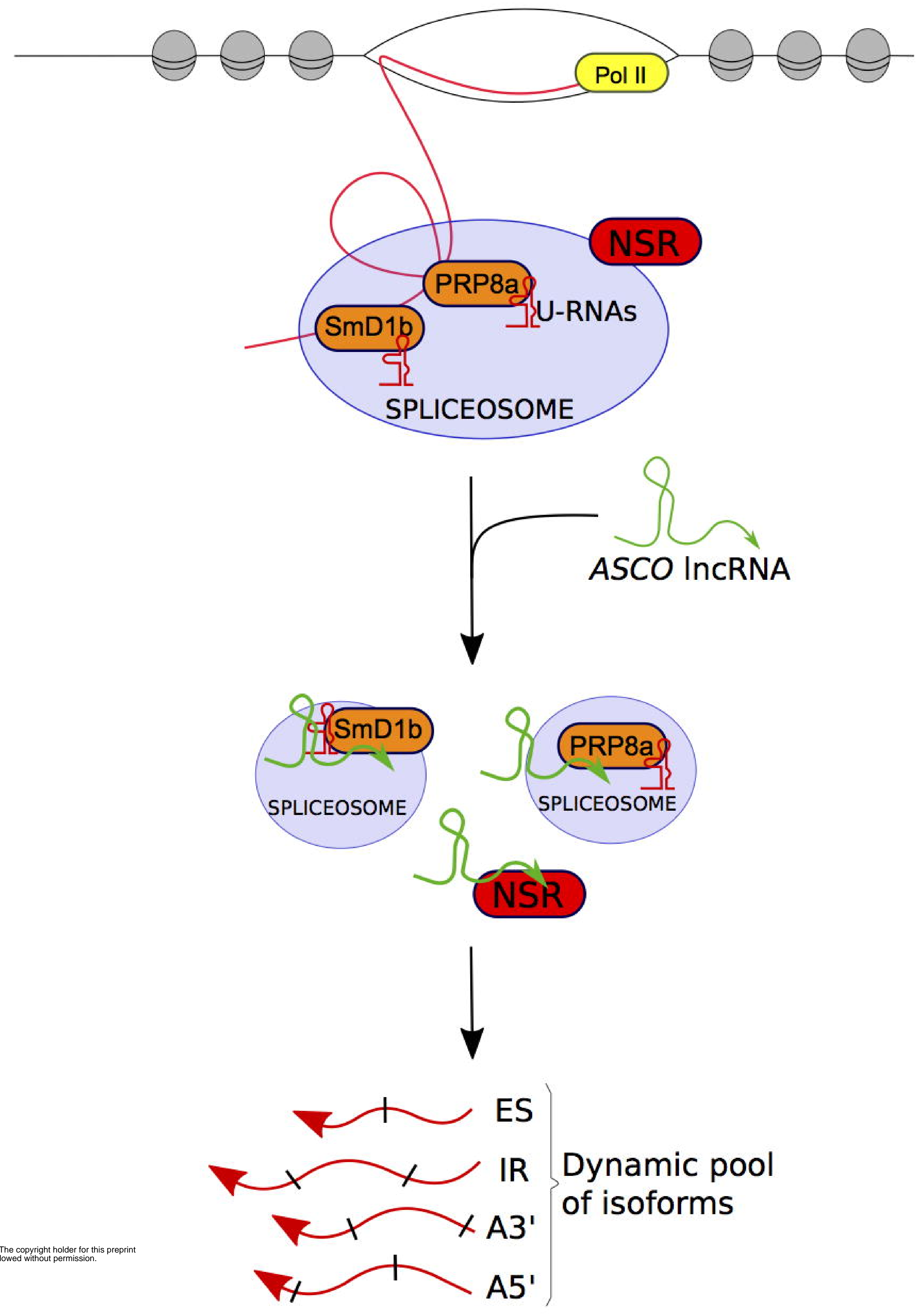